\title{
Implante coclear bilateral sequencial: Resultados em crianças e adolescentes
}

Dissertação apresentada à Faculdade de Medicina da Universidade de São Paulo para obtenção do título de Mestre em Ciências

Programa de Ciências da Reabilitação Área de Concentração: Fonoaudiologia Orientadora: Prof $\stackrel{\text { a }}{\text {. Dr }} \stackrel{\text { a }}{\text {. Ana Claudia }}$ Martinho de Carvalho 


\section{Implante coclear bilateral sequencial: Resultados em crianças e adolescentes}

Dissertação apresentada à Faculdade de Medicina da Universidade de São Paulo para obtenção do título de Mestre em Ciências

Programa de Ciências da Reabilitação Área de Concentração: Fonoaudiologia Orientadora: Prof $\stackrel{\text { a }}{\text {. Dr }} \stackrel{\text { a }}{\text {. Ana Claudia }}$ Martinho de Carvalho 


\section{Dados Internacionais de Catalogação na Publicação (CIP)}

Preparada pela Biblioteca da

Faculdade de Medicina da Universidade de São Paulo

Creprodução autorizada pelo autor

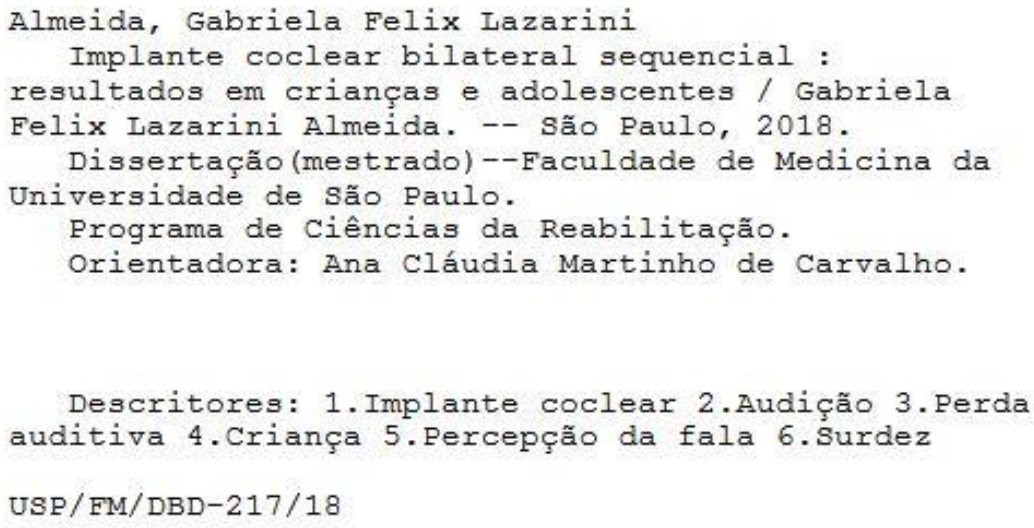




\section{Dedicatória}

Aos meus pais, Paulo e Regina, por serem meus exemplos de coragem e por me ensinarem sempre o caminho da humildade, respeito e da persístêncía em minha trajetóría.

Ao meu irmão, João Vitor, por todos os momentos de descontração e carinho.

Ao meu marido, Djallon, por celebrar comigo cada conquista e pelo apoío incondicional, companheirismo, dedicação e amor.

A eles minha eterna gratidão! 


\section{Agradecimentos}

$\mathcal{A}$ Deus, por me proporcionar sabedoría e capacitação para atuar neste caminho;

Aos meus pais Paulo e Regina e meu irmão João Vitor, por serem meus exemplos de vida e minha maior motivação;

Ao meu marido Djallon, pelo incentivo, paciêncía e por estar ao meu lado em todos os momentos;

A toda minha família, pelo apoío e ensinamentos;

Ao Instituto Alfa de Comunícação e Audição e ao Dr. Orozímbo Alves da Costa pelo auxílío e contríbuição para a execução do projeto;

À minha orientadora Profa. Dra. Ana Cláudía Martinho de Carvalho, pela amizade, pelos conselhos, por ser exemplo de dedicação à profíssão e à sua familía, além de todo o conhecimento compartílhado;

As Profa $^{a}$ Dr $^{a}$ Carla Gentíle Matas e Angelina Nardi Martínez e Dr Orozimbo Alves da Costa que participaram da banca de qualifícação dando valiosas sugestões que contríbuiram para a finalização deste trabalho; 
Aos professores e funcionários do Departamento de Fonoaudiologia da Universidade de São Paulo, pelo apoío;

Às secretárías do programa de pós-graduação, por todo o suporte;

Às amigas Marcella Ferrari Martins e Millena Kreutzfeld, por estarem presentes me incentivando em todos os momentos de dificuldade;

Aos meus amigos, por toda paciência e incentivo;

Às críanças implantadas e suas familias, por colaborarem com este estudo. 
"Consagre ao Senhor todos os seus caminhos, e os seus planos serão bem sucedidos" Provérbios 16:3 


\section{Normatização adotada}

Esta dissertação está de acordo com as seguintes normas, em vigor no momento desta publicação:

Referências: adaptado de International Committee of Medical Journals Editors (Vancouver). Universidade de São Paulo. Faculdade de Medicina. Divisão de Biblioteca e Documentação. Guia de apresentação de dissertações, teses e monografias. Elaborado por Anneliese Carneiro da Cunha, Maria Julia de A. L. Freddi, Maria F. Crestana, Marinalva de Souza Aragão, Suely Campos Cardoso, Valéria Vilhena. 3a ed. São Paulo: Divisão de Biblioteca e Documentação; 2011.

Abreviaturas dos títulos dos periódicos de acordo com List of Journals Indexed in Index Medicus. 


\section{SUMÁRIO}

LISTA DE TABELAS

LISTA DE FIGURAS

LISTA DE ABREVIATURAS E SIGLAS

LISTAS DE SÍMBOLOS

RESUMO

ABSTRACT

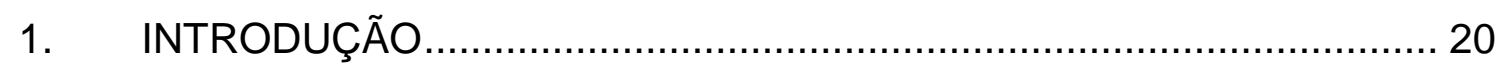

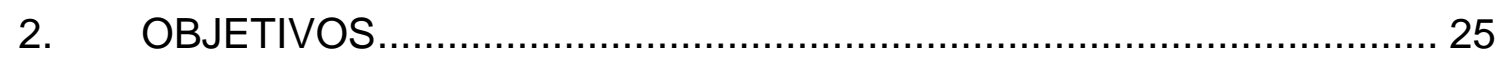

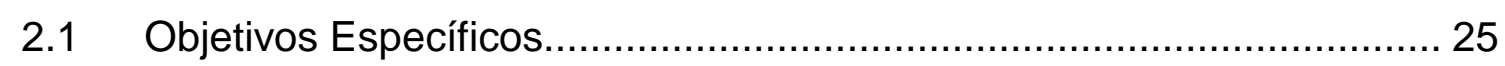

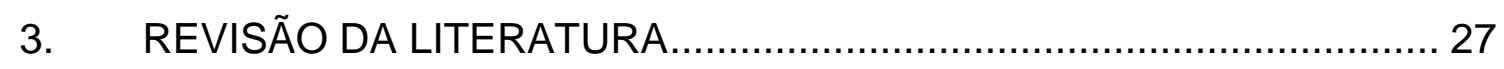

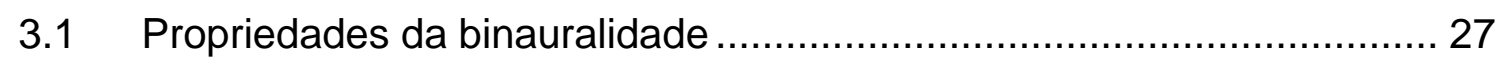

3.2 Implante coclear bilateral em crianças e adolescentes....................... 30

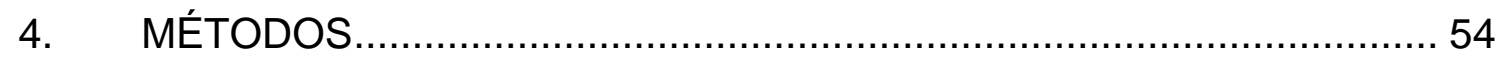

4.1 Tipo de estudo e aspectos éticos ........................................... 54

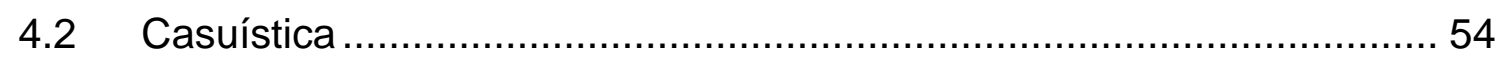

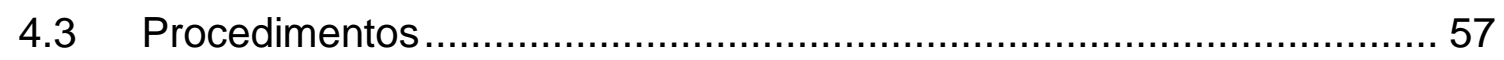

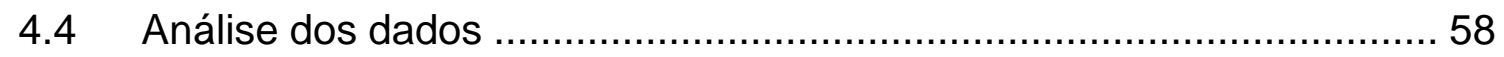

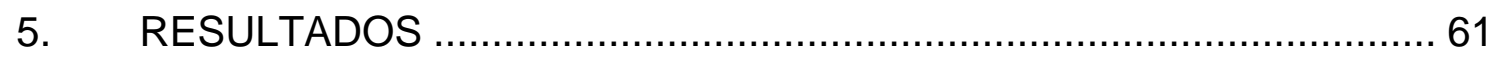

5.1 Reconhecimento de fala no silêncio e no ruído: $1^{\circ} \mathrm{IC}, 2^{\circ}$ IC e IC

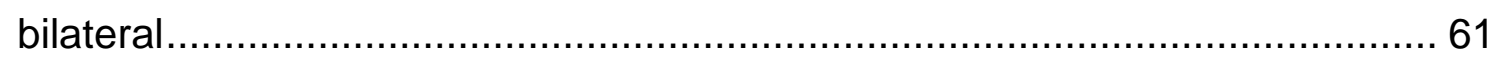

5.2 Intervalo cirúrgico, idade na cirurgia e tempo de uso do $2^{\circ}$ IC e os resultados de reconhecimento de fala no silêncio e no ruído com o $2^{\circ}$ IC e IC bilateral. 65 
5.3 Uso do AASI anterior à segunda cirurgia de IC e os resultados de reconhecimento de fala no silêncio e no ruído com o $2^{\circ}$ IC e com o IC

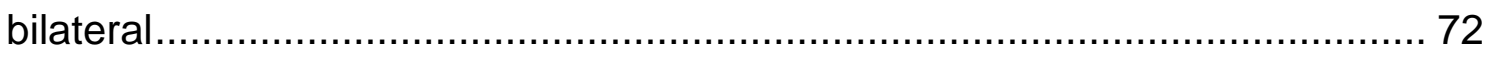

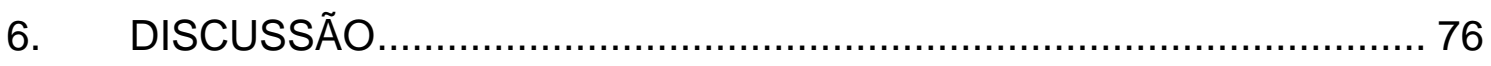

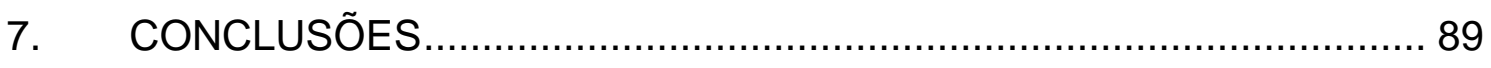

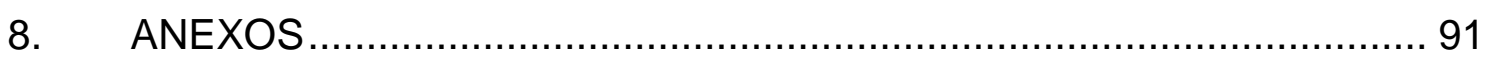

9. REFERÊNCIAS BIBLIOGRÁFICAS ................................................... 106 


\section{LISTA DE TABELAS}

Tabela 1 - Caracterização dos indivíduos participantes da pesquisa 56

Tabela 2 - Valores descritivos para intervalo cirúrgico, tempo de uso do $1^{\circ}$ IC e tempo de uso do $2^{\circ} \mathrm{IC}$, em meses. 56

Tabela 3 - Valores da porcentagem de acertos nos testes de reconhecimento de fala no silêncio e no ruído para as três condições de avaliação 62

Tabela 4 - Comparação da porcentagem de acertos nos testes de reconhecimento de fala no silêncio e no ruído para as três condições de avaliação 64

Tabela 5 - Comparação entre a porcentagem de reconhecimento de fala no silêncio e no ruído, com o uso do $1^{\circ}$ IC, $2^{\circ}$ IC e IC bilateral 64

Tabela 6 - Correlação das porcentagens de acertos para o reconhecimento de fala no silêncio e no ruído com o 2ํIC e IC bilateral e intervalo cirúrgico, idade na cirurgia do $2^{\circ}$ IC e tempo de uso do $2^{\circ}$ IC 65

Tabela 7 - Descrição da porcentagem de acertos nos testes de reconhecimento de fala no silêncio de no ruído segundo o uso do AASI anterior à segunda cirurgia de IC

Tabela 8 - Comparação da porcentagem de acertos no teste de reconhecimento de fala no silêncio e no ruído, em relação ao uso do AASI anterior ao $2^{\circ} \mathrm{IC}$ 74 


\section{LISTA DE FIGURAS}

Figura 1 - Esquema representativo da realização do teste de reconhecimento de fala para a situação silêncio e ruído 57

Figura 2 - Perfis individuais da porcentagem de acertos nos testes de reconhecimento de fala no silêncio de no ruído nas três condições de avaliação 63

Figura 3 - Diagramas de dispersão da porcentagem de acertos no teste de reconhecimento de fala no silêncio para a condição $2^{\circ}$ IC e o intervalo cirúrgico, idade na cirurgia do $2^{\circ}$ IC e tempo de uso do $2^{\circ}$ IC 67

Figura 4 - Diagramas de dispersão da porcentagem de acertos no teste de reconhecimento de fala no ruído para a condição $2^{\circ}$ IC e o intervalo cirúrgico, idade na cirurgia do $2^{\circ}$ IC e tempo de uso do $2^{\circ}$ IC 68

Figura 5 - Diagramas de dispersão da porcentagem de acertos no teste de reconhecimento de fala no silêncio para a condição IC bilateral e o intervalo cirúrgico, idade na cirurgia do $2^{\circ} \mathrm{IC}$ e tempo de uso do

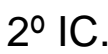
70

Figura 6 - Diagramas de dispersão da porcentagem de acertos no teste de reconhecimento de fala no ruído para a condição IC bilateral e o intervalo cirúrgico, idade na cirurgia do $2^{\circ}$ IC e tempo de uso do 2ㅇIC.

Figura 7 - Valores individuais e médios da porcentagem de acertos de reconhecimento de fala no silêncio e no ruído com o $2^{\circ}$ IC e com IC bilateral de acordo com o uso do AASI anterior ao $2^{\circ}$ IC 73 


\section{LISTA DE ABREVIATURAS E SIGLAS}

AASI

ANS

BKB

et al.

CAPPesq

IC

FMUSP

PBK

QOL

$\mathrm{S} / \mathrm{R}$

SSQ

SUS

TCLE
Aparelho de Amplificação Sonora Individual

Agência Nacional de Saúde Suplementar

Bamford-Kowal-Bench

e colaboradores

Comissão de Ética para Análise de Projetos de Pesquisa

Implante Coclear

Faculdade de Medicina da Universidade de São Paulo

Phonetically Balanced Kindergarten Words

Quality of Life

Sinal-Ruído

Qualities of Hearing Scale

Sistema Único de Saúde

Termo de Consentimento Livre e Esclarecido 


\section{LISTAS DE SÍMBOLOS}

$\mathrm{dB}$

Decibels

dB NPS

Decibels Nível de Pressão Sonora

dB SPL

Decibels Sound Pressure Level 


\section{RESUMO}

Almeida GFL. Implante coclear bilateral sequencial: Resultados em crianças e adolescentes [Dissertação]. São Paulo: Faculdade de Medicina, Universidade de São Paulo; 2018.

INTRODUÇÃO: A utilização do Implante Coclear (IC) bilateral pode promover o desenvolvimento das vias auditivas centrais de maneira simétrica, beneficiando, assim, o desenvolvimento das habilidades auditivas e melhorando a localização sonora e a habilidade de percepção auditiva da fala em situações de ruído competitivo. OBJETIVO: Avaliar a habilidade de reconhecimento de fala em crianças e adolescentes usuários de IC bilateral sequencial, considerando a relação das variáveis: idade cirúrgica, tempo de uso do dispositivo e intervalo entre as cirurgias. METODOLOGIA: Foram avaliados 14 indivíduos com idades entre dez e 16 anos, que receberam indicação cirúrgica para a utilização do IC bilateral sequencial como forma de intervenção no processo de habilitação auditiva. A habilidade de reconhecimento de fala foi avaliada por meio de listas de sentenças construídas na língua portuguesa, apresentadas em duas situações: no silêncio, com intensidade fixa de 60 dB NPS, e no ruído competitivo, com a relação sinal/ruído de $+15 \mathrm{~dB}$. A avaliação foi realizada nas seguintes condições: unilateral com o $1^{\circ}$ IC ativado, unilateral com o $2^{\circ}$ IC ativado e bilateral com ambos os dispositivos ativados. RESULTADOS: Os resultados dos testes de reconhecimento de fala demonstraram melhor desempenho tanto no silêncio quanto no ruído para a condição IC bilateral, quando comparado ao $1^{\circ}$ IC e $2^{\circ}$ IC isoladamente. Um pior resultado de reconhecimento de fala foi encontrado com o uso $2^{0}$ IC isoladamente. Não foi encontrada correlação estatisticamente significante entre idade cirúrgica, intervalo entre as cirurgias e 
tempo de uso do $2^{\circ}$ IC e o desempenho de percepção auditiva da fala para todas as condições avaliadas. O uso do AASI anterior ao $2^{\circ} I C$ beneficiou os resultados de percepção auditiva da fala com o $2^{\circ}$ IC, tanto no silêncio quanto no ruído. CONCLUSÕES: O IC bilateral proporcionou melhor reconhecimento de fala em situações de silêncio e de ruído, quando comparado com o IC unilateral, independente do intervalo entre as cirurgias, da idade cirúrgica e do tempo de uso do $2^{\circ} \mathrm{IC}$. O reconhecimento de fala com o $1^{\circ} \mathrm{IC}$ foi significativamente melhor do que com o $2^{\circ} \mathrm{IC}$, tanto no silêncio quanto no ruído. O uso do AASI anterior ao $2^{\circ}$ IC influenciou o desempenho de reconhecimento de fala com o $2^{\circ}$ IC, tanto no silêncio quanto no ruído.

Descritores: implante coclear; audição; perda auditiva; criança; percepção da fala; surdez. 


\section{ABSTRACT}

Almeida GFL. Sequential bilateral cochlear implant: results in children and adolescents [dissertation]. São Paulo: "Faculdade de Medicina, Universidade de São Paulo"; 2018.

Introduction: The use of bilateral cochlear implants $(\mathrm{Cl})$ may be able to promote symmetrical development of the central auditory pathways, in order to benefit the development of auditory skills and to improve auditory localization and speech perception in noise situations. Purpose: to evaluate the ability of speech recognition in children and adolescents with sequential bilateral $\mathrm{Cl}$, considering the variables: surgical age, time of use of the device and interval between surgeries. Methods: Fourteen individuals between ten and 16 years, who received a surgical indication for sequential bilateral $\mathrm{Cl}$. The speech recognition was evaluated through lists of sentences constructed in Portuguese and presented in two situations: in silence, with fixed intensity of $60 \mathrm{~dB} S P L$ and in competitive noise, with a signal-to-noise ratio of $+15 \mathrm{~dB}$. The evaluation was performed under the following conditions: unilateral with the $1 \mathrm{st} \mathrm{Cl}$; unilateral with the $2 \mathrm{nd} \mathrm{Cl}$ and bilateral. Results: The results of speech recognition tests showed better performance in both silence and noise for bilateral $\mathrm{Cl}$ condition when compared to the 1 st $\mathrm{Cl}$ and $2 \mathrm{nd} \mathrm{Cl}$ alone. Lower results were found with the second $\mathrm{Cl}$ alone. No statistical correlation was found between surgical age, interval between surgeries and time of use of device with speech recognition performance for all conditions. The use of hearing aids prior to the 2 nd $\mathrm{Cl}$ benefited the results of speech recognition with $2 \mathrm{nd} \mathrm{Cl}$ in both silence and noise. Conclusions: Bilateral $\mathrm{Cl}$ provided better speech recognition in both silence and noise situations when compared to unilateral $\mathrm{Cl}$, regardless of the interval 
between surgeries, surgical age and the time of use of the device. Speech recognition with the $1 \mathrm{st} \mathrm{Cl}$ was significantly better than with the $2 \mathrm{nd} \mathrm{Cl}$, both in silence and noise. The use of hearing aids prior to the $2 \mathrm{nd} \mathrm{Cl}$ influenced the performance of speech recognition both in silence and noise.

Descriptors: cochlear implantation; hearing; hearing loss; child; speech perception; deafness. 


\section{Introdução}




\section{INTRODUÇÃO}

A deficiência auditiva é um dos principais distúrbios que podem interferir no desenvolvimento da linguagem e da fala. O Joint Committee on Infant Hearing $(\mathrm{JClH}, 2007)$ recomendou que o diagnóstico desse quadro ocorra até os três meses de vida a fim de tornar possível uma intervenção precoce e minimizar o impacto da privação sensorial auditiva.

Dentre os recursos tecnológicos disponíveis para habilitação e reabilitação da deficiência auditiva neurossensorial de grau severo a profundo estão o Aparelho de Amplificação Sonora Individual (AASI) e o Implante Coclear (IC).

O IC pode ser indicado para indivíduos que não obtêm benefícios para a percepção dos sons da fala com o AASI. Trata-se do mais importante avanço no tratamento de crianças com deficiência auditiva adquirida antes do desenvolvimento da linguagem oral (pré-linguais), especialmente quando realizado nos primeiros anos de vida (Miyamoto et al., 2003; Harrison et al., 2005; Tomblin et al., 2005). O dispositivo proporciona acesso aos sons da fala e a apropriação incidental da linguagem oral (Moret et al., 2007; Yang et al., 2011).

Porém, mesmo diante de toda a tecnologia aplicada aos implantes cocleares da geração atual e do fato de os usuários de IC unilateral apresentarem compreensão da fala em ambientes silênciosos, algumas dificuldades surgem em situações cotidianas, como na localização dos sons e compreensão da fala em ambientes ruidosos (Fu et al., 1998; Nelson e Jin, 2004; Stickney et al., 2004). Tais funções requerem a habilidade da binauralidade, a 
qual pode não ser favorecida com a utilização do IC unilateral (Brown e Balkany, 2007).

Uma possibilidade para o acesso à binauralidade é o uso do AASI na orelha não implantada, em usuários de IC unilateral, que apresentem resíduo auditivo. Denominada estimulação bimodal (Ching et al., 2005), é recomendada pela literatura científica, já que pode trazer vantagens binaurais, como a melhora na percepção auditiva da fala em ambientes ruidosos (Hamzavi et al., 2004; Offeciers et al., 2005; Ching et al., 2007; Ching e Incerti, 2012).

Outra alternativa para promover a binauralidade que vem sendo efetivada nos últimos anos, no contexto internacional, é a indicação do IC bilateralmente (Litovsky et al., 2006b; Gordon e Papsin, 2009;).

Lovett et al. (2010) apontaram três motivações para implantar a segunda orelha: assegurar que a melhor orelha seja estimulada; fornecer um backup, caso haja uma falha no dispositivo, bem como propiciar os benefícios da audição binaural, permitindo uma melhora na habilidade de localização de fontes sonoras e na percepção auditiva da fala em ambientes ruidosos (Moore et al., 2003; Litovsky, 2005).

$\mathrm{Na} 11^{\text {a }}$ Conferência sobre Implantes Cocleares e outras tecnologias implantáveis, realizada em Estocolmo, um grupo de cirurgiões europeus se reuniu, com o objetivo de estabelecer um consenso para que os centros de referência desenvolvessem melhores práticas para o tratamento com o IC. $A$ literatura existente foi avaliada, e a seguinte declaração foi consensualmente acordada: "Bebês e/ou crianças candidatos a implantes cocleares devem ser submetidos a cirurgia simultaneamente, logo que possível, após o diagnóstico definitivo da deficiência auditiva, para que ocorra o desenvolvimento auditivo". 
Foi recomendada também a utilização de uma técnica cirúrgica atraumática para preservar a função coclear, minimizar danos e permitir uma possível reimplantação (Ramsden et al., 2012).

No Brasil, o IC bilateral foi contemplado pelos planos de saúde no seu rol de procedimentos, a partir da Resolução Normativa da Agência Nacional de Saúde Suplementar (ANS) - RN № 261 de 28 de julho de 2011, e no Sistema Único de Saúde (SUS), a partir da Portaria no 2.776/GM/MS, de 18 de dezembro de 2014.

A cirurgia de IC bilateral pode ser realizada de forma simultânea ou sequencial. Em um procedimento simultâneo, os dois dispositivos internos são inseridos em um único ato cirúrgico; em um procedimento sequencial, o segundo dispositivo interno é implantado meses ou anos após a primeira cirurgia. Nos casos de implantação sequencial, pesquisadores da área vêm discutindo os resultados pós-cirúrgicos, em especial, o impacto do intervalo de tempo entre a primeira e a segunda cirurgia para os resultados de reconhecimento de fala (Moret, 2016).

O IC bilateral é uma realidade no Brasil, e o interesse pela segunda cirurgia em pacientes com IC unilateral é crescente. O intervalo entre as cirurgias pode ser de meses ou anos, o que leva à necessidade de se avaliar o desempenho das habilidades auditivas desses indivíduos ao longo do tempo. Entretanto, são escassos os trabalhos na literatura científica com a experiência brasileira de usuários de IC bilateral.

Neste contexto, torna-se de fundamental importância avaliar os benefícios do IC bilateral bem como a influência dos aspectos capazes de favorecer a vantagem bilateral, de modo a auxiliar na indicação de novos candidatos, assim 
como na condução do processo terapêutico fonoaudiológico. 


\section{Objetivos}




\section{OBJETIVOS}

Este estudo teve como objetivo avaliar a habilidade de reconhecimento de fala em crianças e adolescentes usuários de IC bilateral sequencial.

\subsection{Objetivos Específicos}

- Comparar o reconhecimento de fala no silêncio e no ruído com o uso do $1^{\circ}$ IC, do $2^{\circ}$ IC e do IC bilateral;

- Analisar a influência das variáveis: idade cirúrgica, tempo de uso do dispositivo e intervalo entre as cirurgias para o reconhecimento de fala no silêncio e no ruído com o $2^{\circ}$ IC e com o IC bilateral;

- Analisar a influência do uso do AASI anterior ao 20 IC para o reconhecimento de fala no silêncio e no ruído com o $2^{\circ}$ IC e com o IC bilateral. 


\section{Revisão da Literatura}




\section{REVISÃO DA LITERATURA}

Os textos utilizados para embasar a fundamentação teórica deste estudo foram organizados conforme o encadeamento de ideias. Sempre que possível a ordem cronológica foi mantida.

Os temas abordados foram organizados em dois tópicos:

- Propriedades da binauralidade;

- Implante coclear bilateral em crianças e adolescentes.

\subsection{Propriedades da binauralidade}

A audição binaural permite um bom desempenho do sistema auditivo, com uma melhor compreensão da fala no silêncio e em ambientes ruidosos. A melhora da capacidade auditiva é determinada por uma combinação de fenômenos físicos e processos neurológicos que são fundamentalmente de origem central e relacionados à integração do sinal percebido em cada orelha (Colburn et al., 1987).

O fenômeno físico fundamental é denominado "efeito sombra de cabeça", que é amplamente responsável pela melhoria da compreensão da fala no ruído. A cabeça age como uma barreira acústica para as fontes sonoras, de modo que o som e o ruído, provenientes de diferentes locais espaciais, chegam a cada orelha com sinais de tempo e intensidades diferentes. A orelha mais próxima da fonte de ruído terá uma relação sinal/ruído $(S / R)$ inferior à da orelha mais próxima do sinal de fala, proporcionando, portanto, uma vantagem auditiva. O efeito sombra de cabeça é mais eficaz para sons de alta frequência, resultando em 
uma atenuação aproximada de 7 dB (Dillon e Turramurra, 2001).

A audição binaural ocorre devido à capacidade do sistema auditivo central em processar e melhorar a percepção auditiva recebida em qualquer orelha individualmente, combinando a informação que chega em ambas. Tal propriedade é atribuída a dois processos: o efeito "squelch binaural", isto é, a capacidade de selecionar a orelha com a melhor relação $S / R$ quando as fontes de fala e ruído estão espacialmente separadas; e o processo de "somação binaural", isto é, a capacidade de integrar centralmente o som recebido em cada orelha quando fontes de fala e ruído são coincidentes no espaço.

O efeito squelch binaural ocorre porque o sistema nervoso central tem a capacidade de reconhecer e processar as diferenças nos sinais de tempo e intensidade que chegam a cada orelha, o que, em última instância, permite separar melhor a fala do ruído e, posteriormente, melhorar a inteligibilidade do sinal de fala desejado. Já o efeito de somação binaural se refere à vantagem de processar a informação auditiva que chega às orelhas simultaneamente, com informações idênticas de tempo e intensidade em cada uma delas (Müller et al., 2002).

Ching et al. (2004) destacaram que a redundância e a interação binaural são dois processos centrais, os quais, quando combinados, melhoram a relação $\mathrm{S} / \mathrm{R}$ dos sinais acústicos vindos de diferentes direções. A redundância binaural pode ser vista como uma vantagem relacionada à possibilidade de as duas orelhas receberem o mesmo sinal e ruído quando são apresentados igualmente a ambas as orelhas ou à frente do indivíduo. Já a localização sonora é possível pela habilidade do sistema nervoso auditivo central de calcular diferenças mínimas nas características do som que chega em cada orelha. 
Desta forma, a escuta binaural é a capacidade de uso de ambos os hemisférios e a transferência inter-hemisférica na análise da informação apresentada em ambas as orelhas simultaneamente. Ching et al. (2004) descreveram que a oportunidade de entrada em ambas as orelhas deve ser sempre oferecida, e que entre as variáveis que podem influênciar os benefícios bilaterais estão o período de privação auditiva, o grau da perda auditiva e a assimetria no processamento do sinal de entrada entre as orelhas. Além disso, o processamento do sinal pelo IC não garante todas as pistas necessárias para a análise e a integração binaural no sistema nervoso auditivo central. Os resultados da estimulação bilateral dependem dos processos centrais e, consequentemente, da reabilitação e da integração das informações.

Para os indivíduos com perda auditiva neurossensorial de grau profundo em ambas as orelhas, a binauralidade pode ser atingida de duas formas: por meio da estimulação bimodal, que consiste no uso do AASI, quando há audição residual na orelha não implantada, e por meio da estimulação bilateral, na qual o IC é utilizado em ambas as orelhas. Em seus estudos, Gordon et al. (2011) enfatizaram que existem múltiplos períodos sensíveis para a estimulação durante o desenvolvimento das vias auditivas, os quais devem ser considerados para determinar o momento da implantação bilateral. Os autores concluíram que o desenvolvimento da binauralidade é interrompido em indivíduos com perda auditiva neurossensorial de grau profundo e que, considerando a fase de desenvolvimento neuronal em que se encontram, é necessário encurtar o tempo que permanecem em privação sensorial para, assim, evitar ou restringir a reorganização das vias auditivas. Ressaltaram que, se o tempo de espera para a cirurgia do IC bilateral for prolongado, a capacidade de promover ao máximo 
os benefícios da binauralidade poderá ser limitada.

Segundo Litovsky e Gordon (2016) as habilidades auditivas são essenciais para as crianças à medida que crescem, já que fornecem pistas importantes para determinar a localização da fonte sonora no ambiente. A audição binaural tem mecanismos para capturar diferenças entre as orelhas em termos de tempo de chegada e intensidade. Em crianças com audição normal, as habilidades auditivas espaciais são bastante desenvolvidas quando atingem a idade de quatro e cinco anos. Em contraste, a maioria das crianças com deficiência auditiva e que fazem uso do IC unilateral isoladamente não tem oportunidade de experimentar os benefícios da audição binaural. Segundo os autores, um número crescente de crianças recebeu o IC bilateral nos últimos anos, e as evidências sugerem que, embora esse procedimento apresente benefícios em relação à estimulação unilateral, elas geralmente apresentam um desempenho pior do que seus pares ouvintes. Concluíram então que a consequência da privação auditiva durante o desenvolvimento é altamente complexa no que diz respeito aos benefícios e às limitações vividas por crianças que receberam o IC bilateral.

\subsection{Implante coclear bilateral em crianças e adolescentes}

De acordo com Nelson e Jin (2004), o reconhecimento de fala na presença de ruído competitivo com IC unilateral é limitado e sofre impacto negativo quando a resolução espectral é reduzida. Para eles, a dificuldade dos usuários de IC unilateral em compreender a fala em ambientes ruidosos está relacionada a dois fatores: informações espectrais degradadas e limitações na fusão auditiva através de lacunas temporais. Uma questão adicional diz respeito à avaliação de 
crianças que foram adaptadas com AASI na orelha não implantada, com 0 objetivo de proporcionar estimulação das vias neurais. Na literatura, há evidências de que o AASI na orelha não implantada pode oferecer benefícios para a localização sonora e para a compreensão da fala no ruído (Ching et al., 2001).

Ching et al. (2001) avaliaram 16 indivíduos e destacaram que o ajuste adequado do ganho do AASI pode facilitar a integração dos sinais de ambas as orelhas, levando a uma melhor compreensão da fala. Dado que existem vantagens binaurais com o uso de IC e AASI na orelha contralateral ao IC, os profissionais devem sempre ajustar o AASI após a cirurgia de IC para prover melhores benefícios.

De acordo com Kong et al. (2005), o AASI provê melhor informação acústica de estrutura fina em frequências graves quando combinado com informações de envelope de frequência aguda, compensando limitações no processamento de sinal do IC e design de eletrodos, sendo o benefício eletroacústico dependente do resíduo auditivo de cada indivíduo para as baixas frequências.

Sparreboom et al. (2010) realizaram uma revisão sistemática de literatura em usuários de IC unilateral em comparação aos usuários da estimulação bimodal. Verificaram as bases de dados eletrônicas com estudos europeus, norte-americanos e australianos publicados entre outubro de 2006 e junho de 2009. Foram selecionados estudos que compreendessem comparações entre IC bilateral e IC unilateral e / ou IC bilateral e estimulação bimodal, em crianças com perda auditiva neurossensorial de grau severo a profundo. Os resultados foram apresentados de forma qualitativa, sendo verificadas vantagens com o IC bilateral devido à melhora do reconhecimento de fala no silêncio e no ruído. 
Para identificar a prevalência do uso de AASI na orelha contralateral em adultos usuários de IC unilateral, bem como determinar as razões pelas quais alguns pacientes não utilizam AASI contralateral e analisar os efeitos da audição residual nesses indivíduos, Yamaguchi e Goffi-Gomez (2013) realizaram um estudo clínico por meio da aplicação de questionários em 82 pacientes adultos usuários de IC. A prevalência de usuários de AASI contralateral foi determinada em $12 \%$, com um intervalo de confiança de $95 \%$ de 11 a $13 \%$. Cerca de $58,2 \%$ dos não usuários de AASI relataram uma falta de benefício perceptível, mesmo após o uso de aparelhos auditivos, e 23,6\% relataram não ter recebido a opção de usar um AASI. Os usuários de AASI apresentaram uma média de tom puro de $107 \mathrm{~dB}$, enquanto entre os não usuários a média de tom puro foi de $117 \mathrm{~dB}$. Os autores concluíram que há uma baixa prevalência do uso de AASI contralateral ao IC, atribuindo essa ocorrência à falta de audição residual ou falta de benefícios de percepção auditiva da fala com a audição bimodal.

Scherf e Arnold (2014) estudaram a recomendação da estimulação bimodal em diferentes países e as orientações aos usuários de IC em relação a esse aspecto. Profissionais que trabalham com AASI e IC foram convidados a participar de uma pesquisa clínica online multicêntrica internacional, projetada para obter informações acerca das várias abordagens para a audição bimodal e adaptação de dispositivo de IC e AASI. O questionário era composto de 41 perguntas, que foram respondidas, no total, por 65 médicos de 12 países - todos afirmaram que recomendariam a um usuário de IC que usasse um AASI contralateral, se indicado. No entanto, $45 \%$ nunca tinham realizado adaptação de AASI antes ou tinham menos de um ano de experiência. Em geral, não foram encontrados critérios específicos para selecionar candidatos que se ajustassem 
a um AASI. Além disso, uma estratégia para ajustar a regulagem do AASI com o IC não foi utilizada como prática padrão para nenhum dos adultos, sendo disponibilizada para apenas $12 \%$ das crianças. Somente metade dos profissionais entrevistados estava ciente da literatura bimodal, e 60\% deles não haviam indicado o AASI após a ativação do IC. No entanto, se os usuários se queixassem de problemas de qualidade sonora ou resultados ruins de percepção auditiva da fala, era realizada a adaptação bimodal. Os resultados do estudo demostraram que há uma falta de experiência em adaptação de AASI nos centros de IC, e que o uso de procedimentos de adaptação bimodal publicados é deficiente. Os autores relataram que, geralmente, o AASI não é regulado novamente após a ativação do IC, e isso pode contribuir para sua rejeição. Diante disso, defenderam que a inclusão de uma prescrição para os usuários bimodais no software de mapeamento do IC facilitaria a aplicação de um procedimento de balanceamento, podendo aumentar sua implementação na prática clínica.

Fielden e Kitterick (2016) caracterizaram a prática clínica em torno do manejo e da adaptação de AASI contralateral em adultos usuários de IC unilateral, identificando fatores que limitassem a indicação do AASI contralateral ao IC e averiguando a opinião dos audiologistas acerca da audição bimodal. Para tanto, foram enviados questionários online para audiologistas que trabalhavam nos 20 centros de IC para adultos no Reino Unido. Os resultados mostraram que, embora a maioria dos profissionais indicasse ativamente a estimulação bimodal por trazer benefícios de percepção auditiva da fala quando comparada ao IC unilateral, a maioria dos centros não assumiu a responsabilidade pelo AASI contralateral após o IC, apesar de identificar poucos fatores práticos limitantes. 
Embora os entrevistados tenham afirmado que a adaptação da estimulação bimodal era potencialmente mais benéfica do que os dispositivos ajustados unilateralmente, essa adaptação não era uma prática rotineira em todos os centros. Os resultados destacaram algumas inconsistências na adaptação da estimulação bimodal em todo o Reino Unido. Os pontos de vista dos audiologistas sobre a melhor prática parecem estar em desacordo com a natureza e estrutura dos serviços oferecidos atualmente. Evidências mais fortes de que a estimulação bimodal pode ser benéfica seriam necessárias para que os prestadores de serviços justificassem a indicação rotineira da bimodalidade e orientassem as diretrizes para estabelecer a prática clínica de rotina.

Em relação ao IC bilateral, a inserção dos dispositivos pode ser realizada simultaneamente, em uma única cirurgia ou sequencialmente, em dois momentos cirúrgicos. No caso da realização simultânea, os custos podem ser reduzidos, especialmente no que se refere à reabilitação auditiva. Contudo, a cirurgia sequencial permite que a função vestibular possa ser avaliada antes da implantação do segundo lado. Embora o risco de alteração do sistema vestibular após o IC seja limitado, estima-se que uma perda bilateral de hiporreflexia ou arreflexia pode ocorrer em menos de $5 \%$ dos indivíduos que se submetem ao IC simultâneo (Buchman et al., 2004).

Kühn-Inacker et al. (2004) avaliaram a percepção auditiva da fala em 39 crianças de três a nove anos, das quais 35 foram submetidas à cirurgia de IC bilateral sequencial com intervalo entre as cirurgias variando entre um e cinco anos, e quatro foram submetidas à cirurgia de IC bilateral simultâneo. Destas, 32 crianças foram selecionadas por fazerem parte do programa de reabilitação do centro de IC, 14 não atingiram habilidades auditivas em conjunto aberto após 0 
$2^{\circ}$ IC e 18 apresentaram habilidades de percepção auditiva da fala apenas pela via auditiva. Foram apresentadas as listas de palavras a uma relação $S / R$ de +15 dB em 18 crianças nas condições IC unilateral e IC bilateral. A experiência auditiva com o 20 IC variou entre seis e 24 meses. Os autores concluíram que o IC bilateral melhorou o comportamento comunicativo das crianças, especialmente em situações de escuta complexas. Aquelas examinadas com o teste de fala em ruído tiveram melhores resultados na condição bilateral em comparação com a condição unilateral. As influências do intervalo entre as cirurgias, bem como a influência da idade no $1^{\circ}$ IC foram investigadas usando análise de regressão linear. Os resultados mostraram que nenhum desses dois fatores influenciou significativamente os resultados da discriminação de fala em testes com ruído.

Litovsky et al. (2006a) constataram que crianças com estimulação bilateral, sejam elas usuárias de IC bilateral ou de IC e AASI contralateral (estimulação bimodal), mostraram benefícios em medidas de localização sonora. No entanto, crianças com IC bilateral obtiveram melhora significativamente maior do que aquelas com audição bimodal em duas medidas específicas: inteligibilidade da fala e localização sonora. De modo a determinar em que medida a experiência auditiva com o IC bilateral sequencial é capaz de beneficiar a precisão na tarefa de localização sonora, os autores avaliaram esse aspecto em um grupo de crianças que receberam esse dispositivo. Além disso, o estudo investigou a habilidade de localização sonora em crianças que faziam uso combinado do IC e AASI na orelha não implantada. No estudo, foram então avaliados dois grupos: um com 13 indivíduos usuários de IC bilateral (três e 16 anos) e outro com seis indivíduos usuários de IC e AASI na orelha não implantada (quatro e 14 anos). 
Os testes foram realizados em cabina acústica e com alto-falantes. Os estímulos utilizados foram palavras gravadas com voz masculina na intensidade de $60 \mathrm{~dB}$ NPS. Aproximadamente, $70 \%$ das crianças foram capazes de discriminar esquerda e direita e, destas, 77\% tiveram melhor desempenho com o IC bilateral, quando comparadas às usuárias de IC unilateral. Os autores concluíram que crianças usuárias de IC bilateral sequencial representam uma população única de indivíduos que sofreram quantidades variáveis de privação auditiva em cada orelha, e que a maioria delas apresentou um melhor desempenho em localização sonora com IC bilateral, quando comparadas aos seus pares usuários de IC e AASI contralateral, sendo os benefícios do IC bilateral não restritos às crianças mais jovens. Porém, ressaltaram que esses resultados devem ser interpretados com cautela, pois os fatores que podem contribuir para tais benefícios devem ser cuidadosamente avaliados nesta população.

Galvin et al. (2007) investigaram se crianças submetidas ao IC bilateral sequencial após um longo intervalo cirúrgico teriam melhores benefícios na percepção auditiva da fala do que aquelas implantadas unilateralmente após 12 meses de experiência do IC bilateral. Para tanto, consideraram a relação entre o benefício obtido e fatores como intervalo entre as cirurgias, idade no $2^{\circ}$ IC, tempo de uso do $2^{\circ}$ IC e uso do AASI pré-operatório anterior ao $2^{\circ}$ IC. Foram avaliados seis indivíduos, entre cinco e 15 anos de idade, que receberam o IC bilateral sequencial com intervalos entre três, seis e dez anos nas condições: $1^{\circ}$ IC, $2^{\circ}$ IC e IC bilateral. Foi utilizado um teste de percepção auditiva da fala com relação $S / R$ variável até que o nível de desempenho atingisse $80 \%$, e um teste de localização sonora com uma série de alto-falantes posicionados na altura da cabeça a uma distância de 1,15 metros do paciente. Os autores não encontraram 
diferenças significativas em relação à localização sonora, mas relataram benefícios de percepção auditiva da fala com IC bilateral para alguns dos indivíduos avaliados. Por fim, advertiram que tais benefícios não estão necessariamente relacionados com o uso do AASI pré-operatório ao 2ํㅡㄴ, com o menor intervalo entre as cirurgias e com a idade em que foram submetidos ao 2으.

Com o objetivo de medir os efeitos da idade na implantação e experiência após a ativação do 2ํ IC para a percepção auditiva da fala, Peters et al. (2007) avaliaram 30 crianças entre três e 13 anos de idade, que receberam o IC bilateral de maneira sequencial, com um intervalo de tempo mínimo de seis meses. Todas receberam o $1^{\circ} \mathrm{IC}$ antes dos cinco anos de idade e tinham adquirido habilidades de percepção auditiva da fala com o primeiro dispositivo. Os indivíduos foram divididos em três grupos com base na idade no momento da cirurgia do segundo IC: Grupo I, três a cinco anos; Grupo II, cinco a oito anos; e Grupo III, de oito a 13 anos. Foram realizados testes de percepção auditiva da fala no silêncio e no ruído, no momento pré-operatório e em três, seis e 12 meses após o ํㅡ IC, nas condições unilateral e bilateral. Os resultados para a percepção auditiva da fala no silêncio mostraram que as crianças adquiriram reconhecimento de fala em conjunto aberto na segunda orelha dentro de seis meses. No entanto, aquelas com menos de oito anos atingiram habilidade de conjunto aberto de forma mais rápida e com um nível mais alto de capacidade de percepção auditiva da fala aos 12 meses do que as crianças mais velhas. A pontuação do segundo IC para os participantes do Grupo III se manteve muito inferior à da orelha do $1^{\circ}$ IC, mesmo após 12 meses de uso do dispositivo. A percepção auditiva da fala no ruído foi significativamente melhor com IC bilateral do que com qualquer orelha 
sozinha, quando todas as crianças foram analisadas como um único grupo, e para aquelas do Grupo III. No intervalo de teste de nove meses, o desempenho com IC bilateral foi significativamente melhor para todas as condições de ruído. O benefício do IC bilateral no ruído aumentou com o tempo de três a nove meses após a ativação do $2^{\circ}$ IC. Os autores concluíram que o IC bilateral sequencial em crianças de diversas idades tem o potencial de melhorar as habilidades de percepção auditiva da fala na segunda orelha implantada, fornecendo acesso à utilização de mecanismos binaurais, tais como o efeito sombra da cabeça. A melhoria ocorreu ao longo do tempo e de maneira contínua, especialmente durante os seis a 12 meses após a ativação do $2^{\circ}$ IC. Ressaltaram, ainda, que, para determinação do custo-benefício e do impacto do IC bilateral a longo prazo, um acompanhamento prolongado e um número elevado de pacientes devem ser considerados.

Wolfe et al. (2007) avaliaram o reconhecimento de fala em um grupo de 12 crianças que foram submetidas ao IC bilateral sequencial. Para avaliação da percepção auditiva da fala no silêncio, foram utilizados o Teste Lexical e o Teste de Percepção de Discurso Precoce, para cada IC separadamente. Para avaliação do reconhecimento de fala no ruído, foram investigados cada IC separadamente e o IC bilateral, sendo a fala apresentada a $45 \mathrm{~dB}$ e a relação S/R ajustada para o desempenho de $50 \%$ no teste. Os resultados dessas avaliações foram contrastados entre as crianças que receberam o $2^{\circ}$ IC antes dos quatro anos de idade e aquelas que receberam após essa idade. Os autores observaram diferença estatisticamente significativa para as pontuações de reconhecimento de fala em silêncio entre as crianças que receberam seu $2^{\circ}$ IC precocemente e aquelas que o receberam após quatro anos de idade. Ambos 
os grupos obtiveram melhores pontuações no reconhecimento de fala em ruído na condição IC bilateral em relação à condição IC unilateral. No entanto, não houve uma relação estatisticamente significativa entre o desempenho do reconhecimento de fala no ruído e a idade em que a criança foi submetida ao $2^{\circ}$ IC. Aquelas que receberam IC bilateral antes de quatro anos de idade conseguiram um melhor reconhecimento de fala no silêncio para o $2^{\circ} \mathrm{IC}$, em comparação com as que receberam IC bilateral após os quatro anos de idade. Porém, ambos os grupos apresentaram melhores pontuações de reconhecimento de fala no ruído na condição bilateral em relação à condição unilateral.

Steffens et al. (2008) avaliaram os benefícios do IC bilateral sequencial sobre o IC unilateral em um estudo multicêntrico avaliando o reconhecimento de fala no ruído e localização do som de 20 crianças usuárias de IC bilateral sequencial. Os participantes da pesquisa realizaram o $1^{\circ} \mathrm{IC}$ antes dos quatro anos de idade, com intervalo mínimo de um ano entre as cirurgias e experiência auditiva com IC bilateral entre dois meses e quatro anos e sete meses. A vantagem binaural foi avaliada incluindo o reconhecimento de fala no ruído, com estímulo de fala a 70 dB NPS e nível de ruído ajustado individualmente até que os indivíduos atingissem $70 \%$ do reconhecimento do teste. Os autores observaram uma vantagem binaural significativa de $37 \%$ para reconhecimento de fala no ruído para o IC bilateral quando comparado ao IC unilateral. A experiência binaural mostrou correlação moderada com o reconhecimento de fala e com a capacidade de localização. O intervalo entre as cirurgias de IC correlacionou-se em sentido inverso com a vantagem binaural para 
reconhecimento de fala; ou seja, quanto maior o intervalo entre as cirurgias, menor o reconhecimento de fala.

De acordo com Galvin et al. (2008), as crianças que apresentam resultados esperados para a idade com o $1^{\circ}$ IC e recebem o $2^{\circ}$ IC antes dos quatro anos de idade podem obter benefícios adicionais, incluindo melhora no efeito sombra da cabeça e na localização sonora. Em seu estudo, descreveram a adaptação do IC bilateral sequencial e seus benefícios em dez crianças. Embora um indivíduo tenha rejeitado o $2^{\circ}$ IC no momento da ativação dos eletrodos, os outros nove que aceitaram o dispositivo se adaptaram facilmente ao uso bilateral e desenvolveram habilidades auditivas com o $2^{\circ}$ IC. Foram realizados testes de localização sonora e detecção de fala no ruído com uma relação $S / R$ variada, nas condições: $1^{\circ}$ IC, 2ำ IC e com IC bilateral após, no mínimo, seis meses de experiência com o IC bilateral. Todos os indivíduos demonstraram benefícios com IC bilateral no teste de percepção auditiva da fala no ruído, e a maioria demonstrou a habilidade de determinar se o som foi apresentado do lado direito ou esquerdo. Os autores enfatizaram que, nos primeiros seis meses, os resultados variam, e que a idade cirúrgica do $2^{\circ}$ IC pode impactar negativamente os resultados. A maioria dos indivíduos se adaptou bem ao uso de IC bilateral dentro de seis meses e demonstrou algum benefício perceptivo; além disso, de acordo com relatórios familiares, houve também melhora nas situações do cotidiano. Concluíram que a adaptação ao uso do IC bilateral e o desenvolvimento de habilidades auditivas com $02^{\circ}$ IC podem ser esperados dentro de seis meses; no entanto, o domínio do $1^{\circ}$ IC pode permanecer principalmente em situações de escuta difícil. 
Com o objetivo de avaliar os resultados da percepção auditiva da fala e determinar o impacto da duração da surdez, intervalo entre $1^{\circ}$ e $2^{\circ}$ IC e idade no $2^{\circ}$ IC no desempenho na população submetida ao IC bilateral sequencial, Zeitler et al. (2008) realizaram uma revisão retrospectiva em 43 crianças e adolescentes e 22 adultos usuários de IC bilateral sequencial, com intervalo mínimo de seis meses entre o $1^{\circ}$ e $2^{\circ}$ IC. A idade média no momento do $2^{\circ}$ IC em crianças foi de sete anos e o intervalo médio entre as cirurgias de IC, de cinco anos. Cinco crianças receberam o $1^{\circ} \mathrm{IC}$ antes dos 12 meses de idade; dezesseis, aos 12 a 23 meses; nove, entre 24 e 35 meses; e onze, em 36 a 59 meses. Além disso, duas crianças foram implantadas acima dos cinco anos de idade. Em adultos, a média de idade no segundo implante foi de 46,6 anos e o intervalo médio entre as cirurgias de IC, de cinco anos e meio. Foram realizados testes de percepção auditiva da fala no momento pré-operatório do $2^{\circ}$ IC e aos três meses após sua ativação. Como resultados, os autores revelaram melhora significativa com o $2^{\circ}$ IC e IC bilateral, sendo que o longo intervalo entre as cirurgias, idade no $2^{\circ}$ IC e tempo de privação sensorial da segunda orelha não tiveram correlação com os resultados. No entanto, a idade do $1^{\circ} \mathrm{IC}$ influenciou os resultados com o $2^{\circ} \mathrm{IC}$ e IC bilateral nessa população.

Para examinar as habilidades de percepção auditiva da fala em silêncio e ruído em crianças com IC bilateral e avaliar a influência da duração da surdez bilateral e do intervalo entre as cirurgias, Gordon e Papsin (2009) avaliaram 58 crianças com surdez congênita. Destas, 51 receberam o $1^{\circ}$ IC antes dos três anos de idade, sendo o $2^{\circ}$ IC recebido simultaneamente ou após um curto (6-12 meses) ou longo (> 2 anos) intervalo entre as cirurgias. Outras sete crianças apresentaram períodos mais longos de surdez bilateral ( $>3$ anos) antes do $1^{\circ}$ IC 
e receberam o $2^{0}$ IC após um longo intervalo ( $>2$ anos). $\mathrm{O}$ tempo de experiência com IC bilateral variou entre seis a 36 meses. As avaliações foram realizadas em três condições no silêncio: IC na orelha esquerda, IC na orelha direta e IC bilateral. Para a avaliação no ruído, foram utilizadas as condições IC na orelha experiente e IC bilateral. Como resultados, os autores obtiveram que a percepção auditiva da fala foi pior no ruído do que no silêncio, mas melhorias significativas foram encontradas na condição com IC bilateral. Também foram encontrados melhores resultados para as crianças que foram implantadas com um menor tempo de privação sensorial e um menor intervalo de tempo entre as cirurgias. Concluíram então que crianças que tem um menor intervalo cirúrgico podem apresentar melhores resultados com IC bilateral.

Graham et al. (2009) estudaram a existência de uma idade crítica para a indicação do IC bilateral sequencial. Os dados encontrados sob a forma de resultados do teste de percepção auditiva da fala foram coletados de 11 programas de IC no Reino Unido e um no centro na Austrália. Foram recrutados para o estudo 47 crianças e adolescentes com perda auditiva neurossensorial de grau profundo, que foram submetidos ao IC bilateral sequencial. Após a avaliação dos indivíduos com o teste de percepção auditiva da fala BamfordKowal-Bench (BKB) com o 20 IC, os resultados foram os seguintes: $72 \%$ daqueles que receberam o 2 IC até a idade de 13 anos obtiveram $60 \%$ ou mais no teste de sentenças; em contraste, os que receberam o seu $2^{\circ}$ IC com 15 anos ou mais não atingiram níveis adequados de percepção auditiva da fala no teste formal, sendo que dois obtiveram $29 \%$ e $30 \%$, e os demais $7 \%$ ou menos. Após análise dos resultados, os autores sugeriram que é improvável que um $2^{\circ}$ IC recebido após a idade de 16 a 18 anos proporcione, por si só, níveis adequados 
de percepção auditiva da fala. Enfatizaram o conceito de uma "idade crítica" para a implantação da segunda orelha em usuários de IC unilateral, argumentando contra o posicionamento de preservar a segunda orelha para aguardar novas tecnologias ou efeitos de regeneração de células ciliadas e procedimentos semelhantes no futuro. Os resultados do estudo demonstraram que o IC bilateral em crianças com perda auditiva congênita deve ocorrer precocemente.

Em seu estudo, Lovett et al. (2010) avaliaram se o IC bilateral está associado com melhores habilidades auditivas e melhor qualidade de vida quando comparado ao IC unilateral e aos seus pares ouvintes. Foram avaliadas 56 crianças ouvintes e 50 crianças deficientes auditivas, sendo 20 usuárias de IC unilateral; destas, nove eram usuárias de AASI contralateral ao IC e 30 de IC bilateral, sendo 12 submetidas à cirurgia de IC bilateral simultânea e 18 à cirurgia de IC bilateral sequencialmente. Todas as crianças tinham tempo de experiência mínima de seis meses com os dispositivos. Em crianças maiores de quatro anos, foi avaliada a habilidade de localizar os sons vindos de diferentes caixas acústicas. Para as demais, foi aplicado o teste de reconhecimento de palavras no ruído, na qual a relação $S / R$ apresentada foi variada até que fossem atingidos $70 \%$ do teste. Para todas as famílias foram aplicados os questionários de qualidade de vida Quality of Life (QOL) e de qualidade auditiva Qualities of Hearing Scale for parents (SSQ). Como resultados, os autores encontraram um aumento de $18,5 \%$ na precisão da localização sonora e de 3,7 dB na percepção auditiva da fala no ruído com o uso do IC bilateral. As crianças implantadas bilateralmente não atingiram o desempenho obtido pelos seus pares ouvintes. Não houve diferença significativa entre os resultados do IC simultâneo e IC sequencial. 
Em revisão sistemática da literatura com o objetivo de avaliar o efeito do intervalo entre as cirurgias do IC bilateral sequencial em adultos e crianças, Smulders et al. (2011) concluíram que as evidências da literatura sugeriram que o 2 IC pode trazer benefícios de percepção auditiva da fala, mesmo após um intervalo substancial entre as cirurgias, tanto em crianças e adolescentes como em adultos. Os autores estudaram 11 trabalhos, buscados nas bases de dados PubMed, Embase e Cummulative Index to Nursing and Allied Health Literature até 16 de agosto de 2010. Cinco estudos avaliaram adultos com perda auditiva pré-lingual, sendo que, em quatro deles, o IC bilateral não foi afetado pelo intervalo entre as cirurgias, e apenas um estudo relatou um efeito negativo entre o intervalo cirúrgico e a percepção auditiva da fala no silêncio. Sete estudos avaliaram crianças com perdas auditivas pré-linguais e não foi encontrada correlação do longo intervalo entre as cirurgias de IC para o desempenho de localização sonora. Um estudo relatou piores resultados na percepção auditiva da fala no silêncio e dois no ruído, após longos intervalos entre as cirurgias de IC. Embora a heterogeneidade dos estudos tenha favorecido um risco significativo de viés, nenhum deles contraindicou a realização do IC bilateral sequencial.

Com os resultados já descritos na literatura científica, Ramsden et al. (2012) publicaram um consenso com o objetivo de estabelecer que os centros de referência desenvolvessem melhores práticas para o tratamento com o IC. $\mathrm{Na}$ $11^{\text {a }}$ Conferência sobre Implantes Cocleares e outras tecnologias implantáveis, realizada em Estocolmo, um grupo de cirurgiões europeus se reuniu no Fórum de Implantes Cocleares Pediátricos para avaliarem a literatura existente, e a seguinte declaração foi consensualmente acordada: "Bebês e/ou crianças 
candidatos a implantes cocleares devem ser submetidos a cirurgia simultaneamente, logo que possível, após o diagnóstico definitivo da deficiência auditiva, para que ocorra o desenvolvimento auditivo". Foi recomendada também a utilização de uma técnica cirúrgica atraumática para preservar a função coclear, minimizar danos e permitir uma possível reimplantação.

Kim et al. (2013) avaliaram se o intervalo entre as cirurgias do $1^{\circ}$ e $2^{\circ}$ IC interferiram na percepção auditiva da fala no ruído em 42 crianças que foram submetidas ao IC bilateral cirurgicamente sequencial, com idades médias no $1^{0}$ e $2^{\circ}$ IC de quatro e nove anos, respectivamente. Antes de considerar o IC bilateral, a estimulação bimodal foi fortemente recomendada para todos os usuários de IC unilateral. O critério de seleção para IC bilateral no centro de IC em que foi realizado o estudo foi o seguinte: pacientes que, após um teste de audição bimodal, relataram benefícios ausentes ou limitados de seu AASI na orelha contralateral e que obtiveram desempenho esperado para a faixa etária com seu $1^{\circ}$ IC. Todos os indivíduos atingiram $89 \%$ de reconhecimento de monossílabos com o $1^{\circ} \mathrm{IC}$, sendo o intervalo médio entre as cirurgias de cinco anos. A percepção auditiva da fala foi avaliada usando três direções de ruído, em uma relação $\mathrm{S} / \mathrm{R}$ de $+10 \mathrm{~dB}$. Os indivíduos foram divididos em três grupos de acordo com o intervalo entre as cirurgias (grupo l: três a quatro anos; grupo II: cinco a seis anos; e grupo III: sete a nove anos), e os resultados do teste foram comparados entre eles. As habilidades de percepção auditiva da fala no silêncio utilizando o $2^{\circ}$ IC tiveram melhores resultados e/ou foram semelhantes ao $1^{\circ}$ IC após um ano do $2^{\circ}$ IC. A percepção auditiva da fala foi significativamente melhor usando IC bilateral do que somente $01^{\circ}$ IC nas três condições de ruído. Os grupos II e III com intervalos entre as cirurgias mais longos (> 5 anos) alcançaram 
desempenho próximo ao nível do grupo I com um intervalo menor. Esses indivíduos obtiveram benefícios auditivos funcionais significativamente melhores com IC bilateral em comparação com o $1^{\circ}$ IC. Não foi observada influência do intervalo entre as cirurgias nos testes com e sem ruído, já que o grupo de crianças mais velhas também obteve benefícios binaurais funcionais com IC bilateral. Os autores concluíram que o IC bilateral sequencial também deve ser recomendado quando há um longo intervalo entre as cirurgias.

Para IIlg et al. (2013), todos os pacientes devem ser encorajados a continuar usando o AASI contralateral ao $1^{\circ} \mathrm{IC}$, de modo a manter a atividade neural aferente. Os autores estudaram os prováveis preditores para melhores resultados de percepção auditiva da fala no silêncio e no ruído após a cirurgia do IC bilateral sequencial com um longo intervalo entre as cirurgias. Foram analisados: idade no $1^{\circ} \mathrm{IC}$, intervalo entre as cirurgias do $1^{\circ}$ e $2^{\circ} \mathrm{IC}$, tempo de uso de AASI anterior ao $2^{\circ}$ IC, tempo de uso do IC bilateral. Para esse fim, investigaram os dados de 73 crianças e adolescentes, com idade média no $1^{\circ}$ IC de dois anos e no $2^{\circ}$ IC de 11,5 anos que foram submetidos à cirurgia de IC bilateral sequencial com intervalo mínimo de cinco anos entre as cirurgias. Todos os indivíduos utilizavam AASI contralateral após o $1^{\circ}$ IC, e estavam divididos conforme seu tempo de uso: entre zero e um ano; um e três anos e entre três e 16 anos. Eles foram avaliados pelos testes de monossílabos e sentenças, no silêncio e no ruído, com uma intensidade fixa de 65 dB NPS e relação S/R de +10 dB nas condições: $1^{\circ}$ IC, $2^{\circ}$ IC e IC bilateral. Os autores observaram que para aqueles que usaram o AASI de zero a um ano, a média de acertos foi de $15,36 \%$ no silêncio e $0,94 \%$ no ruído; enquanto para os que usaram o dispositivo por um a três anos, foi de $24,5 \%$ no silêncio e $0,73 \%$ no ruído. No entanto, para 
os indivíduos que tiveram experiência com o AASI de três a 16 anos, os resultados foram $41,23 \%$ no silêncio e $8,19 \%$ no ruído. Concluíram então que o maior tempo de experiência bimodal melhora os resultados de percepção auditiva da fala após o IC bilateral, destacando, ainda, que o menor intervalo entre as cirurgias e o maior tempo de uso do $2^{\circ}$ IC geram melhores resultados. Não houve correlação da idade no $1^{\circ}$ IC com os testes de percepção auditiva da fala.

Após realizarem uma revisão sistemática na qual compararam os efeitos do IC bilateral simultâneo com o IC bilateral sequencial, avaliando o impacto do intervalo entre as cirurgias e idade no $2^{\circ}$ IC, Lammers et al. (2014) encontraram quatro estudos comparativos entre IC bilateral simultâneo com sequencial. Destes, três relataram melhor percepção auditiva da fala e desenvolvimento expressivo da linguagem no decorrer de um ano de uso do IC bilateral para a cirurgia simultânea. Das 19 publicações sobre o impacto do intervalo entre as cirurgias, o risco de viés foi baixo-moderado para sete estudos que foram derivados de cinco diferentes populações estudadas. Em duas dessas populações, não foi encontrado impacto no intervalo entre as cirurgias, enquanto que em três, um intervalo mais longo foi associado a um menor desenvolvimento da fala e da linguagem. Estudos observacionais sugeriram que o IC bilateral simultâneo em crianças pode estar associado ao melhor desenvolvimento da fala e linguagem e que um intervalo prolongado entre as cirurgias poderia ocasionar impacto negativo nesses aspectos. Contudo, os autores concluíram que são necessários estudos aleatórios para demonstrar se o IC bilateral simultâneo é, de fato, superior ao IC bilateral sequencial. 
Após examinarem as variáveis que afetam os resultados de percepção auditiva da fala em crianças e adolescentes usuários de IC bilateral sequencial, Friedmann et al. (2015) ressaltaram que este deve ser considerado mesmo após um longo período de privação sensorial na segunda orelha implantada e com um intervalo prolongado entre as cirurgias de IC. Fizeram parte do estudo 25 crianças e adolescentes com idade média no $1^{\circ}$ IC de cinco anos; no 20 IC, 13,5 anos com intervalo médio de oito anos entre as cirurgias. Todos foram avaliados com o 1 IC, 2으 IC e com o IC bilateral em momentos pré e pós-cirúrgico, por meio de testes de percepção auditiva da fala, Phonetically Balanced Kindergarten Words (PBK), e sentenças no ruído com relação S/R variada. Os resultados para o teste PBK foram: com o 1ํ IC, 83,0\%; com o 2ㅇ IC, 56,5\%; e com o IC bilateral, $86,8 \%$. As pontuações das sentenças no ruído foram $89,5 \%$ com o $1^{\circ}$ IC, $74,2 \%$ com o $2^{\circ}$ IC e $94,4 \%$ com o IC bilateral. Os autores concluíram que, apesar de a idade média no $2^{\circ}$ IC ser de 13,5 anos, o IC bilateral sequencial revelou melhora nos testes de percepção auditiva da fala com o $2^{\circ}$ IC e com IC bilateral.

Para determinar se o intervalo de tempo entre as cirurgias do $1^{\circ}$ e $2^{\circ}$ IC interferiu nos resultados de percepção auditiva da fala, Kocdor et al. (2016) avaliaram em um centro de IC da Carolina do Norte nos Estados Unidos 240 crianças, que tinham no mínimo doze meses de experiência com o $2^{\circ}$ IC, e que foram submetidas ao IC bilateral cirurgicamente sequencial, com idade média para o $1^{\circ}$ IC de três anos e para o $2^{\circ}$, de seis anos. Para avaliar a percepção auditiva da fala em conjunto aberto, foi utilizado o teste PBK, que é constituído por listas foneticamente balanceadas de 50 palavras monossílabas. $O$ teste foi realizado em cabine acústica utilizando estímulos gravados ou a viva voz, sendo 
apresentado a 60 dB NPS para cada orelha separadamente. Obteve-se melhor pontuação no teste PBK para o $1^{\circ}$ IC, de 83,8\%, e 67,5\% para o 2ํ IC. Após a análise, foram encontrados melhores resultados em indivíduos com um intervalo entre as cirurgias de IC menor do que três a quatro anos. Em intervalos de cirurgia maiores ou iguais a sete anos, poucos indivíduos atingiram reconhecimento de fala com o $2^{\circ} \mathrm{IC}$ separadamente. Os autores concluíram que, sempre que possível, o $2^{\circ}$ IC deve ser recebido com intervalo máximo de três a quatro anos, no sentido de maximizar resultados em pacientes com perda auditiva neurossensorial profunda.

Moret (2016) descreveu a percepção auditiva da fala de crianças e adolescentes após a realização do IC bilateral sequencial e verificou a correlação dos resultados obtidos com as variáveis: idade no $1^{\circ}$ IC, idade no $2^{\circ}$ IC, intervalo entre as cirurgias de IC e desempenho de linguagem oral. O estudo retrospectivo descritivo foi realizado com 28 crianças e adolescentes usuários de IC bilateral sequencial, com idade média no $1^{\circ}$ IC de 25 meses, no $2^{\circ}$ IC de 105 meses e intervalo médio de 80 meses entre as cirurgias de IC. Foram estudados os resultados do teste de reconhecimento de sentenças no silêncio e no ruído na avaliação pré-cirúrgica do IC bilateral sequencial, e após três, seis e 12 meses de uso do IC bilateral. Como resultados, a autora observou que, na avaliação inicial, quatro $(14,3 \%)$ crianças e adolescentes apresentavam a habilidade de reconhecimento de sentenças no ruído com IC unilateral, mantendo essa habilidade após 12 meses de uso do IC bilateral. Outros 15 (53,6\%) indivíduos desenvolveram essa habilidade ao longo dos 12 meses de uso do IC bilateral. $O$ total de nove $(32,1 \%)$ indivíduos não desenvolveu a habilidade de reconhecimento de sentenças no ruído. O valor mínimo de reconhecimento de 
sentenças no ruído foi de $0,0 \%$ e o máximo de $99,0 \%$, demonstrando grande variabilidade entre os indivíduos. Os resultados relativos à avaliação inicial foram significantemente inferiores aos obtidos nos momentos três, seis e 12 meses de uso do IC bilateral, demonstrando evolução crescente dos resultados de reconhecimento de fala no ruído ao longo de doze meses. O estudo concluiu que crianças e adolescentes submetidos ao IC bilateral sequencial com idades e intervalos variados entre as cirurgias de IC podem desenvolver a percepção auditiva da fala no ruído; contudo, houve uma tendência dos indivíduos com menor idade na cirurgia do $1^{\text {o }}$ IC apresentarem melhores resultados na percepção auditiva da fala no silêncio e no ruído, e uma tendência de melhores resultados com idade maior na cirurgia do $2^{\circ}$ IC.

Devido ao número crescente de crianças que receberam IC bilateral sequencial, Bianchin et al. (2017) realizaram um estudo retrospectivo em 27 crianças submetidas ao IC bilateral sequencial entre os anos 2000 e 2015, com o objetivo de avaliar a percepção auditiva da fala e a influência do intervalo entre as cirurgias nesses resultados. Os indivíduos apresentavam intervalo curto (um a três anos), médio (quatro a seis anos) e longo (sete a 12 anos) entre as cirurgias. Todos foram submetidos aos testes de percepção auditiva da fala no silêncio e no ruído com relação $S / R$ de $+10 \mathrm{~dB}$, em três condições: $1^{\circ} \mathrm{IC}, 2^{\circ} \mathrm{IC} \mathrm{e}$ IC bilateral. Como resultados, obtiveram que o teste no ruído foi significativamente melhor com IC bilateral do que com cada IC isoladamente, para os três grupos. Pequenas melhorias foram observadas em silêncio, especialmente no terceiro grupo (seis a 12 anos). Os benefícios do $2^{\circ}$ IC nas crianças submetidas à cirurgia precocemente e com curto intervalo entre elas foram mais evidentes. No entanto, os autores concluíram que, mesmo após um 
longo período de surdez e com intervalos maiores entre as cirurgias, deve-se considerar o IC bilateral sequencial.

Com a finalidade de determinar o intervalo ideal entre $1^{\circ} \mathrm{IC}$ e $2^{\circ} \mathrm{IC}$ na cirurgia de IC bilateral sequencial, Illg et al. (2017) realizaram uma análise retrospectiva em 250 crianças e adolescentes operados entre os anos de 1995 e 2011. Destes, 157 indivíduos receberam o $2^{\circ}$ IC com intervalo menor do que quatro anos, e 93 em um intervalo maior que quatro anos. Todos foram avaliados após realizarem os testes de percepção auditiva da fala de monossílabos e sentenças no silêncio e no ruído (com relação S/R de $+10 \mathrm{~dB}$ ) em três condições de avaliação: $1^{\circ}$ IC, $2^{\circ}$ IC e IC bilateral. Os resultados foram avaliados considerando a idade no $1^{\circ}$ IC e o intervalo entre as cirurgias. Concluíram que, se $01^{\circ} \mathrm{IC}$ for realizado dentro do período de máxima plasticidade neuronal, ou seja, antes de quatro anos de idade, os resultados serão melhores do que se a segunda cirurgia ocorrer após essa idade. Também foi encontrada diferença estatisticamente significante para os resultados dos testes de percepção auditiva da fala do $1^{\circ} \mathrm{IC}$, quando comparado ao $2^{\circ} \mathrm{IC}$, em todos os indivíduos, sendo que esses resultados foram dependentes do intervalo entre as cirurgias de IC; ou seja, os indivíduos com intervalo menor de quatro anos obtiveram melhores resultados de percepção auditiva da fala com o $2^{\circ} \mathrm{IC}$, e todos apresentaram melhores resultados com IC bilateral.

Reeder et al. (2017) avaliaram o desenvolvimento do reconhecimento de fala do $2^{\circ}$ IC e do IC bilateral e a habilidade de localização em crianças e adolescentes implantados sequencialmente. Foram avaliados 24 indivíduos com idade média na primeira cirurgia de cinco anos e na segunda, de 14,2 anos. As 
avaliações foram realizadas a cada três meses durante 24 meses após o IC bilateral, sendo as condições de teste: $1^{\circ}$ IC e $2^{\circ}$ IC isoladamente e IC bilateral.

Os autores encontraram um desenvolvimento gradual para o $2^{\circ} \mathrm{IC}$ e melhores resultados no silêncio no segundo ano de uso do IC bilateral, enquanto na situação de ruído os resultados foram limitados. Em todas as condições de avaliação, os resultados da segunda orelha foram inferiores ao $1^{\circ}$ IC, e o IC bilateral apresentou resultados sempre superiores. Concluíram então que crianças mais velhas implantadas sequencialmente com longo intervalo entre as cirurgias podem obter reconhecimento de fala na segunda orelha implantada. Contudo, o desempenho pode ser limitado, a taxa de evolução pode ser gradual e o uso contínuo do AASI na orelha contralateral ao $1^{\circ}$ IC, bem como o menor intervalo entre cirurgias podem levar a melhores resultados. 
Métodos 


\section{MÉTODOS}

\subsection{Tipo de estudo e aspectos éticos}

Trata-se de um estudo transversal, realizado em um centro de IC da rede privada da cidade de São Paulo, denominado Alfa Instituto de Comunicação e Audição. Os indivíduos foram crianças e adolescentes com perda auditiva neurossensorial bilateral que receberam indicação cirúrgica para a utilização do IC bilateral como forma de intervenção no processo de habilitação auditiva.

Os procedimentos de seleção e avaliação dos pacientes foram iniciados após os processos éticos pertinentes: autorização da instituição onde foi realizada a pesquisa (anexo A), aprovação da comissão de ética em pesquisa da Faculdade de Medicina da Universidade de São Paulo (CAPPesq FMUSP) $n^{\circ}$ 1754869 (anexo B) e assinatura de Termo de Consentimento Livre e Esclarecido pelos pais ou respectivos responsáveis pelo paciente (anexo C).

\subsection{Casuística}

A amostra foi composta por 14 crianças e adolescentes usuários de IC bilateral sequencial, com idades variando entre dez anos e cinco meses a 16 anos e dez meses.

Os seguintes critérios de inclusão foram considerados na presente pesquisa:

- Perda auditiva neurossensorial severa à profunda bilateral;

- Realização do 1ㅇIC até os 36 meses de idade; 
- Intervalo entre a primeira e a segunda cirurgia de IC igual ou superior a 12 meses;

- Tempo de uso do IC bilateral maior ou igual a 12 meses;

- Uso efetivo do IC bilateral (mínimo de oito horas diárias);

- Realização de acompanhamento médico e fonoaudiológico pós-cirúrgico.

Os indivíduos selecionados realizaram o $1^{\circ}$ IC com idade média de 29 meses (mínimo de 14 meses e máximo de 36 meses) e o 2ํIC com idade média de 120 meses (mínimo de 64 meses e máximo de 183 meses), com intervalo médio entre as cirurgias de 91 meses (mínimo de 28 meses e máximo de 158 meses), sendo $14,3 \%$ do sexo feminino e $85,7 \%$ do sexo masculino. Onze indivíduos (78,6\%) apresentaram etiologia da deficiência auditiva de causa desconhecida (idiopática), em dois indivíduos (14,3\%) a deficiência auditiva ocorreu em decorrência de neuropatia auditiva de causa multifatorial e em uma criança $(7,1 \%)$, em decorrência de ototoxidade. Nove crianças $(64,3 \%)$ faziam uso do AASI anterior ao $2^{\circ}$ IC e cinco não faziam uso desse dispositivo (35,7\%).

A descrição das características clínicas dos indivíduos de pesquisa encontra-se na tabela 1. 
Tabela 1 - Caracterização dos indivíduos participantes da pesquisa

\begin{tabular}{|c|c|c|c|c|c|c|}
\hline $\begin{array}{c}\text { Indivídu } \\
0\end{array}$ & Sexo & Etiologia & $\begin{array}{l}\text { Idade na } \\
\text { cirurgia do } \\
1^{\circ} \text { IC (em } \\
\text { meses) }\end{array}$ & $\begin{array}{c}\text { Idade na } \\
\text { cirurgia do } 2^{\circ} \\
\text { IC (em } \\
\text { meses) }\end{array}$ & $\begin{array}{l}\text { Uso do } \\
\text { AASI } \\
\text { anterior } \\
\text { ao } 2 \text { o IC }\end{array}$ & $\begin{array}{c}\text { Idade no } \\
\text { Teste (em } \\
\text { meses) }\end{array}$ \\
\hline 1 & $M$ & Neuropatia & 29 & 125 & Sim & 147 \\
\hline 2 & $M$ & Idiopática & 25 & 183 & Não & 196 \\
\hline 3 & $M$ & Idiopática & 30 & 113 & Sim & 139 \\
\hline 4 & $M$ & Neuropatia & 32 & 110 & Sim & 147 \\
\hline 5 & M & Idiopática & 14 & 110 & Sim & 125 \\
\hline 6 & $M$ & Idiopática & 25 & 136 & Não & 148 \\
\hline 7 & M & Idiopática & 24 & 70 & Sim & 133 \\
\hline 8 & $F$ & Ototoxidade & 33 & 114 & Sim & 147 \\
\hline 9 & $M$ & Idiopática & 32 & 131 & Sim & 146 \\
\hline 10 & M & Idiopática & 36 & 133 & Não & 194 \\
\hline 11 & $F$ & Idiopática & 36 & 122 & Sim & 134 \\
\hline 12 & M & Idiopática & 28 & 120 & Sim & 169 \\
\hline 13 & $M$ & Idiopática & 36 & 64 & Não & 160 \\
\hline 14 & $M$ & Idiopática & 26 & 152 & Não & 164 \\
\hline
\end{tabular}

Legenda: F= Feminino; $M=$ Masculino; IC= Implante Coclear; AASI= Aparelho de Amplificação Sonora Individual

A caracterização dos indivíduos de pesquisa em relação às variáveis de intervalo entre as cirurgias, tempo de uso do $1^{\circ} \mathrm{IC}$ e tempo de uso do $2^{\circ} \mathrm{IC}$ está descrita na tabela 2.

Tabela 2 - Valores descritivos para intervalo cirúrgico, tempo de uso do $1^{\circ} \mathrm{IC}$ e tempo de uso do $2^{\circ} I C$, em meses

\begin{tabular}{ccccccc}
\hline Variável & $\mathbf{N}$ & Média & $\begin{array}{c}\text { Desvio } \\
\text { padrão }\end{array}$ & Mínimo & Mediana & Máximo \\
\hline Intervalo entre 1ㅇ e 2ㅇ IC & 14 & 91,2 & 31,2 & 28 & 94 & 158 \\
Tempo de uso do 1ㅇ IC & 14 & 118,7 & 29,8 & 46 & 113 & 168 \\
Tempo de uso do 20 IC & 14 & 32,6 & 26,2 & 12 & 20,5 & 84 \\
\hline
\end{tabular}

Legenda: $I C=$ Implante Coclear; $N=$ número amostral 


\subsection{Procedimentos}

A avaliação do reconhecimento de fala foi realizada por meio da aplicação de listas de sentenças construídas para Língua Portuguesa, propostas por Valente (1998) (anexo D), disponíveis em material gravado em CD Player e apresentadas em cabina acústica, utilizando um audiômetro de dois canais conectado a um amplificador em campo livre, nas seguintes situações:

- Silêncio: As sentenças foram apresentadas em uma caixa acústica a oㅡㅁ azimute, na intensidade fixa de $60 \mathrm{~dB}$ NPS, com o indivíduo a um metro do alto-falante;

- Ruído: As sentenças foram apresentadas em uma caixa acústica a 0o azimute, na intensidade fixa de 60 dB NPS, com o indivíduo a um metro do alto-falante e com ruído competitivo (ruído de festa) gravado em CD apresentado a $180^{\circ}$ azimute, com relação $\mathrm{S} / \mathrm{R}$ de $+15 \mathrm{~dB}$.

A figura 1 descreve o modo de apresentação das sentenças e do ruído competitivo para a avaliação dos participantes de pesquisa.

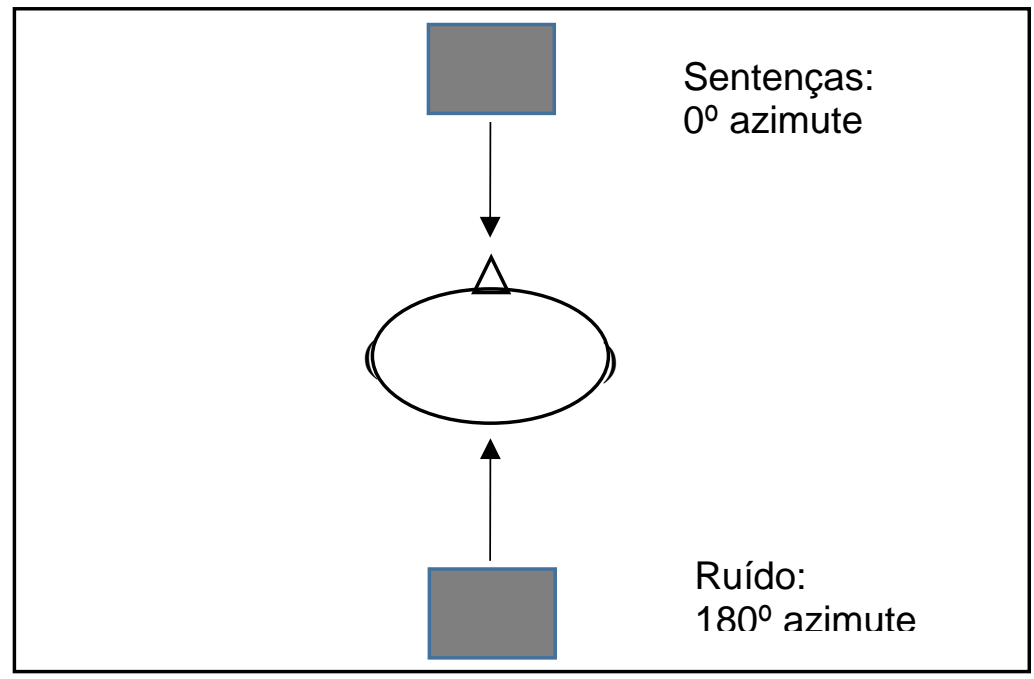

Figura 1 - Esquema representativo da realização do teste de reconhecimento de fala para a situação silêncio e ruído 
Os resultados dos testes foram obtidos em porcentagem (\%), com pontuação variando entre 0 e 100\%, sendo que, quanto maior a pontuação, melhor o desempenho na habilidade de reconhecimento de fala.

\subsection{Análise dos dados}

Os resultados de reconhecimento de fala no silêncio foram comparados àqueles obtidos no ruído, nas condições: $1^{\circ} \mathrm{IC}, 2^{\circ} \mathrm{IC}$, e IC bilateral. Para as análises, foram utilizadas medidas descritivas (média e desvio padrão), assim como o Coeficiente de correlação de Pearson e o teste não paramétrico de Wilcoxon para amostras pareadas.

A comparação da média dos acertos de reconhecimento de fala no silêncio e no ruído com o 1 IC foi realizada por meio do teste t-pareado. A suposição de normalidade das diferenças foi avaliada por meio da construção do gráfico de probabilidade normal.

O coeficiente de correlação de Pearson foi utilizado para a avaliação da correlação existente entre as variáveis: idade na cirurgia do $2^{\circ} \mathrm{IC}$, intervalo entre as cirurgias e tempo de uso do $2^{\circ} \mathrm{IC}$ e as porcentagens de acerto no silêncio e no ruído com o $2^{\circ} \mathrm{IC}$ e com o IC bilateral.

Uma análise descritiva dos resultados de reconhecimento de fala com o $2^{\circ}$ IC e com o IC bilateral no silêncio e no ruído foi realizada entre os indivíduos que utilizaram AASI anterior ao $2^{\circ} \mathrm{IC}$ e entre aqueles que não faziam uso de AASI. Para a comparação dos resultados obtidos em cada grupo, foi realizada uma análise não paramétrica por meio do teste de Mann-Whitney para amostras independentes. O método de Tukey foi utilizado para comparar as médias das porcentagens de acertos no silêncio e no ruído entre os grupos. 
A análise foi realizada com o auxílio dos aplicativos Minitab - versão 17, SPSS - versão 18 e SPSS - versão 25.

Nos testes de hipótese foi adotado nível de significância de 5\%, e foram assinalados com o asterisco $\left({ }^{*}\right)$ os valores de $p$ considerados estatisticamente significantes. 


\section{Resultados}




\section{RESULTADOS}

Os dados obtidos no presente estudo serão apresentados a seguir de acordo com as análises realizadas:

- Comparação dos resultados de reconhecimento de fala entre o $1^{\circ}$ IC, $2^{\circ}$ IC e IC bilateral no silêncio e no ruído;

- Relação entre as variáveis: idade na cirurgia, tempo de uso do dispositivo e intervalo cirúrgico para os resultados de reconhecimento de fala no silêncio e no ruído, com o $2^{\circ}$ IC e com o IC bilateral;

- Relação existente entre o uso do AASI anterior ao $2^{\circ} \mathrm{IC}$ e os resultados de reconhecimento de fala no silêncio e no ruído, com o $2^{\circ}$ IC e com o IC bilateral.

5.1 Reconhecimento de fala no silêncio e no ruído: $1^{\circ}$ IC, $2^{\circ}$ IC e IC bilateral

No que se referiu à habilidade de reconhecimento de fala, a porcentagem média de acertos obtida com o IC bilateral foi maior do que as pontuações encontradas com o $1^{\circ} \mathrm{IC}$ e com o $2^{\circ} \mathrm{IC}$ isoladamente (respectivamente $89 \%$, $56,4 \%$ e 94,7\% para a situação em silêncio e 74,1\%, 48,6\% e 88,9\% na presença de ruído competitivo) (Tabela 3). 
Tabela 3 - Valores da porcentagem de acertos nos testes de reconhecimento de fala no silêncio e no ruído para as três condições de avaliação

\begin{tabular}{cccccccc}
\hline Situação & Condição & N & Média & $\begin{array}{c}\text { Desvio } \\
\text { padrão }\end{array}$ & Mínimo & Mediana & Máximo \\
\hline \multirow{2}{*}{ Silêncio } & $1^{\circ}$ IC & 14 & 89,0 & 12,6 & 70 & 95 & 100 \\
& $2^{\circ}$ IC & 14 & 56,4 & 37,6 & 0 & 65 & 100 \\
& IC Bilateral & 14 & 94,7 & 8,3 & 80 & 100 & 100 \\
\hline \multirow{3}{*}{ Ruído } & $1^{\circ}$ IC & 14 & 74,1 & 12,8 & 56 & 78 & 100 \\
& $2^{\circ}$ IC & 14 & 48,6 & 29,0 & 0 & 59 & 88 \\
& IC Bilateral & 14 & 88,9 & 10,6 & 68 & 92 & 100 \\
\hline
\end{tabular}

Legenda: IC= Implante Coclear; $\mathrm{N}=$ número amostral

Os perfis individuais da porcentagem de acertos obtidos para a tarefa de reconhecimento de fala no silêncio e no ruído com o $1^{\circ} \mathrm{IC}$, com o $2^{\circ} \mathrm{IC}$ e com o IC bilateral estão descritos na figura 2. Todos os indivíduos apresentaram reconhecimento de fala igual ou superior a $70 \%$ com o $1^{\circ}$ IC. Uma vantagem auditiva no reconhecimento de fala foi observada com o uso do IC bilateral, tanto no silêncio quanto no ruído, independentemente dos resultados obtidos com o 2ำ IC isoladamente. 


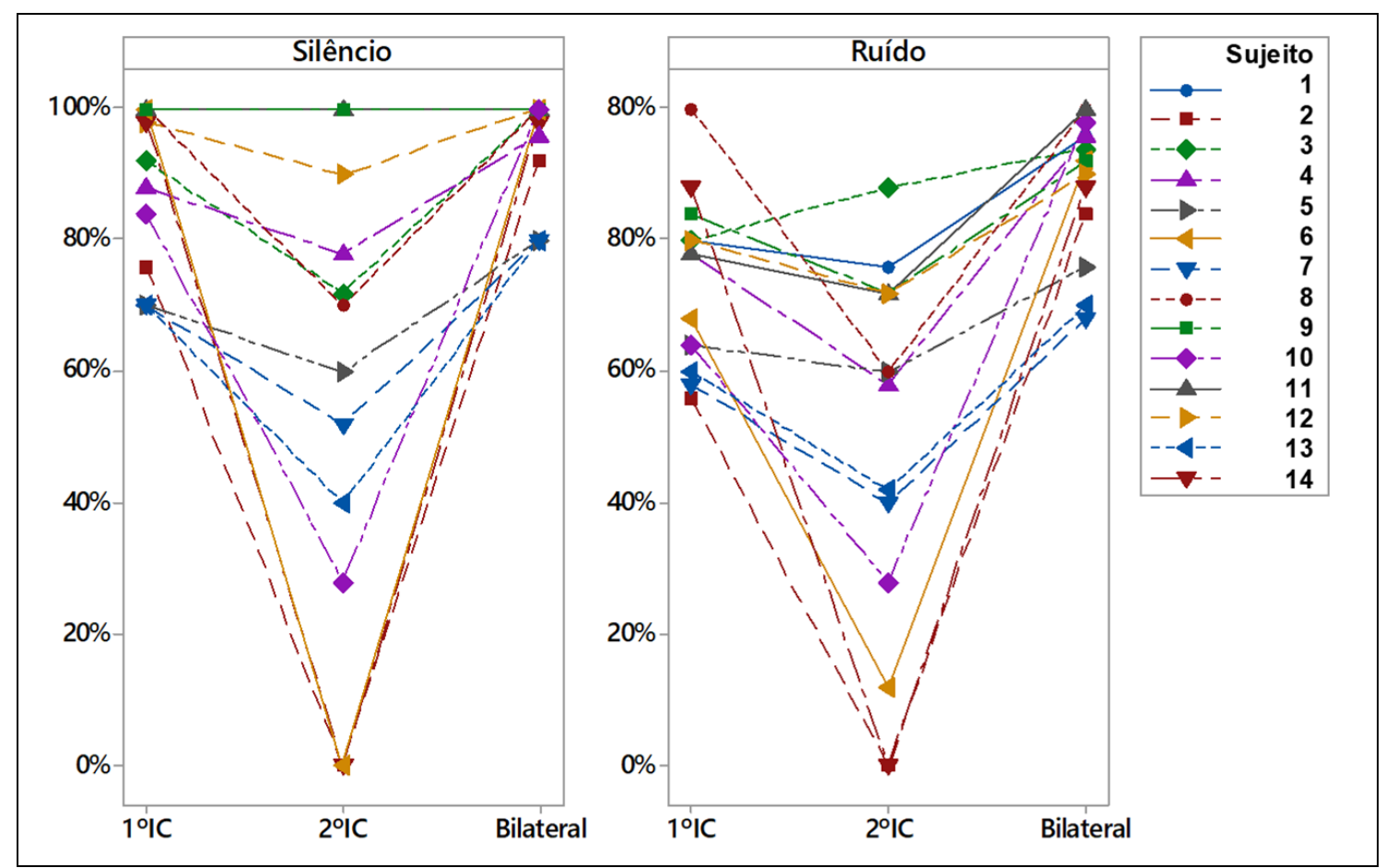

Figura 2 - Perfis individuais da porcentagem de acertos nos testes de reconhecimento de fala no silêncio de no ruído nas três condições de avaliação

Na comparação do desempenho de reconhecimento de fala com o $1^{\circ} \mathrm{IC}$, com o $2^{\circ}$ IC e com o IC bilateral, foram encontradas diferenças estatisticamente significantes para todas as condições de avaliação. $O$ melhor desempenho foi encontrado com o IC bilateral, tanto no silêncio quanto no ruído, quando comparado com o $1^{\circ} \mathrm{IC}$ e com o $2^{\circ} \mathrm{IC}$ isoladamente. Na análise do desempenho de cada IC separadamente, os valores médios de reconhecimento de fala com o $1^{\circ}$ IC foram significativamente maiores do que com o $2^{\circ} \mathrm{IC}$, tanto no silêncio quanto no ruído (Tabela 4). 
Tabela 4 - Comparação da porcentagem de acertos nos testes de reconhecimento de fala no silêncio e no ruído para as três condições de avaliação

\begin{tabular}{|c|c|c|c|}
\hline Situação & Condição & $\begin{array}{c}\text { Porcentagem de } \\
\text { acertos } \\
\text { Média ( } \pm \mathrm{DP})\end{array}$ & p-valor \\
\hline Silêncio & $\begin{array}{c}1^{\circ} \mathrm{IC} \\
2^{\circ} \mathrm{IC} \\
\mathrm{IC} \text { bilateral }\end{array}$ & $\begin{array}{c}89,0( \pm 12,6) \\
56,4( \pm 37,6) \\
94,7( \pm 8,3)\end{array}$ & $\begin{array}{c}1^{\circ} \text { IC vs } 2^{\circ} \mathrm{IC}=0,003^{*} \\
1^{\circ} \mathrm{IC} \text { vs IC bilateral }=0,011^{*} \\
2^{\circ} \mathrm{IC} \text { vs IC bilateral }=0,003^{*}\end{array}$ \\
\hline Ruído & $\begin{array}{c}1^{\circ} \mathrm{IC} \\
2^{\circ} \mathrm{IC} \\
\mathrm{IC} \text { bilateral }\end{array}$ & $\begin{array}{l}74,1( \pm 12,8) \\
48,6( \pm 29,0) \\
88,9( \pm 10,6)\end{array}$ & $\begin{array}{c}1^{\circ} \text { IC vs } 2^{\circ} I C=0,003^{*} \\
1^{\circ} \text { IC vs IC bilateral }=0,002^{*} \\
2^{\circ} \text { IC vs IC bilateral }=0,001^{*}\end{array}$ \\
\hline
\end{tabular}

Legenda: IC= Implante Coclear; $\mathrm{DP}=$ Desvio Padrão; vs= versus; ${ }^{*} \mathrm{p}$-valor $<5 \%$

A comparação do reconhecimento de fala para as situações de silêncio e ruído demonstrou que, a porcentagem média de acertos no silêncio foi significativamente maior do que a obtida com ruído para a condição com o $1^{\circ}$ IC $(p=0,001)$ e com o IC bilateral $(p=0,003)$. Com o uso do $2^{\circ} I C$, não foi encontrada diferença estatisticamente significante entre o reconhecimento de fala no silêncio e no ruído $(p=0,066)$ (Tabela 5$)$.

Tabela 5 - Comparação entre a porcentagem de reconhecimento de fala no silêncio e no ruído, com o uso do $1^{\circ}$ IC, $2^{\circ}$ IC e IC bilateral

\begin{tabular}{cccc}
\hline \multicolumn{4}{c}{$\begin{array}{c}\text { Porcentagem de acertos } \\
\text { Média ( } \pm \mathrm{DP})\end{array}$} \\
Condição & Silêncio & Ruído & p-valor \\
\hline $1^{\circ}$ IC & $89,0( \pm 12,6)$ & $74,1( \pm 12,8)$ & $0,001^{*}$ \\
$2^{\circ}$ IC & $56,4( \pm 37,6)$ & $48,6( \pm 29,0)$ & 0,066 \\
IC bilateral & $94,7( \pm 8,3)$ & $88,9( \pm 10,6)$ & $0,003^{*}$ \\
\hline
\end{tabular}

Legenda: IC= Implante Coclear; DP= Desvio Padrão; ${ }^{*} \mathrm{p}$-valor $<5 \%$ 
5.2 Intervalo cirúrgico, idade na cirurgia e tempo de uso do $2^{\circ}$ IC e os resultados de reconhecimento de fala no silêncio e no ruído com o 2o IC e IC bilateral.

A análise da influência das variáveis intervalo cirúrgico, idade na cirurgia do $2^{\circ}$ IC e tempo de uso do $2^{\circ}$ IC para os resultados de reconhecimento de fala com o 2 IC e com o IC bilateral demonstraram não haver correlação estatisticamente significante entre o desempenho auditivo com o $2^{\circ}$ IC e com o IC bilateral e tais variáveis, tanto no silêncio quanto no ruído (Tabela 6).

Tabela 6 - Correlação das porcentagens de acertos para o reconhecimento de fala no silêncio e no ruído com o 2º IC e IC bilateral e intervalo cirúrgico, idade na cirurgia do $2^{\circ}$ IC e tempo de uso do $2^{\circ}$ IC

\begin{tabular}{ccccc}
\hline & Situação & $\begin{array}{c}\text { Intervalo } \\
\text { entre 10 e 20 } \\
\text { IC }\end{array}$ & $\begin{array}{c}\text { Idade na } \\
\text { cirurgia 20 IC }\end{array}$ & $\begin{array}{c}\text { Tempo de } \\
\text { uso 20 IC }\end{array}$ \\
\hline $\begin{array}{c}\text { Reconhecimento } \\
\text { de fala com 20 IC }\end{array}$ & Silêncio & $\begin{array}{c}r=-0,28 \\
\mathrm{p}=0,339\end{array}$ & $\begin{array}{c}\mathrm{r}=-0,35 \\
\mathrm{p}=0,214\end{array}$ & $\begin{array}{c}\mathrm{r}=-0,06 \\
\mathrm{p}=0,852\end{array}$ \\
& Ruído & $\begin{array}{c}\mathrm{r}=-0,33 \\
\mathrm{p}=0,251\end{array}$ & $\begin{array}{c}\mathrm{r}=-0,43 \\
\mathrm{p}=0,128\end{array}$ & $\begin{array}{c}\mathrm{r}=-0,03 \\
\mathrm{p}=0,922\end{array}$ \\
\hline \multirow{2}{*}{$\begin{array}{c}\text { Reconhecimento } \\
\text { de fala com IC } \\
\text { bilateral }\end{array}$} & Silêncio & $\mathrm{r}=0,50$ & $\mathrm{r}=0,56$ & $\mathrm{r}=-0,48$ \\
& & $\mathrm{p}=0,067$ & $\mathrm{p}=0,035$ & $\mathrm{p}=0,084$ \\
& Ruído & $\mathrm{r}=0,38$ & $\mathrm{r}=0,48$ & $\mathrm{r}=-0,52$ \\
& & $\mathrm{p}=0,178$ & $\mathrm{p}=0,080$ & $\mathrm{p}=0,054$ \\
\hline
\end{tabular}

Legenda: $I C=$ Implante Coclear; $r=$ coeficiente de correlação de Pearson; $p=p$-valor

No entanto, um pior desempenho na habilidade de reconhecimento auditivo com o 2 IC foi encontrado nos indivíduos que receberam o 2 IC em idade mais avançada e que apresentavam maior intervalo cirúrgico e menor tempo de uso do segundo dispositivo. Os diagramas de dispersão apresentados nas figuras 3 e 4 descrevem o reconhecimento de fala no silêncio e no ruído com o $2^{\circ}$ IC em 
relação ao intervalo cirúrgico, à idade na cirurgia do $2^{\circ}$ IC e ao tempo de uso do 2IC. 


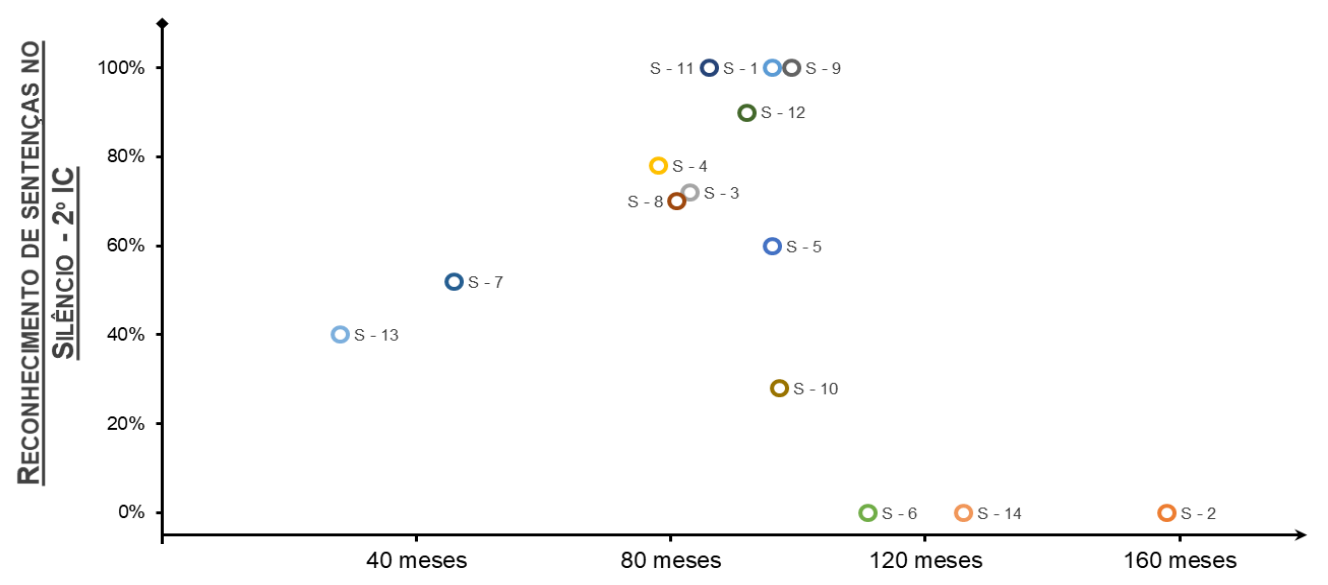

INTERVALO CIRÚRGICO ENTRE $1^{\circ}$ IC E 2० IC

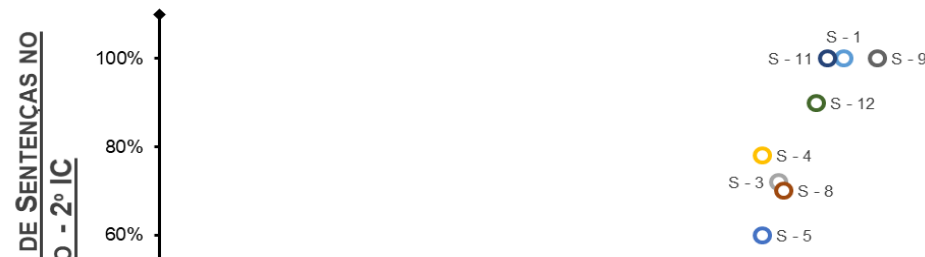

Os-7

OS-13

OS -10

$20 \%$

-6 Os $-14 \quad$ Os -2

50 meses

150 meses

200 meses

IDADE NA CIRURGIA DO 2० IC

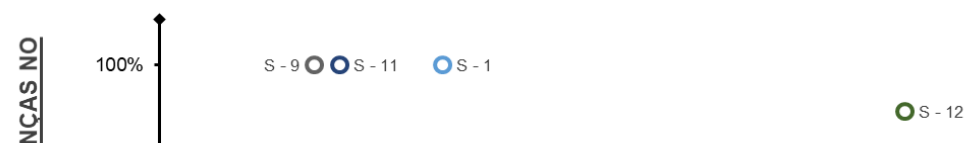

Os-3 Os-8

Os-5

Os-7

OS -13

Os - 10

$20 \%$

S-14OS- 6 OS-2

20 meses

40 meses

60 meses

80 meses

TEMPO DE USO DO $2^{\circ}$ IC

Figura 3 - Diagramas de dispersão da porcentagem de acertos no teste de reconhecimento de fala no silêncio para a condição $2^{0}$ IC e o intervalo cirúrgico, idade na cirurgia do $2^{\circ}$ IC e tempo de uso do $2^{\circ}$ IC 

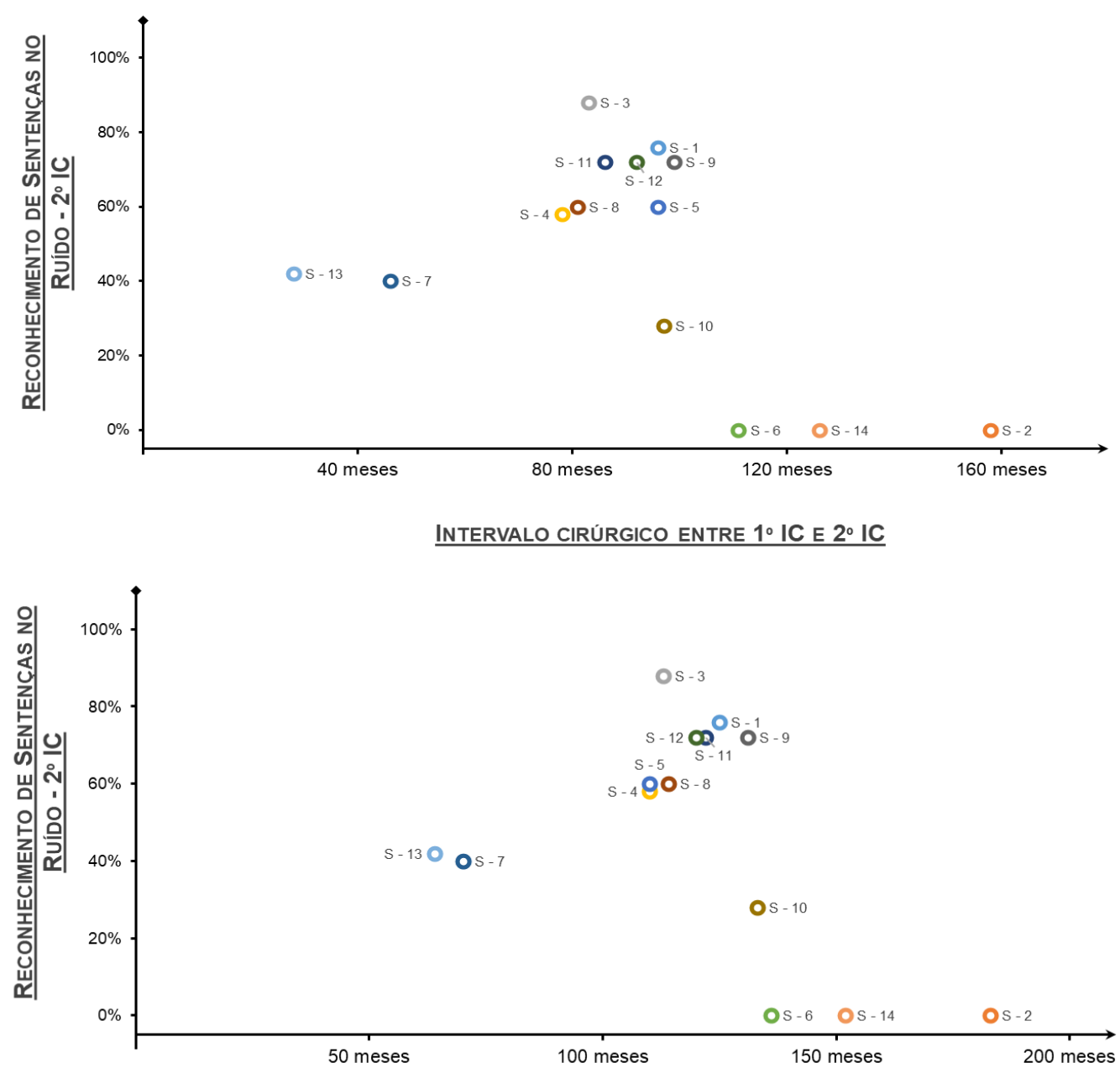

IDADE NA CIRURGIA DO 2० IC

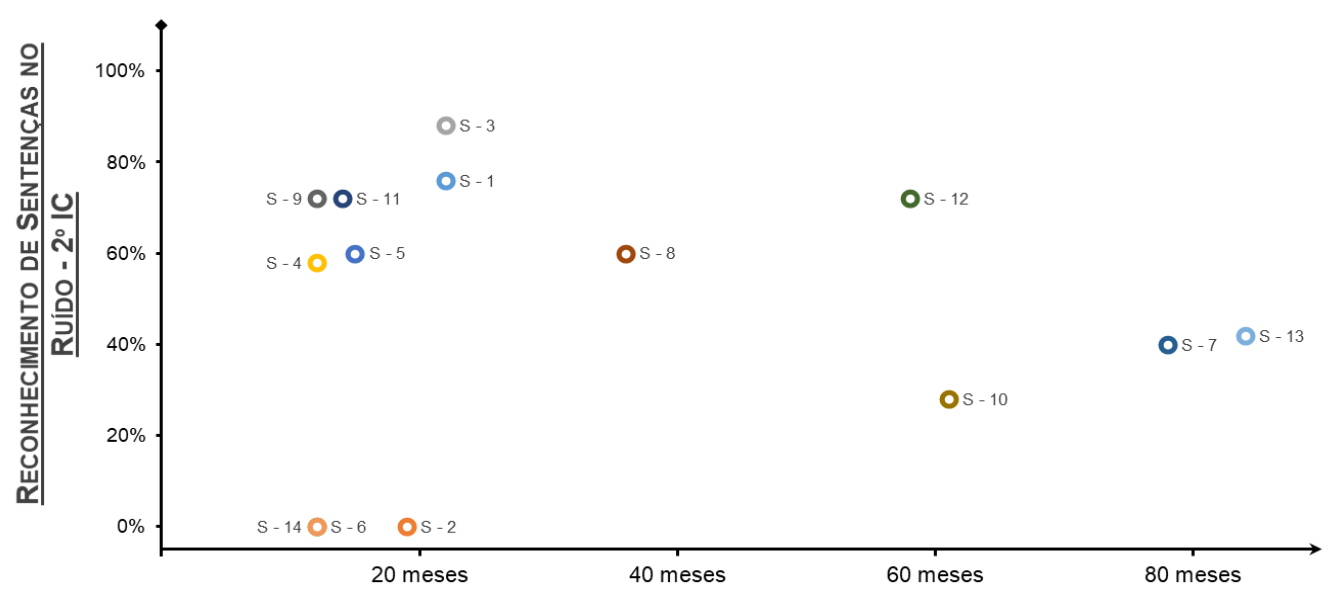

TEMPO DE USO DO $2^{\circ}$ IC

Figura 4 - Diagramas de dispersão da porcentagem de acertos no teste de reconhecimento de fala no ruído para a condição $2^{\circ}$ IC e o intervalo cirúrgico, idade na cirurgia do $2^{\circ} \mathrm{IC}$ e tempo de uso do $2^{\circ} \mathrm{IC}$ 
Em relação ao IC bilateral, uma vantagem auditiva bilateral na tarefa de reconhecimento auditivo, tanto no silêncio quanto no ruído, foi encontrada para todos os participantes de pesquisa, independentemente do intervalo cirúrgico, da idade na cirurgia e tempo de uso do $2^{\circ}$ IC. As figuras 5 e 6 apresentam os diagramas de dispersão demonstrando o reconhecimento auditivo no silêncio e no ruído e as variáveis intervalo cirúrgico, idade na cirurgia do $2^{\circ}$ IC e tempo de uso do $2^{\circ} \mathrm{IC}$. 


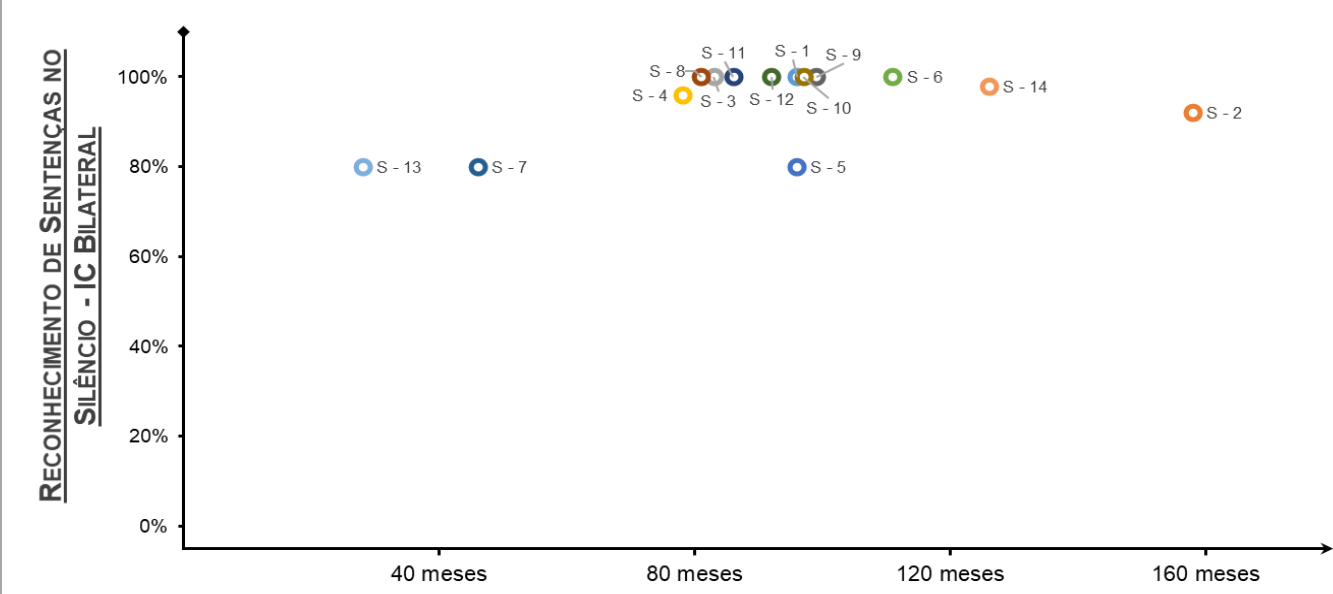

INTERVALO CIRÚRGICO ENTRE 1० IC E 2。 IC

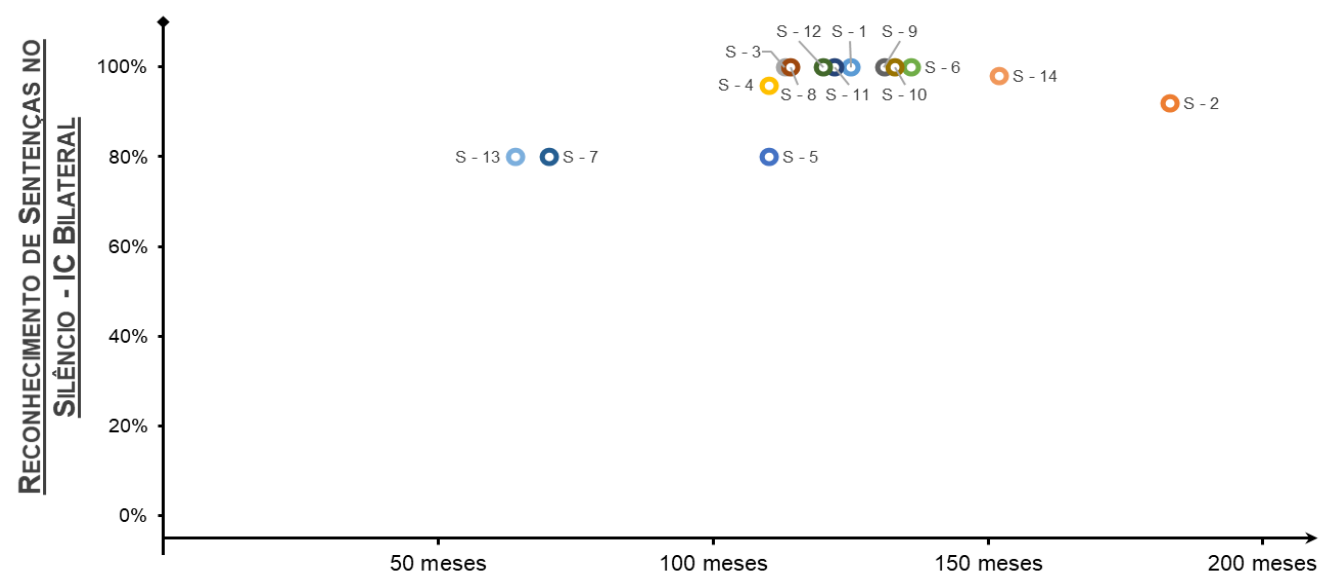

IDADE NA CIRURGIA DO 2० IC

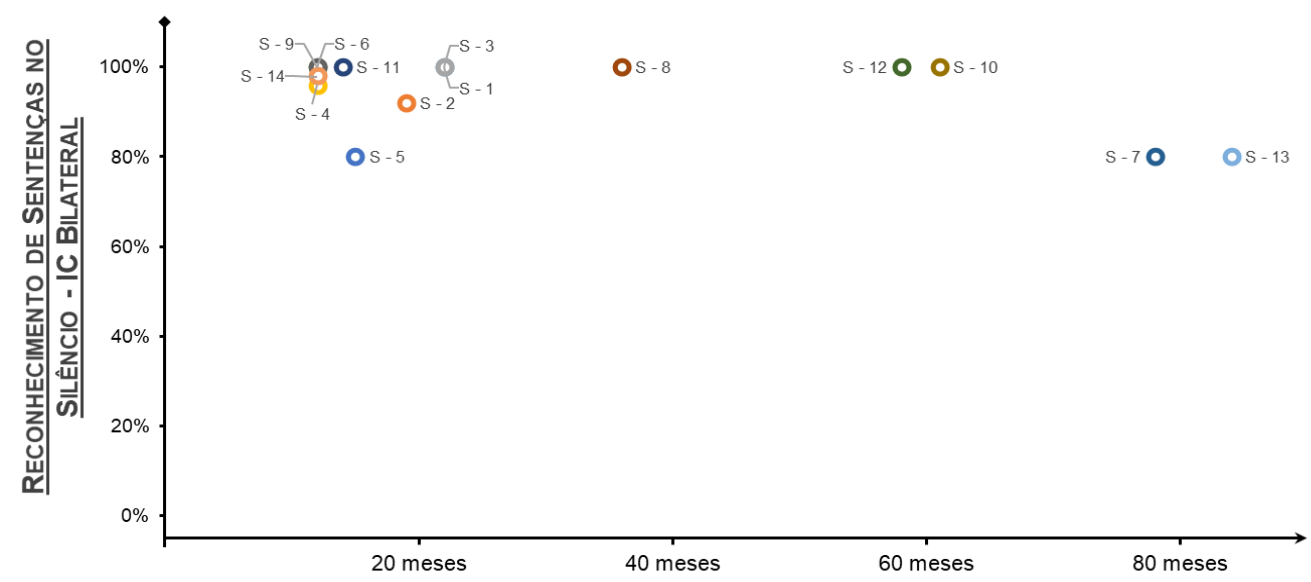

TEMPO DE USO DO $2^{\circ}$ IC

Figura 5 - Diagramas de dispersão da porcentagem de acertos no teste de reconhecimento de fala no silêncio para a condição IC bilateral e o intervalo cirúrgico, idade na cirurgia do $2^{\circ}$ IC e tempo de uso do $2^{\circ}$ IC 

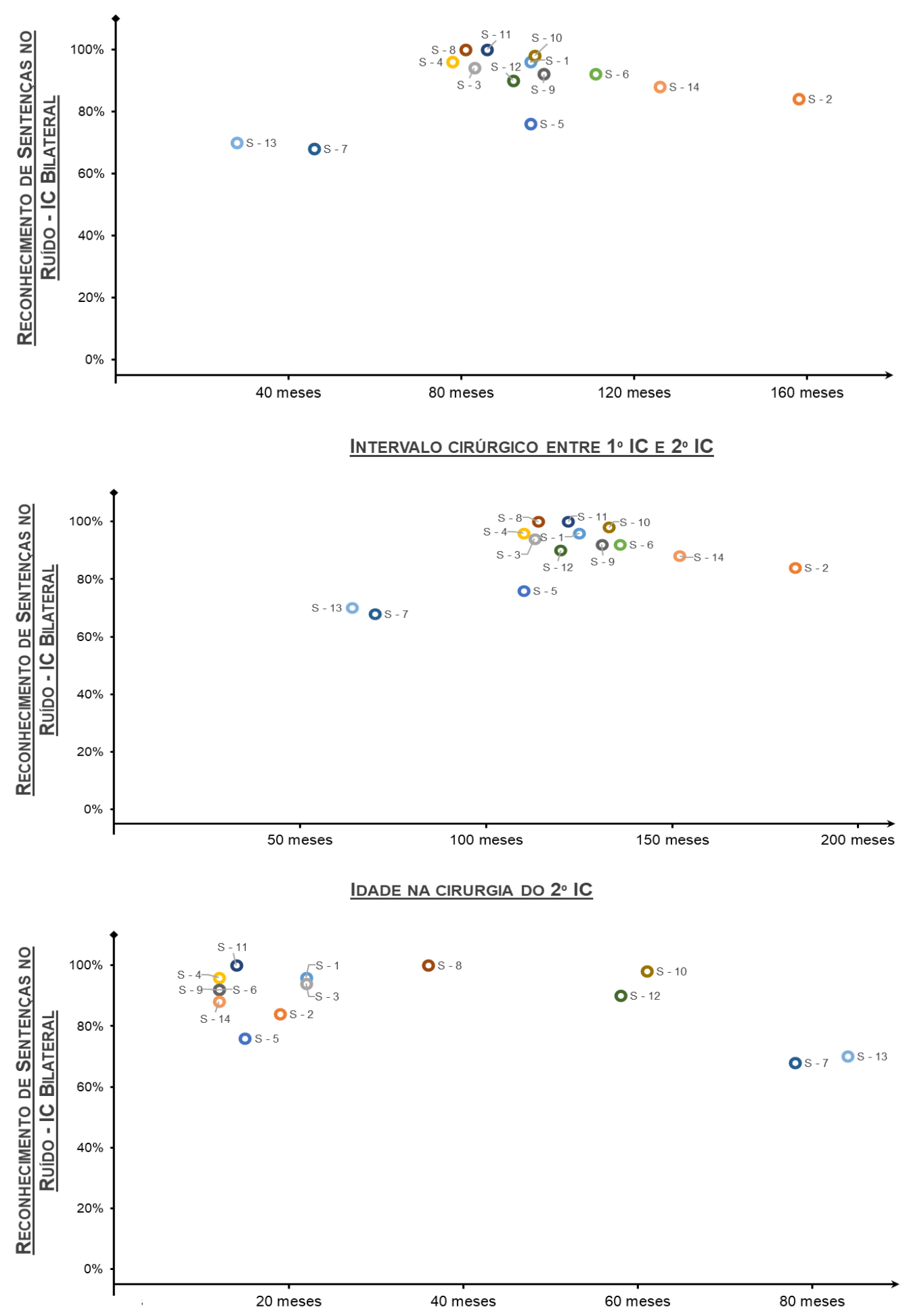

TEMPO DE USO DO 2० IC

Figura 6 - Diagramas de dispersão da porcentagem de acertos no teste de reconhecimento de fala no ruído para a condição IC bilateral e o intervalo cirúrgico, idade na cirurgia do $2^{\circ}$ IC e tempo de uso do $2^{\circ}$ IC 
5.3 Uso do AASI anterior à segunda cirurgia de IC e os resultados de reconhecimento de fala no silêncio e no ruído com o $2^{\circ}$ IC e com o IC bilateral

Em relação à influência do uso do AASI anterior à segunda cirurgia para a habilidade de reconhecimento de fala no silêncio e no ruído, foi encontrado um melhor desempenho auditivo, tanto no silêncio quanto no ruído, com o $2^{\circ}$ IC isoladamente e com IC bilateral para o grupo de indivíduos que fez uso do AASI anteriormente ao $2^{\circ} \mathrm{IC}$.

Os valores individuais e médios do reconhecimento de fala no silêncio e no ruído com o $2^{\circ}$ IC e com IC bilateral em relação ao uso do AASI anterior ao $2^{\circ}$ IC estão descritos abaixo (Tabela 7 e Figura 7).

Tabela 7- Descrição da porcentagem de acertos nos testes de reconhecimento de fala no silêncio de no ruído segundo o uso do AASI anterior à segunda cirurgia de IC

\begin{tabular}{ccccccccc}
\hline & Situação & $\begin{array}{c}\text { Uso } \\
\text { AASI }\end{array}$ & N & Média & DP & Mín. & Med. & Máx. \\
\hline & Silêncio & Não & 5 & 13,6 & 19,1 & 0 & 0 & 40 \\
\multirow{2}{*}{$\begin{array}{c}\text { Reconhecimento } \\
\text { de sentenças } \\
\text { com 20 IC }\end{array}$} & Sum & 9 & 80,2 & 18,2 & 52 & 78 & 100 \\
\cline { 2 - 8 } & Ruído & Não & 5 & 16,4 & 18,4 & 0 & 12 & 42 \\
& Sim & 9 & 66,4 & 13,7 & 40 & 72 & 88 \\
\hline \multirow{2}{*}{$\begin{array}{c}\text { Reconhecimento } \\
\text { de sentenças } \\
\text { com IC bilateral }\end{array}$} & Silêncio & Não & 5 & 94,0 & 8,5 & 80 & 98 & 100 \\
\cline { 2 - 8 } & & Sim & 9 & 95,1 & 8,7 & 80 & 100 & 100 \\
\hline
\end{tabular}

Legenda: $\mathrm{AASI}=$ Aparelho de Amplificação Sonora Individual; $\mathrm{N}=$ número amostral; DP= Desvio Padrão; Mín= Mínimo; Med= Mediana; Máx= Máximo 


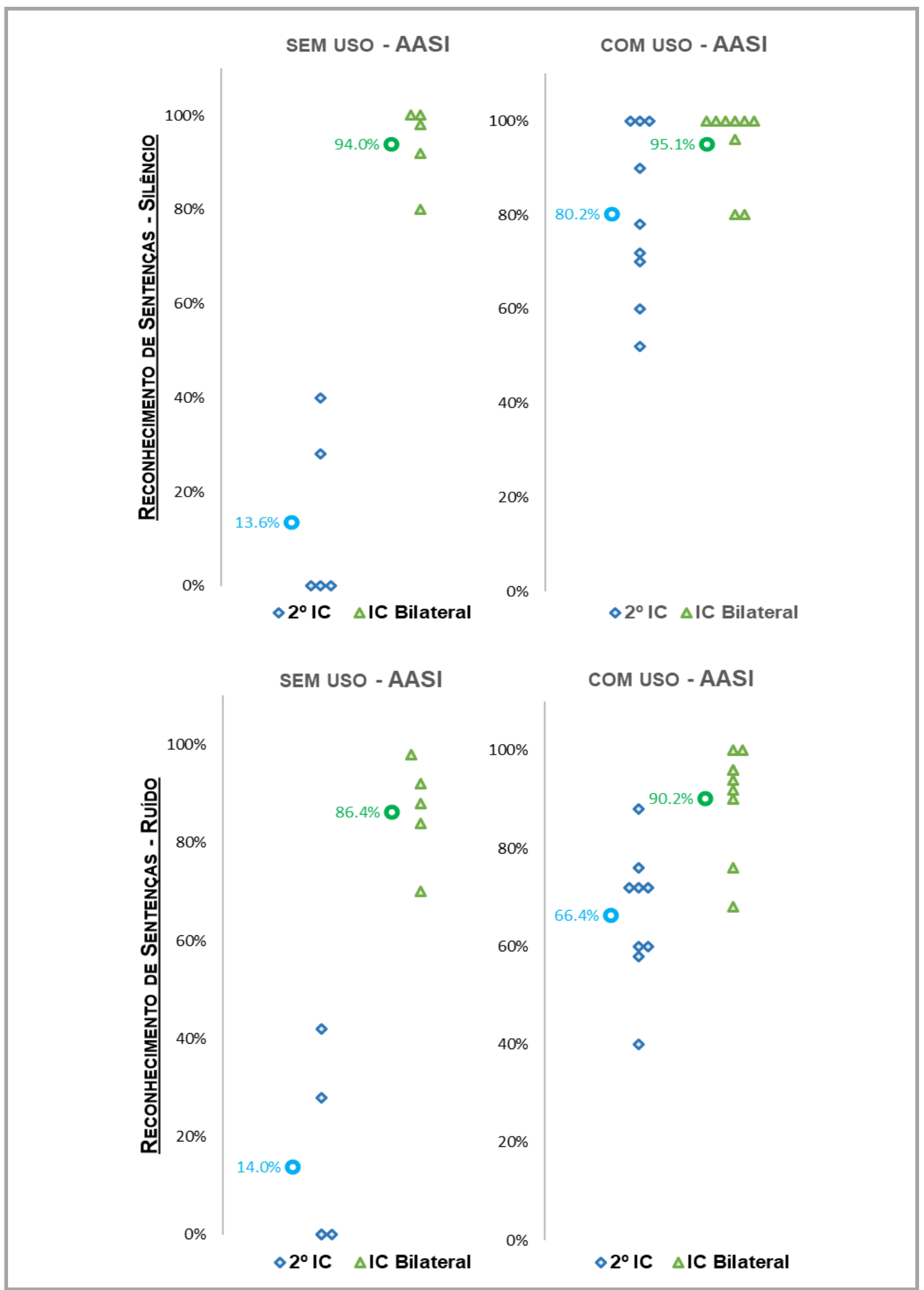

Figura 7 - Valores individuais e médios da porcentagem de acertos de reconhecimento de fala no silêncio e no ruído com o $2^{\circ}$ IC e com IC bilateral de acordo com o uso do AASI anterior ao $2^{\circ}$ IC 
Uma diferença estatisticamente significante foi encontrada para os resultados de reconhecimento de fala com o uso do $2^{\circ} \mathrm{IC}$, tanto no silêncio $(p=0,001)$ quanto no ruído $(p=0,002)$, para o grupo de indivíduos que utilizou o AASI na orelha contralateral ao $1^{\circ}$ IC. Na avaliação do desempenho com o IC bilateral, não foram encontradas diferenças estatisticamente significantes para o reconhecimento de fala no silêncio $(p=0,606)$ e no ruído $(p=0,364)$ entre os indivíduos que fizeram e não fizeram uso da amplificação sonora individual anterior à segunda cirurgia (Tabela 8).

Tabela 8 - Comparação da porcentagem de acertos no teste de reconhecimento de fala no silêncio e no ruído, em relação ao uso do AASI anterior ao $2^{\circ}$ IC

\begin{tabular}{|c|c|c|c|c|}
\hline & \multicolumn{4}{|c|}{ Porcentagem de acertos } \\
\hline & & \multicolumn{2}{|c|}{ Média ( \pm DP) } & \multirow{2}{*}{ p-valor } \\
\hline & & Com AASI $(n=9)$ & Sem AASI $(n=5)$ & \\
\hline \multirow{2}{*}{ Silêncio } & $2^{\circ} \mathrm{IC}$ & $80,2( \pm 18,2)$ & $13,6( \pm 19,1)$ & $0,001^{*}$ \\
\hline & IC bilateral & $95,1( \pm 8,7)$ & $94,0( \pm 8,5)$ & 0,606 \\
\hline \multirow{2}{*}{ Ruído } & $2^{\circ} \mathrm{IC}$ & $66,4( \pm 13,7)$ & $16,4( \pm 18,3)$ & $0,002^{*}$ \\
\hline & IC bilateral & $90,2( \pm 11,0)$ & $86,4( \pm 10,5)$ & 0,364 \\
\hline
\end{tabular}

Legenda: $I \mathrm{C}=$ Implante Coclear; AASI= Aparelho de Amplificação Sonora Individual; $\mathrm{n}=$ número amostral $\mathrm{DP}=$ Desvio Padrão; ${ }^{*} \mathrm{p}$-valor $<5 \%$ 


\section{Discussão}




\section{DISCUSSÃO}

Este estudo teve como objetivo avaliar a habilidade de reconhecimento de fala em crianças e adolescentes submetidos ao IC bilateral sequencial por meio da avaliação do reconhecimento de fala no silêncio e no ruído.

As habilidades auditivas decorrentes da binauralidade podem ser alcançadas em indivíduos com deficiência auditiva severa a profunda de duas maneiras: por meio do uso combinado do IC e do AASI na orelha contralateral, denominada estimulação bimodal, indicada em indivíduos que apresentam audição residual na orelha não implantada; e por meio da estimulação bilateral, com o uso do IC em ambas as orelhas, realizado de maneira simultânea ou sequencial.

Dentre as vantagens da estimulação bimodal, destacam-se o melhor reconhecimento de fala, de melodia e de música. No entanto, essa estimulação é vista como uma possibilidade em indivíduos que apresentam audição residual suficiente para a obtenção de benefícios com a amplificação sonora, sendo o IC bilateral considerado nos casos em que a audição bimodal não é efetiva (Litovsky et al., 2006a; Ching et al., 2007; Melo et al., 2013).

Em comparação com a estimulação monoaural, a estimulação bilateral resulta em melhor qualidade sonora, redução do esforço auditivo e melhora da qualidade de vida, pois a entrada auditiva em ambas as orelhas favorece a localização sonora e o reconhecimento de fala no ruído por uma combinação do 
efeito de sombra da cabeça, somação binaural e efeito squelch binaural (Müller et al., 2002; Offeciers et al., 2005; Peters et al., 2007).

Com a consolidação dos benefícios do IC unilateral e a ampliação nos critérios de indicação na população pediátrica, a possibilidade de indicação do IC bilateral sequencial passou a compor o cenário clínico atual, uma vez que um número significativo de crianças que receberam o IC nos primeiros anos de vida podem ser potenciais candidatas ao IC bilateral sequencial.

O impacto funcional da estimulação bilateral pode ser especialmente importante para a população pediátrica, à medida que a complexidade das situações de escuta aumenta conforme a idade, em particular para os ambientes educacionais e sociais em que as crianças estão inseridas. Além disso, a possibilidade de um maior e melhor aprendizado incidental, bem como a redução no esforço auditivo e cognitivo necessário para a execução de tarefas de vida diária podem compor as vantagens obtidas com o uso do IC bilateral.

Nesse sentido, a avaliação e indicação do IC bilateral em crianças e adolescentes com longos intervalos cirúrgicos caracterizam-se como um dos desafios da prática clínica contemporânea.

A literatura científica da área tem destacado os benefícios do IC bilateral no que se refere às habilidades de localização sonora e reconhecimento de fala em situações de ruído competitivo em crianças e adultos. No entanto, um consenso ainda não foi definido, em relação ao intervalo cirúrgico desejável e necessário para a obtenção dos benefícios advindos do IC bilateral sequencial (Van Hoesel e Tyler, 2003; Laszig et al., 2004; Ching et al., 2007; Galvin et al., 2007; Galvin 
et al., 2008; Lammers et al., 2014; Sparreboom et al., 2011; Friedmann et al., 2015).

A idade de implantação do IC é reconhecidamente um fator capaz de impactar os resultados pós-cirúrgicos em crianças, sendo este aspecto considerado como um preditor para o desenvolvimento das habilidades auditivas e de linguagem (Sharma et al., 2002a; Sharma et al.,2002b; Sharma et al., 2004).

Diversos autores destacaram a influência da idade na cirurgia do $1^{\circ}$ IC como um importante aspecto a ser considerado nos resultados do IC bilateral (Galvin et al., 2008; Zeitler et al., 2008; Friedmann et al., 2015; Moret, 2016; Illg et al., 2017). Todas as crianças do presente estudo receberam o $1^{\circ} \mathrm{IC}$ antes dos três anos de idade, ou seja, no período mais sensível ao desenvolvimento e maturação do sistema auditivo (Tabela 1). Sendo assim, o uso contínuo e efetivo do $1^{\circ}$ IC por um longo período de tempo e o desenvolvimento da habilidade de reconhecer e interpretar a mensagem enviada via IC, possivelmente contribuiu para a adaptação e obtenção de resultados positivos com o IC bilateral.

Outros aspectos capazes de influênciar positivamente os resultados do IC e que foram encontrados nos indivíduos da presente pesquisa também merecem destaque, dentre eles o uso efetivo dos dispositivos e a participação efetiva em um programa de habilitação auditiva (Kirk et al., 2002; Baumgartner et al., 2002; Mauer, 2002; Sharma et al., 2004; Sharma et al., 2005; Moret et al., 2007; Sharma et al., 2007).

No que se referiu ao desempenho auditivo, todos os indivíduos desta pesquisa apresentavam bons resultados de reconhecimento de fala apenas pela via auditiva com o $1^{\circ}$ IC no silêncio ( $\left.\geq 70 \%\right)$. No entanto, apesar do bom 
desempenho com o IC unilateral, uma maior dificuldade foi encontrada para a tarefa de reconhecimento de fala na presença de ruído competitivo, demonstrando assim os desafios auditivos enfrentados nas situações de escuta complexa do dia a dia (Figura 2 e Tabela 3).

As dificuldades vivenciadas nas situações auditivas que requerem 0 desenvolvimento de habilidades complexas, especialmente as situações de ruído competitivo, podem ter motivado a decisão pelo IC bilateral nos indivíduos de pesquisa, mesmo diante de um longo intervalo de tempo entre as cirurgias (Tabela 2).

Um dos questionamentos destacados pela comunidade clínica e científica em relação ao IC bilateral sequencial diz respeito às habilidades a serem alcançadas com o $2^{\circ} \mathrm{IC}$; ou seja, se será possível alcançar o mesmo desempenho do $1^{\circ} \mathrm{IC}$, de que maneira e em quanto tempo. Um menor intervalo entre as cirurgias pode proporcionar vantagens bilaterais em um menor espaço de tempo, além de facilitar o aprendizado incidental das habilidades auditivas e de linguagem oral na população pediátrica que adquiriu a deficiência auditiva antes do desenvolvimento da linguagem oral (Illg et al., 2013; Friedmann et al., 2015; Illg et al., 2017).

Os resultados do presente estudo demonstraram que o desempenho auditivo com IC bilateral foi superior àqueles encontrados com o $1^{\circ}$ IC e com 0 $2^{\circ}$ IC isoladamente, com diferença estatisticamente significante para a condição IC bilateral tanto no silêncio quanto no ruído, quando comparada às outras condições de avaliação (Tabela 4). Esses resultados corroboram com outros estudos atuais, os quais demonstraram a possibilidade de obtenção de 
vantagens bilaterais mesmo em indivíduos com grandes intervalos entre as cirurgias (Sparreboom et al., 2011; Kim et al., 2013; Bianchin et al., 2017; Reeder et al., 2017).

Uma diferença estatisticamente significante foi encontrada na comparação de desempenho entre o $1^{\circ}$ e $\circ 2^{\circ}$ IC no silêncio e no ruído sugerindo, portanto, uma assimetria entre as vias auditivas e uma predominância do primeiro lado implantado em relação ao $2^{\circ}$ IC (Figura 2 e Tabelas 3 e 4). Esses achados estão de acordo com a literatura científica, na qual crianças que fizeram uso do IC unilateral por muitos anos antes de receber o $2^{\circ}$ IC apresentaram assimetrias na via auditiva e na função cortical as quais refletiram em uma diferença no desempenho auditivo com o 2 IC (Gordon et al., 2008; Gordon e Papsin, 2009; Gordon et al., 2010; Gordon et al., 2011).

Três indivíduos de pesquisa (S2, S6 e S14), embora apresentassem vantagens auditivas na avaliação com o IC bilateral, não foram capazes de reconhecer a fala com o uso do $2^{\circ}$ IC isoladamente (Figura 2). Nesse contexto, é importante destacar que esses indivíduos além de apresentarem menor tempo de experiência auditiva com o $2^{\circ} \mathrm{IC}$, realizaram a cirurgia do $2^{\circ} \mathrm{IC}$ em idade mais avançada e com isso apresentavam maiores intervalos de tempo entre as cirurgias (Figuras 3 e 4). Os resultados do presente estudo estão de acordo com a literatura científica a qual destacou que o domínio do $1^{\circ}$ IC em relação ao $2^{\circ}$ IC pode ocorrer em indivíduos com maior intervalo cirúrgico e especialmente em situações de ruído competitivo (Bianchin et al., 2017). Mesmo com uma vantagem bilateral significativa, quanto maior o intervalo cirúrgico, maior pode 
ser a diferença entre o desempenho do $1^{\circ}$ e do $2^{\circ}$ IC (Scherf et al., 2009; StromRoum et al., 2012; Reeder et al., 2017).

Além disso, uma implantação mais tardia do $2^{\circ}$ IC pode requerer um maior tempo de uso para a obtenção do desempenho máximo oferecido pela estimulação elétrica. Com isso, os resultados do $2^{\circ}$ IC podem melhorar ao longo do tempo, com decorrente aumento na vantagem bilateral, especialmente para as situações de ruído competitivo. Segundo a literatura, uma vantagem de 3 a 4 dB pode ser obtida na condição bilateral e esta vantagem pode ser influenciada pelo tempo de uso e pela idade em que o $2^{\circ}$ IC foi realizado (Galvin et al., 2008; Sparreboom et al., 2011). Ademais, a otimização dos resultados com o $2^{\circ}$ IC pode requerer um treinamento auditivo específico, com horas de uso diário apenas com o $2^{\circ}$ IC (Kim et al., 2013).

Ainda que tenham sido obtidas diferenças de desempenho entre os dois lados ( $1^{\circ} \mathrm{IC}$ e $2^{\circ} \mathrm{IC}$ isoladamente), todos os indivíduos avaliados no presente estudo faziam uso contínuo de ambos os dispositivos, mesmo após um longo intervalo de tempo entre as cirurgias. Assim sendo, o acesso às redes neurais estabelecidas pelo $1^{\circ} \mathrm{IC}$, bem como a integração da estimulação vinda de ambos os lados pode ser capaz de facilitar o aprendizado das habilidades auditivas com o $2^{\circ}$ IC e favorecer o uso efetivo do IC bilateral (IIlg et al., 2017).

No que se referiu à comparação dos resultados de reconhecimento auditivo no silêncio e no ruído, a porcentagem de acertos no teste no silêncio foi significativamente maior do que a obtida no teste com ruído para as condições $1^{\circ}$ IC e IC bilateral. Com uso do $2^{\circ}$ IC isoladamente, a média do reconhecimento de fala na situação de ruído foi menor do que àquela encontrada no silêncio, 
porém, não foi encontrada uma diferença estatisticamente significante (Tabela 5). Estes resultados estão de acordo com a literatura científica, a qual já havia descrito os desafios encontrados para a percepção auditiva da fala nas situações de ruído competitivo e a vantagem do IC bilateral para esta habilidade auditiva complexa (Nascimento e Bevilacqua, 2005; Gordon e Papsin, 2009; Kim et al., 2013; Illg et al., 2013; Sbompato et al., 2015; Reeder et al., 2017; Bianchin et al., 2017).

Para os indivíduos do presente estudo, o IC bilateral sequencial contemplou as expectativas em relação à vantagem auditiva em habilidades de escuta complexa, com benefícios na percepção auditiva da fala na presença de ruído competitivo. Esses resultados corroboram com os dados apresentados na literatura, segundo os quais o reconhecimento de fala é significantemente melhor com o uso do IC bilateral, quando comparado ao IC unilateral (Kühn-Inacker et al., 2004; Peters et al., 2007; Wolfe et al., 2007; Galvin et al., 2008; Steffens et al., 2008; Lovett et al., 2010; Sparreboom et al., 2011; Kim et al., 2013).

Em relação à influência da idade no $2^{0} \mathrm{IC}$ e do intervalo de tempo entre as cirurgias para os resultados do IC bilateral, não restam dúvidas que tanto a reorganização cortical quanto o processamento auditivo central podem ser favorecidos quando o $2^{\circ}$ IC é realizado mais precocemente e com um menor intervalo de tempo entre as cirurgias.

Um maior intervalo cirúrgico pode acarretar em uma maior dependência do $1^{\circ}$ IC, menor plasticidade auditiva do segundo lado implantado e uma diminuição na motivação em relação ao uso de um outro dispositivo, o qual não atingiu os resultados do $1^{\circ} \mathrm{IC}$. Entretanto, ainda não está claro se existe uma idade e/ou 
um período crítico para a indicação do $2^{\circ}$ IC neste grupo de crianças com deficiência auditiva pré-lingual que fazem uso do IC unilateral há muitos anos (Sparreboom et al., 2011; Reeder et al., 2017; Bianchin et al., 2017).

Os resultados do presente estudo demonstraram que não houve correlação estatisticamente significante entre o intervalo entre as cirurgias, a idade na cirurgia do $2^{\circ}$ IC e o tempo de uso do $2^{\circ}$ IC para os resultados de reconhecimento de fala no silêncio e no ruído com o $2^{\circ}$ IC e com IC bilateral (Tabela 6).

Esses dados estão de acordo com outros estudos que já haviam destacado benefícios para o reconhecimento de fala com a estimulação bilateral sequencial, sem qualquer efeito adverso, em crianças e adolescentes que receberam o $2^{\circ}$ IC em idade mais avançada e com longos intervalos cirúrgicos (Kühn-Inacker et al., 2004; Ramsden et al., 2005; Wolfe et al., 2007; Zeitler et al., 2008; Smulders et al., 2011; Kim et al., 2013; Illg et al., 2013; Friedmann et al., 2015; Moret, 2016). No entanto, Galvin et al. (2008) destacaram a possibilidade de abandono do $2^{\circ}$ IC como efeito adverso em indivíduos com longos intervalos cirúrgicos e enfatizaram, portanto, a importância da orientação e aconselhamento familiar para este grupo clínico de casos.

Há de se considerar que a adaptação e o desempenho do $2^{\circ}$ IC pode estar facilitado em função da preservação da via auditiva correspondente. Nesse sentido, todos os indivíduos de pesquisa apresentavam bom desempenho auditivo com o $1^{\circ} \mathrm{IC}$, denotando desta maneira, um sistema auditivo central com capacidades plásticas suficientes para favorecer o desenvolvimento das habilidades auditivas a partir da estimulação elétrica fornecida pelo IC bilateral. 
Por outro lado, a indicação do $2^{\circ} \mathrm{IC}$ em idade mais avançada, com maior intervalo cirúrgico e consequentemente com maior tempo de privação sensorial pode não favorecer o desenvolvimento de conexões neurais, gerando resultados inferiores para a segunda orelha implantada e piores resultados de reconhecimento de fala (Sharma et al., 2005; Peters et al., 2007; Papsin e Gordon, 2008; Steffens et al., 2008; Graham et al., 2009; Gordon e Papsin, 2009; Illg et al., 2013; Kocdor et al., 2016; Illg et al., 2017; Reeder et al., 2017). Entretanto Zeitler et al. (2008), Illg et al. (2013), Friedmann et al. (2015) e Moret (2016) encontraram uma correlação positiva entre a idade no $2^{\circ}$ IC e o intervalo entre as cirurgias; ou seja, quanto maior a idade e o intervalo entre as cirurgias de IC melhores foram os resultados de reconhecimento de fala.

Certamente a idade em que os indivíduos foram submetidos ao $1^{\circ}$ IC interferiu positivamente nos resultados deste estudo, visto que a estimulação com o $1^{\circ}$ IC durante o período de máxima plasticidade neuronal possibilitou o acesso auditivo e o desenvolvimento de um sistema auditivo mais preparado para a estimulação com o $2^{\circ} \mathrm{IC}$, mesmo com um longo intervalo cirúrgico (Moret, 2016; Bianchin et al., 2017, Illg et al., 2017, Reeder et al., 2017).

No presente estudo, o uso do AASI anterior ao 2 $2^{\circ}$ IC pareceu interferir positivamente nos resultados de reconhecimento de fala com o uso do $2^{\circ} \mathrm{IC}$, tanto no silêncio quanto no ruído. Para o IC bilateral, mesmo sem diferença estatisticamente significante, uma tendência de melhor reconhecimento de fala tanto no silêncio quanto no ruído foi encontrada no grupo de indivíduos que fez uso da audição bimodal (Tabelas 7 e 8 e Figura 7). 
Embora a literatura científica não tenha descrito de maneira detalhada a influência da audição bimodal para a percepção auditiva da fala após o $2^{\circ}$ IC, IIlg et al. (2013) destacaram que o uso do AASI anterior ao $2^{\circ}$ IC pareceu ser um preditor para o melhor reconhecimento de fala, visto que, quanto maior o tempo de experiência com AASI anterior ao $2^{\circ}$ IC, melhores foram os resultados. Os autores ressaltaram ainda que, mesmo com audição residual mínima, os usuários de IC unilateral devem ser encorajados a continuar o uso do AASI contralateral ao $1^{\circ}$ IC, no sentido de manter a atividade neural aferente. Reeder et al. (2017) sugeriram que o uso efetivo do AASI na orelha não implantada durante o intervalo entre as cirurgias pode melhorar os resultados de reconhecimento de fala com o $2^{\circ}$ IC e com IC bilateral, mesmo com resíduo auditivo mínimo.

No presente estudo, o uso do AASI anterior ao $2^{\circ}$ IC pode ter beneficiado as propriedades binaurais, considerando que o desempenho para a habilidade complexa de reconhecimento de fala na presença de ruído competitivo foi superior para os usuários de estimulação bimodal anterior ao $2^{\circ}$ IC. A literatura científica ressaltou a importância do uso efetivo do AASI contralateral ao IC para a estimulação das vias auditivas, bem como para a preservação da audição residual na orelha não implantada. É consenso que longos períodos de estimulação unilateral podem resultar em alterações da via auditiva de modo a impor limitações provenientes da privação sensorial auditiva prolongada (Gatehouse, 1992; Gelfand e Silman, 1993; Palmer, 1999; Ching et al., 2005; Jiwani et al., 2016). 
Neste sentido, convém mencionar que a magnitude da privação sensorial exercida pelo uso do IC unilateral deve ser avaliada em cada indivíduo, considerando a audição residual existente no lado não implantado, o uso efetivo do AASI contralateral, bem como o percurso de habilitação auditiva realizado.

Mesmo com um número reduzido de indivíduos que fizeram uso do AASI contralateral ao longo da experiência com o IC unilateral, os resultados do presente estudo suportam a indicação clínica de encorajar e reforçar o uso do AASI contralateral em crianças com deficiência auditiva adquirida antes do desenvolvimento da linguagem oral, já que em um futuro breve, esse grupo clínico de casos poderão compor os candidatos ao IC bilateral. Mesmo com acesso limitado aos sons de fala, a estimulação acústica pode auxiliar na manutenção e estimulação da via auditiva para uma posterior estimulação elétrica via IC (Reeder et al., 2017).

Na prática clínica, uma grande variabilidade em relação ao uso do AASI contralateral é observada, não sendo possível definir o percentual de pacientes que fazem uso da estimulação elétrica e acústica combinada após o $1^{\circ}$ IC. A literatura científica sugeriu que apenas 10 a 25\% dos usuários de IC unilateral constituem-se como usuários bimodais (Tyler et al., 2002; Fitzpatrick et al., 2009; Yamaguchi e Goffi-Gomez, 2013). Em um estudo multicêntrico internacional, o total dos usuários bimodais representou apenas 32\% (Scherf e Arnold, 2014). Diversos aspectos podem ser considerados na justificativa do não uso do AASI contralateral ao IC, entre eles, a falta de audição residual e, consequentemente, a ausência de benefícios para a percepção auditiva da fala, a falta de orientação dos profissionais no momento pré-operatório e as dificuldades encontradas na 
aquisição e manutenção do AASI (Yamaguchi e Goffi-Gomez, 2009; Yamaguchi e Goffi-Gomez, 2013).

Outra questão a ser considerada é o fato de que o AASI não é, usualmente, reprogramado após a ativação do IC unilateral, e isso pode contribuir para sua rejeição. A inclusão de uma regra prescritiva específica entre os softwares de programação facilitaria a aplicação de um procedimento de balanceamento e poderia aumentar o uso da estimulação bimodal na prática clínica. A experiência limitada em adaptação de AASI nos centros de IC, bem como o número reduzido de procedimentos disponíveis para adaptação bimodal podem contribuir para o grande número de usuários de IC unilateral que não fazem uso do AASI contralateral (Scherf e Arnold, 2014).

Por fim, para todos os indivíduos do presente estudo, a melhora da habilidade de reconhecimento de fala com o IC bilateral fortaleceu e consolidou o uso de ambos os dispositivos de maneira contínua e efetiva. No entanto, a indicação do IC bilateral sequencial em crianças e adolescentes com longos intervalos de tempo entre as cirurgias deve ser realizada de maneira cuidadosa e criteriosa.

Uma orientação detalhada aos candidatos do IC bilateral sequencial e às suas famílias deve ser realizada, considerando a variabilidade dos resultados encontrados na literatura científica. Mesmo diante de resultados encorajadores, é fundamental avaliar as vantagens bilaterais ao longo do tempo, bem como analisar os inúmeros fatores capazes de influenciar os benefícios binaurais a serem obtidos a partir da utilização do IC bilateral. 
Conclusões 


\section{CONCLUSÕES}

A avaliação do reconhecimento de fala em crianças e adolescentes usuários de IC bilateral sequencial demonstrou os seguintes efeitos positivos para a estimulação auditiva bilateral:

- Melhor desempenho de reconhecimento de fala com o uso do IC bilateral, tanto no silêncio quanto no ruído, quando comparado com o $1^{\circ}$ IC e $2^{\circ}$ IC isoladamente. O reconhecimento de fala com o $1^{\circ}$ IC foi significativamente melhor do que com o $2^{\circ} \mathrm{IC}$, tanto no silêncio quanto no ruído.

- Não foi encontrada correlação estatisticamente significante entre idade na cirurgia do $2^{\circ} \mathrm{IC}$, tempo de uso do dispositivo e intervalo entre as cirurgias e o reconhecimento de fala no silêncio e no ruído com $2^{\circ}$ IC e com o IC bilateral.

- O uso do AASI anterior ao 2 IC influenciou positivamente o desempenho de reconhecimento de fala com o $2^{\circ} \mathrm{IC}$, tanto no silêncio quanto no ruído. 
Anexos 


\section{ANEXOS}

ANEXO A - Autorização da instituição onde foi realizada a pesquisa

São Paulo, 01 de fevereiro de 2016

Venho por meio desta elucidar que a Fonoaudióloga Gabriela Felix Lazarini, portadora do RG 46272 260-0 e do CRFa 18217, está autorizada a ser inserida em nossas atividades com intuitos acadêmicos e proposta de coletar dados referentes a nossos pacientes para fins de projeto de pesquisa.

Atenciosamente,

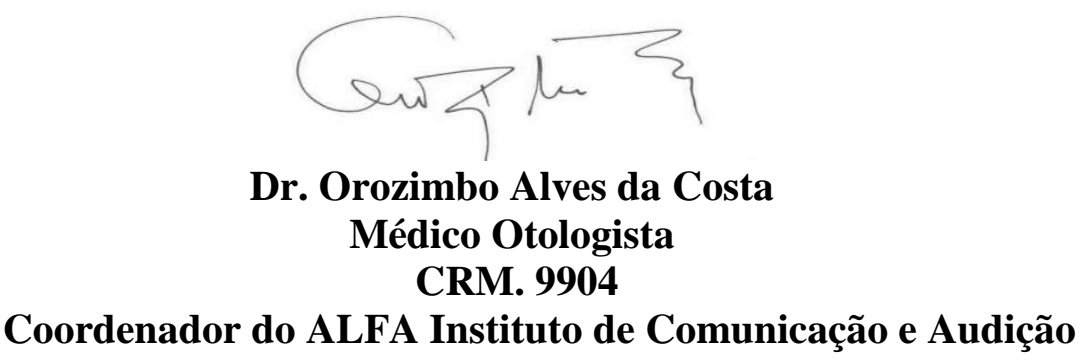


ANEXO B - Ofício de aprovação do projeto emitido pelo Comitê de Ética em

Pesquisa da FMUSP

\section{FACULDADE DE MEDICINA DA UNIVERSIDADE DE SÃO PAULO - FMUSP}

\section{PARECER CONSUBSTANCIADO DO CEP}

\section{DADOS DO PROJETO DE PESQUISA}

Título da Pesquisa: Implante Coclear Bilateral em Crianças

Pesquisador: Ana Claudia Martinho de Carvalho

Área Temática:

Versão: 1

CAAE: 59609216.7 .0000 .0065

Instituição Proponente: Faculdade de Medicina da Universidade de São Paulo

Patrocinador Principal: Financiamento Próprio

DADOS DO PARECER

Número do Parecer: 1.754 .869

Apresentação do Projeto:

INTRODUÇÃO: $O$ implante coclear revolucionou o modo com que indivíduos com deficiência auditiva de grau profundo interagem com outros individuos e com o meio ambiente, já que uma significativa melhora na de percepção da fala tem sido descrita em todas as faixas etárias. Estudos mostram que o implante coclear bilateral melhora o desempenho de localização sonora e da percepção da fala no silêncio e no ruído, em adultos e crianças, independentemente do tempo entre a cirurgia e a idade do paciente. OBJETIVO: Avaliar - desenvolvimento das habilidades auditivas em crianças usuárias de implante coclear (IC) bilateral sequencial. METODOLOGIA: Estudo clínico transversal, a ser realizado um grupo de crianças que receberam indicação cirúrgica para a utilização do Implante Coclear (IC) bilateral como forma de intervenção no processo de habilitação auditiva. Serão realizados testes de percepção da fala, pertinentes à idade $e$ nivel de desenvolvimento do sujeito de pesquisa nas seguintes situações: condição unilateral com o primeiro IC ativado; condição unilateral com o segundo IC ativado e condição bilateral. PRINCIPAIS CONTRIBUIÇÕES DO ESTUDO: Os resultados obtidos poderâo contribuir para uma melhor compreensão dos efeitos da estimulação elétrica bilateral em crianças que foram submetidas a cirurgia de Implante Coclear bilateral sequencial.

Objetivo da Pesquisa:

Avaliar o desenvolvimento das habilidades auditivas em crianças usuárias de implante coclear (IC)

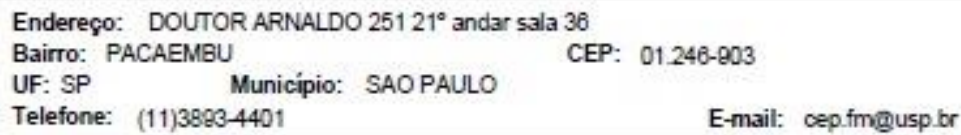




\section{FACULDADE DE MEDICINA DA UNIVERSIDADE DE SÃO PAULO - FMUSP}

Contunuaç5o do Parecer. 1.754 .869

bilateral sequencial.

Avaliação dos Riscos e Beneficios:

risco abaixo - avaliação fonoaudiológica

Comentários e Considerações sobre a Pesquisa:

Projeto com desenho de estudo adequado

Considerações sobre os Termos de apresentação obrigatória:

Adequado

Recomendações:

Explicar que com esse tamanho amostral as estimativas poderá ter baixa precisão

Conclusões ou Pendências e Lista de Inadequações:

Aprovado

Considerações Finais a critério do CEP:

Este parecer foi elaborado baseado nos documentos abaixo relacionados:

\begin{tabular}{|l|l|c|l|c|}
\hline \multicolumn{1}{|c|}{ Tipo Documento } & \multicolumn{1}{|c|}{ Arquivo } & Postagem & \multicolumn{1}{c|}{ Autor } & Situação \\
\hline $\begin{array}{l}\text { Informaçōes Básicas } \\
\text { do Projeto }\end{array}$ & $\begin{array}{l}\text { PB_INFORMAÇOES_BASICAS_DO_P } \\
\text { ROJETO_750550.pdf }\end{array}$ & $\begin{array}{c}01 / 09 / 2016 \\
10: 47: 38\end{array}$ & & Aceito \\
\hline Outros & DocCepFmusp.pdf & $\begin{array}{c}01 / 09 / 2016 \\
10: 46: 51\end{array}$ & $\begin{array}{l}\text { Ana Claudia Martinho } \\
\text { de Carvalho }\end{array}$ & Aceito \\
\hline Folha de Rosto & folha.pdf & $\begin{array}{c}05 / 07 / 2016 \\
10: 44: 35\end{array}$ & $\begin{array}{l}\text { Ana Claudia Martinho } \\
\text { de Carvalho }\end{array}$ & Aceito \\
\hline $\begin{array}{l}\text { Projeto Detalhado / } \\
\text { Brochura } \\
\text { Investigador }\end{array}$ & brochura.pdf & $\begin{array}{c}30 / 06 / 2016 \\
11: 46: 46\end{array}$ & $\begin{array}{l}\text { Ana Claudia Martinho } \\
\text { de Carvalho }\end{array}$ & Aceito \\
\hline $\begin{array}{l}\text { TCLE / Termos de } \\
\text { Assentimento / } \\
\text { Justificativa de } \\
\text { Ausência }\end{array}$ & TCLE.pdf & $30 / 06 / 2016$ \\
$11: 38: 47$ & $\begin{array}{l}\text { Ana Claudia Martinho } \\
\text { de Carvalho }\end{array}$ & Aceito \\
\hline
\end{tabular}

Situação do Parecer:

Aprovado

Necessita Apreciação da CONEP:

Não

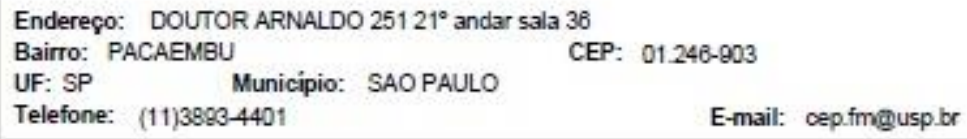


ANEXO C - Termo de consentimento livre e esclarecido

\section{FACULDADE DE MEDICINA DA UNIVERSIDADE DE SÃO PAULO TERMO DE CONSENTIMENTO LIVRE E ESCLARECIDO}

DADOS DE IDENTIFICAÇÃO DO INDIVÍDUO DA PESQUISA OU RESPONSÁVEL LEGAL

1. NOME:

DOCUMENTO DE IDENTIDADE №: SEXO: $M \square F \square$

DATA NASCIMENTO:

ENDEREÇO

№

APTO

BAIRRO: CIDADE

CEP: TELEFONE: DDD ..)

2. RESPONSÁVEL LEGAL NATUREZA (grau de parentesco, tutor, curador etc.) DOCUMENTO DE IDENTIDADE: SEXO: $M \square F \square$ DATA NASCIMENTO. .................... ENDEREÇO:

\section{DADOS SOBRE A PESQUISA}

1. TíTULO DO PROTOCOLO DE PESQUISA: "Implante Coclear Bilateral em Crianças" PESQUISADOR: Ana Claudia Martinho de Carvalho CARGO/FUNÇÃO: Docente INSCRIÇÃO CONSELHO REGIONAL № 9584 UNIDADE DO HCFMUSP: Departamento de Fisioterapia, Fonoaudiologia e Terapia Ocupacional da FMUSP. 3. AVALIAÇÃO DO RISCO DA PESQUISA:

$\begin{array}{ll}\text { RISCO MíNIMO } & X \\ \text { RISCO BAIXO } & \square\end{array}$

4. DURAÇÃO DA PESQUISA: 24 meses 


\section{FACULDADE DE MEDICINA DA UNIVERSIDADE DE SÃO PAULO}

Estas informações estão sendo coletadas para a sua participação voluntária no estudo: "Implante Coclear bilateral em crianças", o qual tem como objetivo avaliar as habilidades auditivas de crianças usuárias de implante coclear bilateral.

Serão realizados testes indolores, em cabina acústica, com o objetivo de avaliar a maneira pela qual seu filho (a) é capaz de compreender os sons da fala utilizando o implante coclear.

As informações obtidas neste estudo poderão contribuir para o melhor conhecimento dos efeitos da estimulação elétrica em ambos os ouvidos em crianças com implante coclear bilateral.

Os dados obtidos durante a pesquisa serão sigilosos, sendo os mesmos utilizados somente para esta pesquisa. As informações serão analisadas em conjunto com outros pacientes, não sendo divulgada a identificação de nenhum dos participantes.

É garantida, a qualquer momento, a sua liberdade de retirada de consentimento, deixando de participar do estudo, sem qualquer prejuízo à continuidade de seu tratamento na Instituição.

O paciente ou responsável poderá obter esclarecimentos a qualquer pergunta ou esclarecimento acerca dos procedimentos, riscos, benefícios e outros assuntos relacionados à pesquisa. O principal investigador da pesquisa é a Dra. Ana Claudia Martinho de Carvalho, que pode ser encontrada no endereço Rua Cipotânea 51 Cidade Universitária, Tel. 3091-7455. Caso tenha alguma consideração ou dúvida sobre a ética da pesquisa, entre em contato com o Comitê de Ética em Pesquisa (CEP) - Rua Ovídio Pires de Campos, 225 - 5ำ andar - tel.: 3069-6442 ramais 16, 17, 18 ou 20, FAX: 3069-6442 ramal 26 - E-mail: cep.fm@usp.br

Não haverá despesas pessoais para você em qualquer fase do estudo, incluindo exames e consultas. Também não haverá compensação financeira relacionada à sua participação. Se existir qualquer despesa adicional, ela será absorvida pelo orçamento da pesquisa.

Acredito ter sido suficientemente informado a respeito das informações que li ou que foram lidas para mim, descrevendo o estudo "Implante coclear bilateral em crianças".

Eu discuti com a Dra. Ana Claudia Martinho de Carvalho sobre a minha decisão em participar deste estudo. Ficaram claros quais são os propósitos do estudo os procedimentos a serem realizados, seus desconfortos e riscos, as garantias de confidencialidade e de esclarecimentos permanentes. Ficou claro também que minha participação é isenta de despesas e que tenho garantia do acesso a tratamento hospitalar quando necessário. Concordo voluntariamente em participar deste estudo e poderei retirar o meu 
consentimento a qualquer momento, antes ou durante o mesmo, sem penalidades ou prejuízo ou perda de qualquer benefício que eu possa ter adquirido, ou no meu atendimento neste Serviço.

Assinatura do paciente/representante legal

Data 11

11


ANEXO D - Listas de Sentenças construídas na Língua Portuguesa

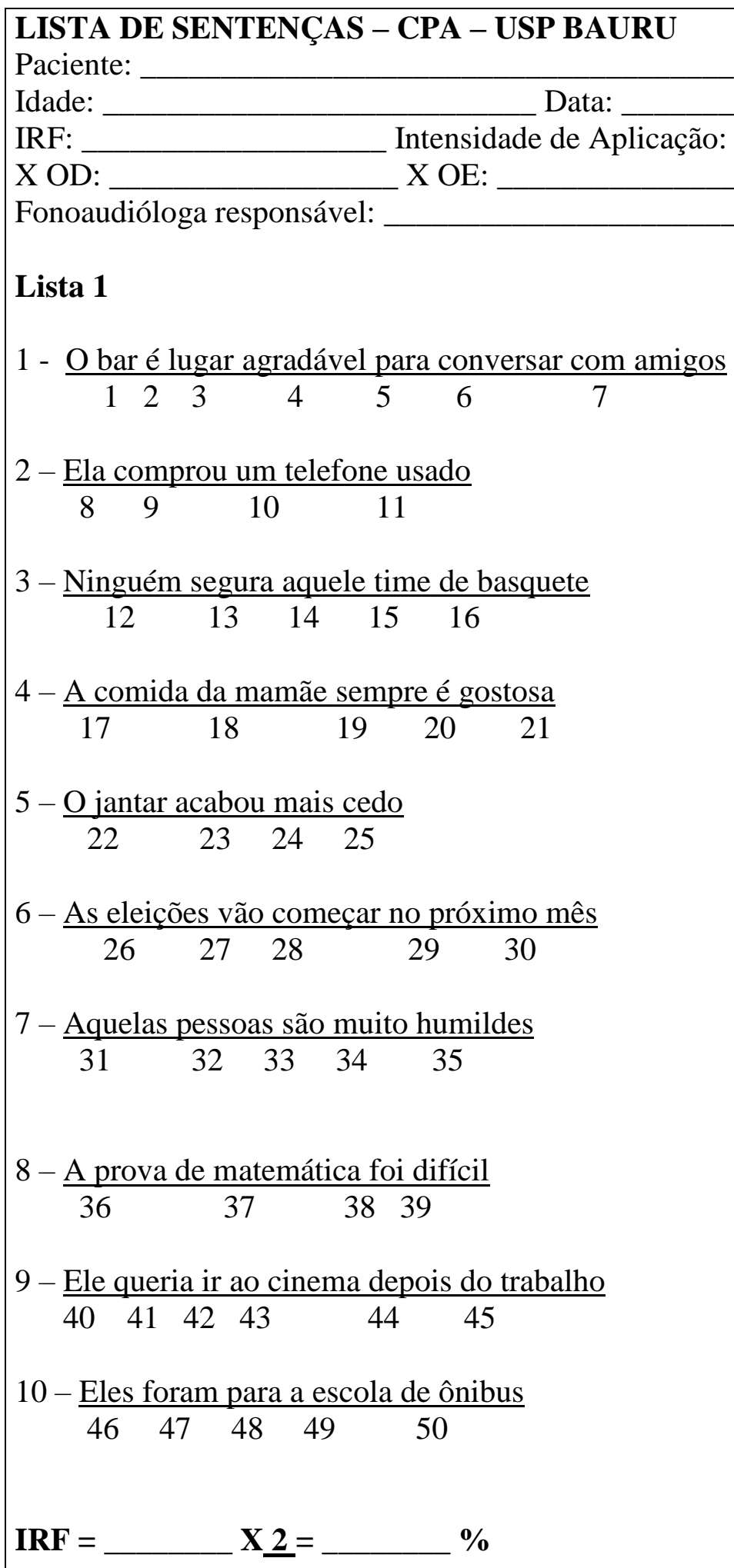
Prontuário: 


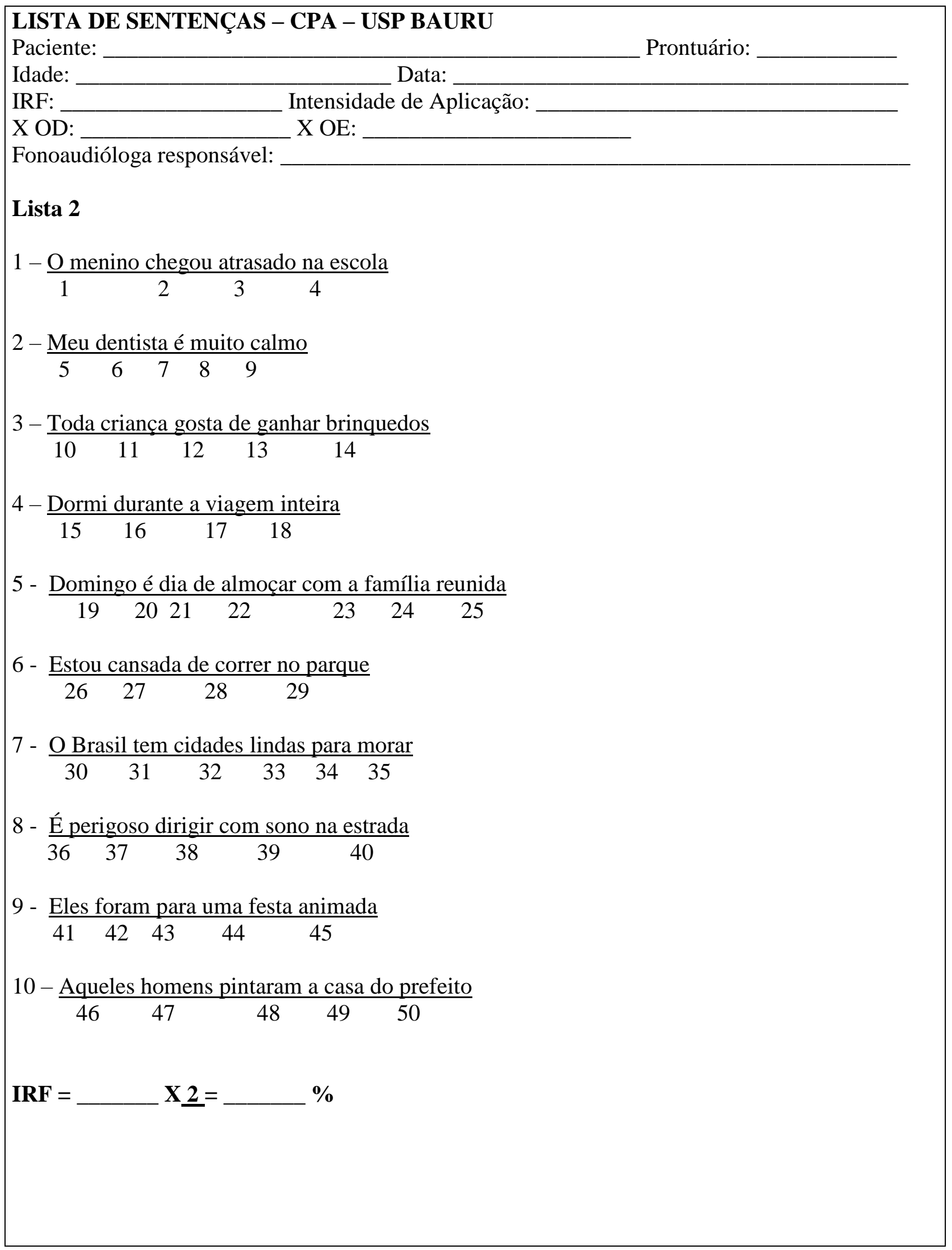




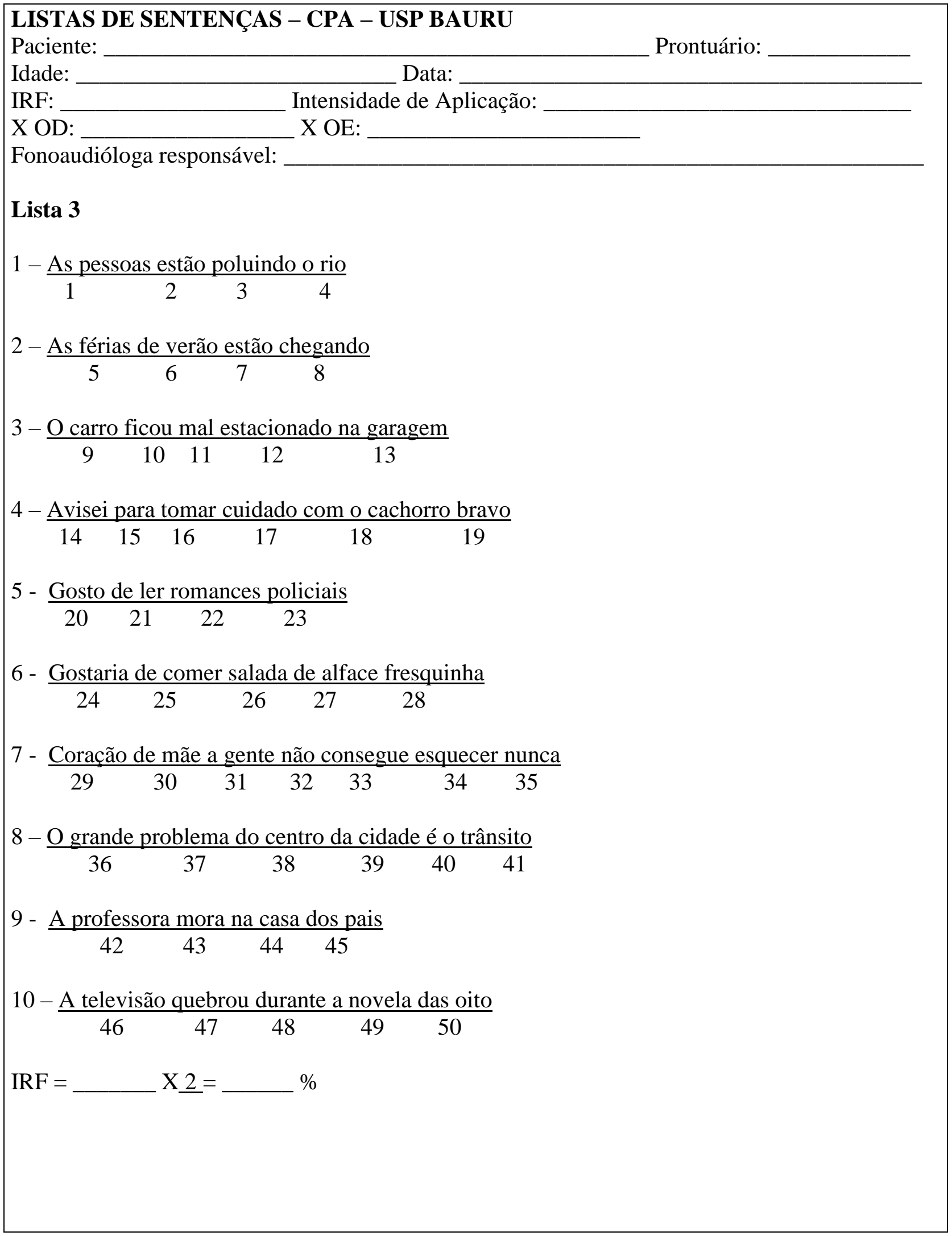




\section{LISTAS DE SENTENÇAS - CPA - USP BAURU}

Paciente: Prontuário:

Idade:

Data:

IRF: Intensidade de Aplicação:

$\mathrm{X}$ OD: $\mathrm{X} O \mathrm{OE}$ :

Fonoaudióloga responsável:

\section{Lista 4}

1 - $\underline{\mathrm{O} \text { aluno precisa estudar para fazer o exame }}$

$\begin{array}{llllll}1 & 2 & 3 & 4 & 5 & 6\end{array}$

2 - A secretária faltou dois dias no trabalho

$$
\begin{array}{lllll}
7 & 8 & 9 & 10 & 11
\end{array}
$$

3 - O peixe ficou agitado dentro do aquário

$\begin{array}{lllll}12 & 13 & 14 & 15 & 16\end{array}$

4 - O médico foi visitar o doente

$\begin{array}{llll}17 & 18 & 19 & 20\end{array}$

5 - A enfermeira trabalha no hospital para idosa

$\begin{array}{lllll}21 & 22 & 23 & 24 & 25\end{array}$

6 - Aquele telefone não funciona

$\begin{array}{llll}26 & 27 & 28 & 29\end{array}$

7 - $\underline{\text { O trabalho ajuda o homem à crescer na vida }}$

$\begin{array}{lllll}30 & 31 & 32 & 33 & 34\end{array}$

8 - A temperatura vai mudar este final de semana

$$
\begin{array}{llllll}
35 & 36 & 37 & 38 & 39 & 40
\end{array}
$$

9 - Aquele casal tem dois filhos lindos

$$
\begin{array}{llllll}
41 & 42 & 43 & 44 & 45 & 46
\end{array}
$$

10 - Ganhei uma cesta de ovos de páscoa

$$
\begin{array}{llll}
47 & 48 & 49 & 50
\end{array}
$$

$\mathrm{IRF}=$ $\mathrm{X} \underline{2}=$ $\%$ 


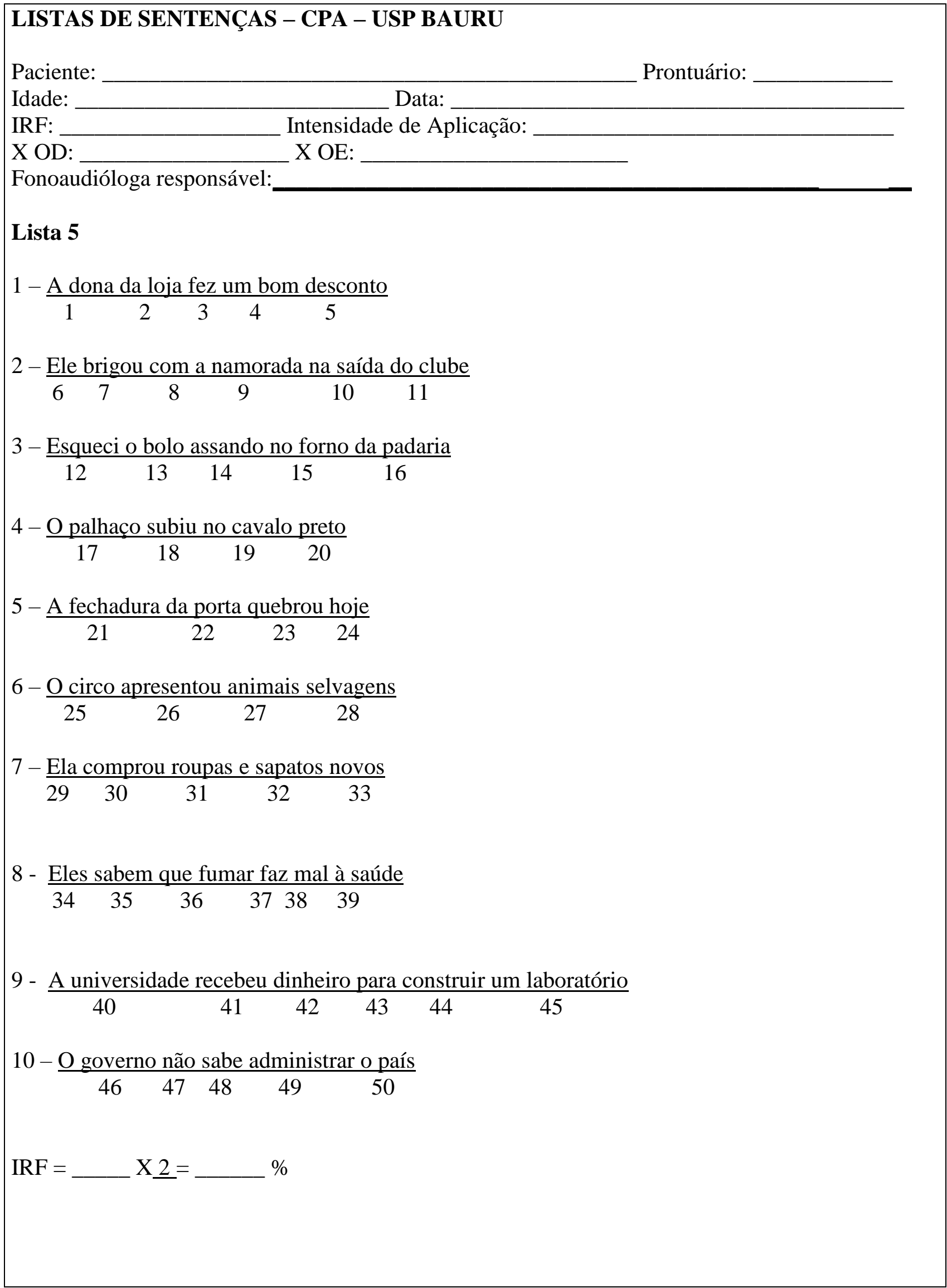




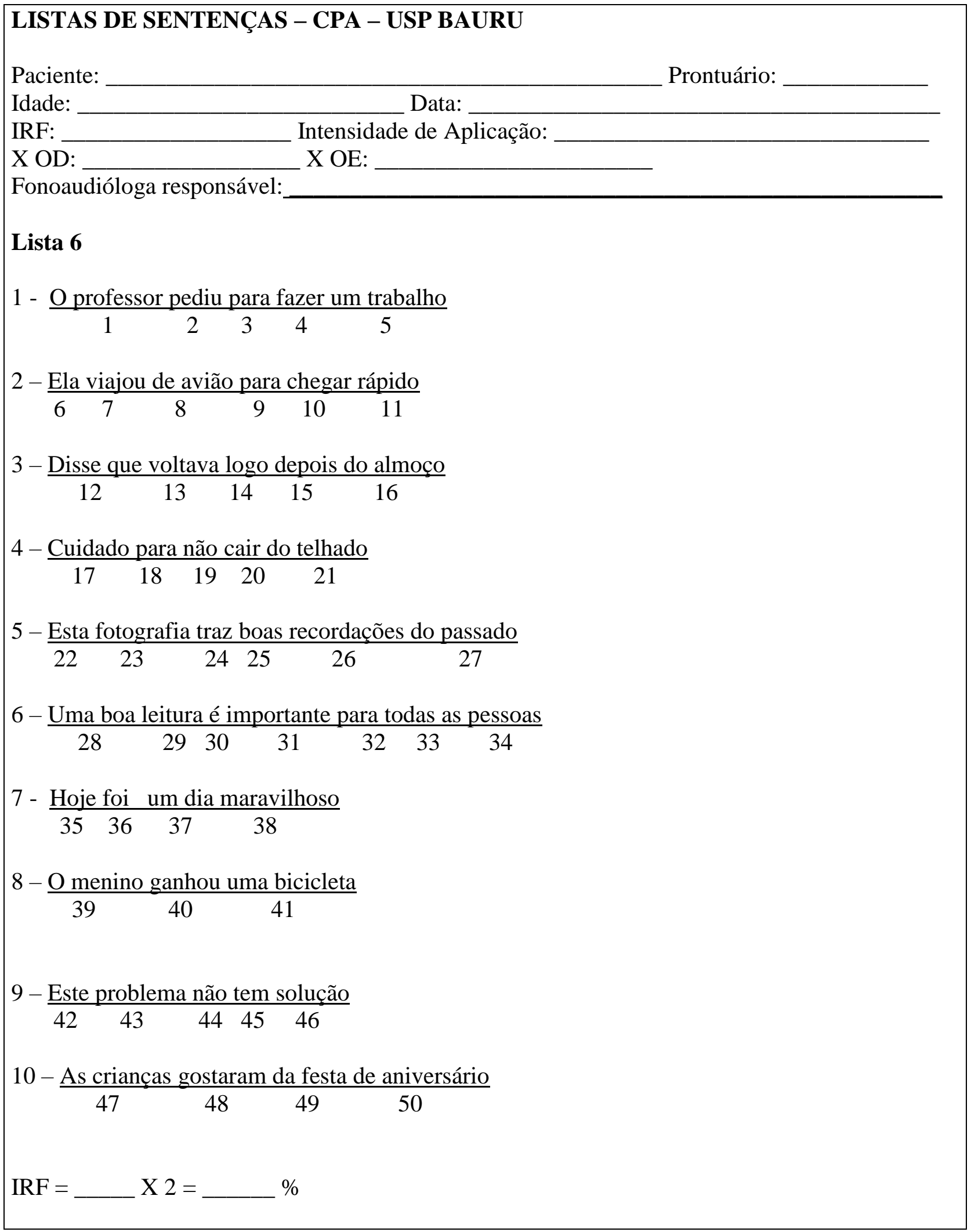




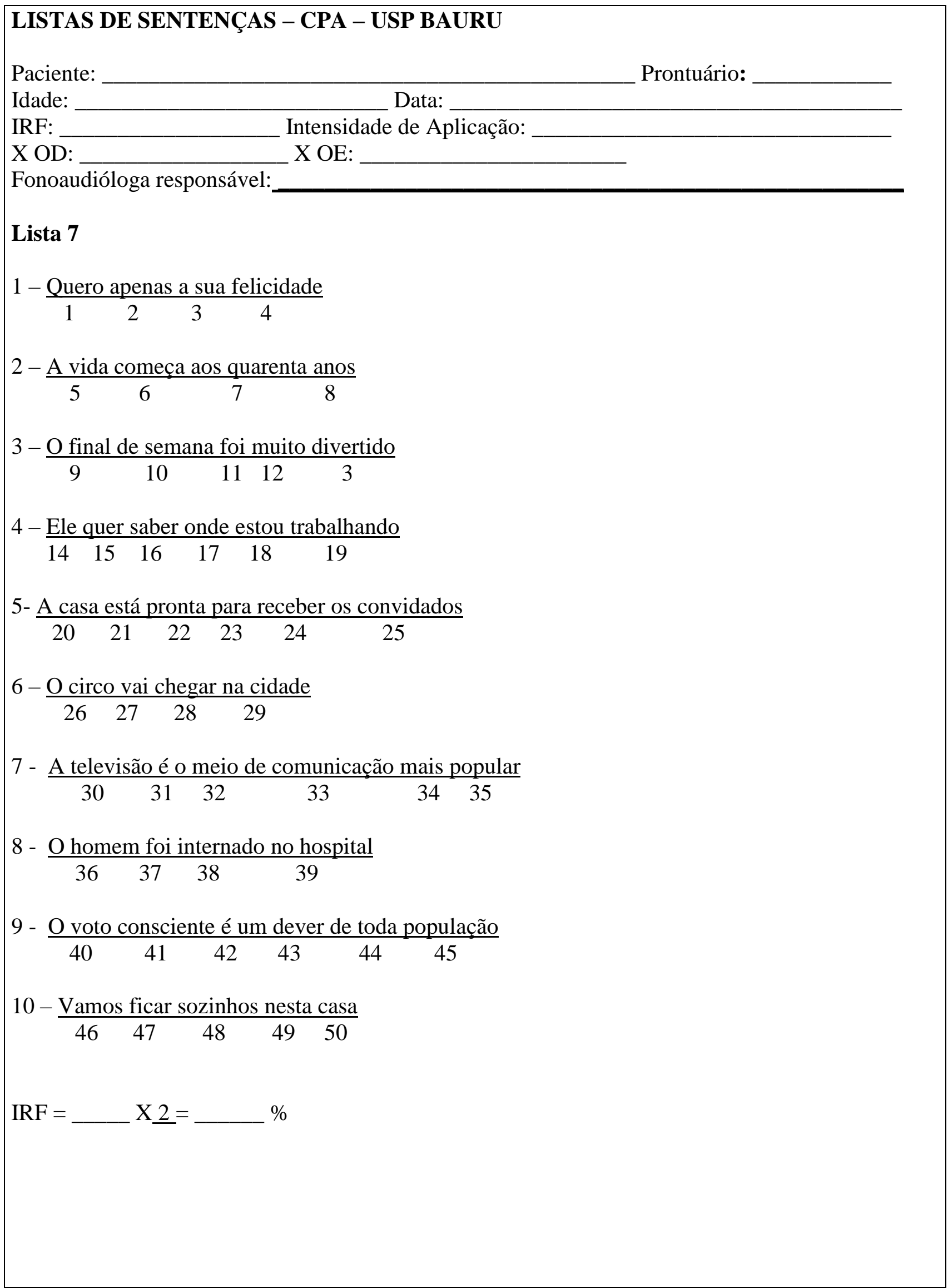




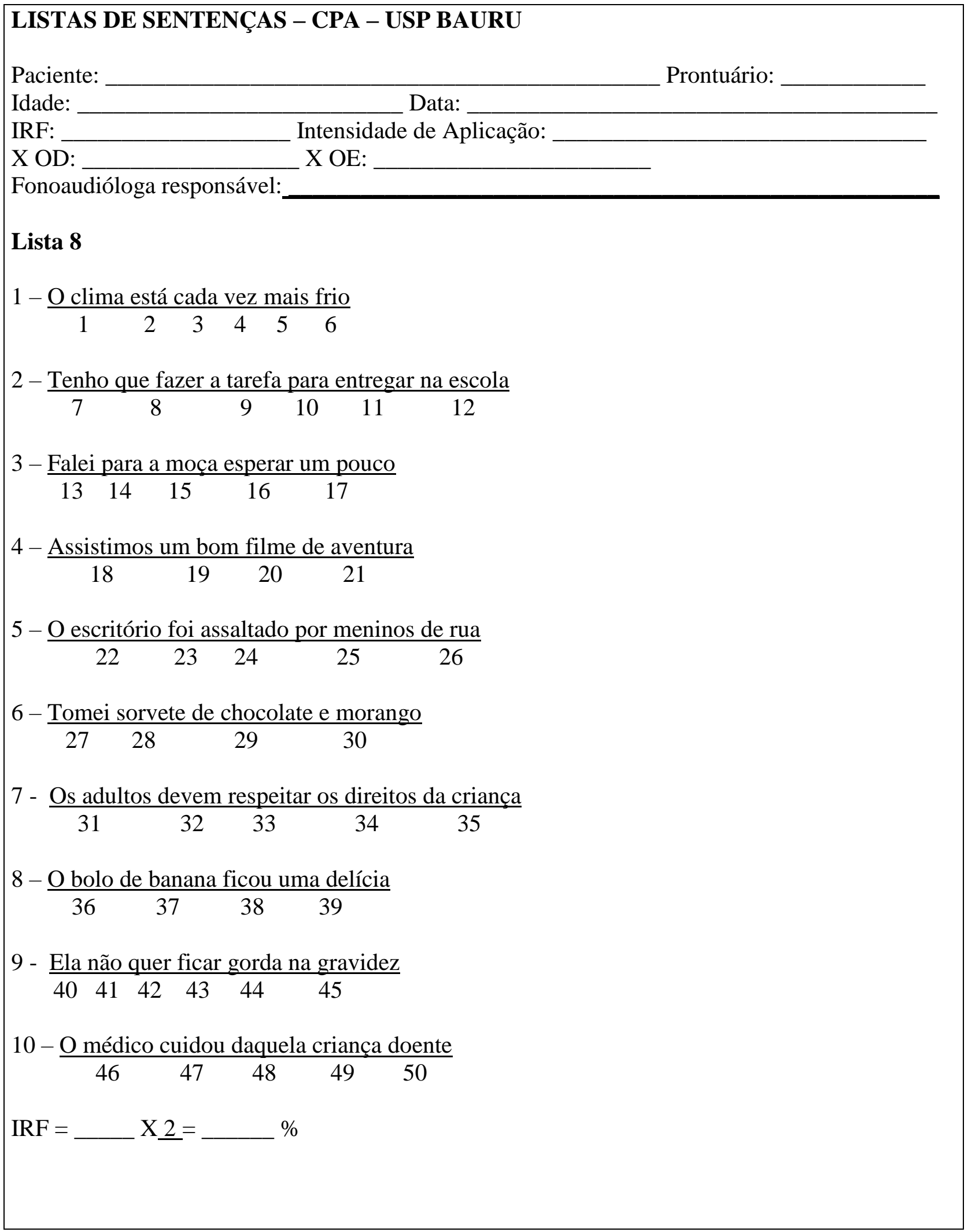


Referências Bibliográficas 


\section{REFERÊNCIAS BIBLIOGRÁFICAS}

1. Joint Committee on Infant Hearing $(\mathrm{JClH})$. Year 2007 Position Statement: principles and Guidelines for early hearing detection and intervention programs. Pediatrics. 2007;120(4):898-921.

2. Baumgartner WD, Pok SM, Egelierler B, Franz P, Gstoettner W, Hamzavi J. The role of age in pediatric cochlear implantation. Int $J$ Pediatr Otorhinolaryngol. 2002;62(3):223-8.

3. Bianchin G, Tribi L, Formigoni P, Russo C, Polizzi V. Sequential pediatric bilateral cochlear implantation: The effect of time interval between implants. Int J Pediatr Otorhinolaryngol. 2017;102:10-4.

4. Brown KD, Balkany TJ. Benefits of bilateral cochlear implantation: a review. Curr Opin Otolaryngol Head Neck Surg. 2007;15(5):315-8.

5. Buchman CA, Joy J, Hodges A, Telischi FF, Balkany TJ. Vestibular effects of cochlear implantation. Laryngoscope. 2004;114(103):1-22.

6. Ching TY, Hill M, Brew J, Incerti P, Priolo S, Rushbrook E. The effect of auditory experience on speech perception, localization, and functional performance of children who use a cochlear implant and a hearing aid in opposite ears. Int J Audiol. 2005;44(12):677-90.

7. Ching TY, Psarros C, Hill M, Dillon H, Incerti P. Should children who use cochlear implants wear hearing aids in the opposite ear? Ear Hear. $2001 ; 22(5): 365-80$.

8. Ching TYC, Incerti P, Hill M. Binaural beneficts for adults who use hearing aids and cochlear implants in opposite ears. Ear Hear. 2004;25(1):9-21. 
9. Ching TYC, Incerti P. Bimodal fitting or bilateral cochlear implantation? In: Wong L, Hickson L (eds.). Evidence based practice in audiologic intervention. San Diego: Plural Publishing, 2012. p. 213-33.

10. Ching TYC, Wanrooy EV, Dillon H. Binaural-Bimodal Fitting or Bilateral Implantation for Managing Severe to Profound Deafness: A Review. Trends Amplif. 2007;11(3):161-92.

11. Colburn HS, Zurek PM, Durlach NI. Binaural directional hearing Impairments and aids. In: Directional Hearing. New York, NY: Springer-Verlag, 1987:261-78.

12. Dillon H. Turramurra NSW. Aparelhos auditivos. Boomerang Press Austrália, 2001.

13. Fielden CA, Kitterick PT. Contralateral acoustic hearing aid use in adult unilateral cochlear implant recipients: Current provision, practice, and clinical experience in the UK. Cochlear implants international. 2016:17(3):132-145.

14. Fitzpatrick EM, Seguin C, Schramm D, Chenier J, Armstrong S. Users' experience of a cochlear implant combined with a hearing aid. Int $J$ Audiol. 2009;48(4):172-82.

15. Friedmann DR, Green J, Fang Y, Ensor K, Roland JT, Waltzman SB. Sequential bilateral cochlear implantation in the adolescent population. The Laryngoscope. 2015;125 (8):1952-8.

16. Fu QJ, Shannon RV, Wang X. Effects of noise and spectral resolution on vowel and consonant recognition: acoustic and electric hearing. J Acoust Soc Am. 1998;104(6):3586-96. 
17. Galvin KL, Mok M, Dowell RC, Briggs RJ. 12-Month post-operative results for older children using sequential bilateral implants. Ear Hear. 2007;28(2):19S-21S.

18. Galvin KL, Mok M, Dowell RC, Briggs RJ. Speech detection and localization results and clínical outcomes for children receiving sequential bilateral cochlear implants before four years of age. Int $J$ Audiol. 2008;47(10):636-46. doi: 10.1080/14992020802203314 .

19. Gatehouse S. The time course and magnitude of perceptual acclimatization to frequency responses: evidence from monaural fitting of hearing aids. J Acoust Soc Am. 1992;92(3)1258-68.

20. Gelfand SA, Silman S. Apparent auditory deprivation in children: implications of monaural versus binaural amplification. J Am Acad Audiol. 1993;4(5):313-8.

21. Gordon KA, Valero J, van Hoesel R, Papsin BC. Abnormal timing delays in auditory brainstem responses evoked by bilateral cochlear implant use in $\begin{array}{llll}\text { children. Otol } & \text { 2008;29(2):193-8. }\end{array}$ 10.1097/mao.0b013e318162514c.

22. Gordon KA, Papsin, BC. Benefits of Short Interimplant Delays in Children Receiving Bilateral Cochlear Implants. Otol Neurotol. 2009;30(3):319-31.

23. Gordon KA, Wong DD, Papsin BC. Cortical function in children receiving bilateral cochlear implants simultaneously or after a period of interimplant delay. Otol Neurotol. 2010;31(8):1293-9. doi: 10.1097/MAO.0b013e3181e8f965. 
24. Gordon KA, Jiwani S, Papsin BC. What is the optimal timing for bilateral cochlear implantation in children? Cochlear Implants Int. 2011;12(2):8-14. doi: $10.1179 / 146701011 \times 13074645127199$.

25. Graham J, Vickers D, Eyles J, Brinton J, Al Malky G, Aleksy W, et al. Bilateral sequential cochlear implantation in the congenitally deaf child: evidence to support the concept of a 'critical age' after which the second ear is less likely to provide an adequate level of speech perception on its own. Cochlear Implants Int. 2009;10(3):119-41. doi: 10.1002/cii.419.

26. Hamzavi J, Pok SM, Gstoettner W, Baumgartner W. Speech perception with a cochlear implant used in conjunction with a hearing aid in the opposite ear. Int J Audiol. 2004;43(2):61-5.

27. Harrison RV, Gordon KA, Mount RJ. Is there a critical period for cochlear implantation in congenitally deaf children? Analyses of hearing and speech perception performance after implantation. Dev Psychobiol. 2005;46(3):252-61. 28. Illg A, Giourgas A, Kral A, Büchner A, Lesinski-Schiedat A, Lenarz T. Speech comprehension in children and adolescents after sequential bilateral cochlear implantation with long interimplant interval. Otol Neurotol. 2013;34(4):682-9. doi: 10.1097/MAO.0b013e31828bb75e.

29. Illg, A, Sandner C, Büchner A, Lenarz T, Kral A, Lesinski-Schiedat A. The Optimal inter-implant interval in pediatric sequential bilateral implantation. Hear Res. 2017. In press. doi: 10.1016/j.heares.2017.10.010.

30. Jiwani S, Papsin BC, Gordon KA. Early unilateral cochlear implantation promotes mature cortical asymmetries in adolescents who are deaf. Human brain mapping. 2016;37(1):135-152. 
31. Kim JS, Kim LS, Jeong SW. Functional benefits of sequential bilateral cochlear implantation in children with long inter-stage interval between two implants. Int J Pediatr Otorhinolaryngol. 2013;77(2):162-9.

32. Kirk KI, Miyamoto RT, Lento CL, Ying E, O'Neill T, Fears B. Effects of age at implantation in young children. Ann Otol Rhinol Laryngol. 2002;189:6973.

33. Kocdor P, Iseli CE, Teagle HF, Woodard J, Park L, Zdanski CJ, et al. The effect of interdevice interval on speech perception performance among bilateral, pediatric cochlear implant recipients. Laryngoscope. 2016;126(10):2389-94. doi: 10.1002/lary.26012.

34. Kong YY, Stickney GS, Zeng FG. Speech and melody recognition in binaurally combined acoustic and electric hearing. $J$ Acoust Soc Am. 2005;117:1351-61.

35. Kühn-Inacker H, Shehata-Dieler W, Müller J, Helms J. Bilateral cochlear implants: a way to optimize auditory perception abilities in deaf children? Int $J$ Pediatr Otorhinolaryngol. 2004;68(10):1257-66.

36. Lammers MJ, Venekamp RP, Grolman W, Heijden GJ. Bilateral cochlear implantation in children and the impact of the inter-implant interval Laryngoscope. 2014;124:993-9.

37. Laszig R, Aschendorff A, Stecker M, Müller-Deile J, Maune S, Dillier N, et al. Benefits of bilateral electrical stimulation with the Nucleus cochlear implant in adults: 6-month postoperative results. Otol Neurotol. 2004;25:958-68 38. Litovsky RY, Johnstone PM, Godar SP. Benefits of bilateral cochlear implants and/or hearing aids in children. Int J Audiol. 2006a;45(1):S78-S91. 
39. Litovsky RY, Parkinson A, Arcaroli J, Sammeth C. Simultaneous Bilateral. Cochlear Implantation in Adults: A Multicenter Clínical Study. Ear Hear. 2006b;27(6):714-31.

40. Litovsky RY, Gordon K. Bilateral cochlear implants in children: Effects of auditory experience and deprivation on auditory perception. Hear Res. 2016;338:76-87. doi: 10.1016/j.heares.2016.01.003.

41. Litovsky RY. Speech intelligibility and spatial release from masking in young children. J Acoust Soc Am. 2005;117(5):3091-9.

42. Lovett RE, Kitterick PT, Hewitt CE, Summerfield AQ. Bilateral or unilateral cochlear implantation for deaf children: an observational study. Arch Dis Child. 2010;95:107-12.

43. Maurer J, Collet L, Pelster H, Truy E, Gallégo S. Auditory late cortical response and speech recognition in Digisonic cochlear implant users. Laryngoscope. 2002;112:2220-4.

44. Melo TM, Bevilacqua MC, Tanamati LF. Resultados do implante coclear bilateral em crianças e adultos: revisão de literatura. Distúrb Comun. 2013;25(2):267-76.

45. Miyamoto RT, Houston DM, Kirk KI, Perdew AE, Svirsky MA. Language development in deaf infants following cochlear implantation. Acta. Otolaryngol., Stockolm. 2003;123(2):241-4.

46. Moore BCJ. An introduction to the psychology of hearing. 5th ed. London: Academic Press; 2003.

47. Moret ALM. Percepção auditiva da fala em crianças e adolescentes com implante coclear bilateral sequencial. Adriane Lima Mortari Moret. - Bauru, 
2016. 80 p. Tese (Livre-Docência) - Faculdade de Odontologia de Bauru. Universidade de São Paulo.

48. Moret ALM, Bevilacqua MC; Costa OA. Implante coclear: audição e linguagem em crianças deficientes auditivas pré-linguais. Pró-Fono R. Atual. Cient. 2007;19(3):295-304.

49. Müller J, Schön F, Helms J. Compreensão da fala em silêncio e ruído em usuários bilaterais do sistema de implante coclear MED-EL COMBI 40/40 +. Ear Hear. 2002;23:198-206.

50. Nascimento LT, Bevilacqua MC. Avaliação da percepção da fala com ruído competitivo em adultos com implante coclear. Rev. Bras. Otorrinolaringol. 2005;71(4):432-8.

51. Nelson PB, Jin SH. Factors affecting speech understanding in gated interference: cochlear implant users and normal-hearing listeners. J Acoust Soc Am. 2004;115:2286-94.

52. Offeciers E, Morera C, Müller J, Huarte A, Shallop J, Cavinstitiallé L. International consensus on bilateral cochlear implants and bimodal stimulation. Acta Oto-laryngol. 2005;125(9):918-9.

53. Palmer C. Deprivation and acclimatization in the human auditory system: do they happen? Do they matter? Hear J. 1999;52(11):23-4.

54. Papsin BC, Gordon KA. Bilateral cochlear implants should be the standard for children with bilateral sensorineural deafness. Curr Opin Otolaryngol Head Neck Surg. 2008;16(1):69-74. 
55. Peters BR, Litovsky R, Parkinson A, Lake J. Importance of age and postimplantation experience on speech perception measures in children with sequential bilateral cochlear implants. Otol Neurotol. 2007;28(5):649-57.

56. Ramsden R, Greenham P, O'Driscoll M, Mawman D, Proops D, Craddock L, et al. Evaluation of bilaterally implanted adults subjects with Nucleus 24 cochlear implant system. Otol Neurotol. 2005;26(5):988-98.

57. Ramsden JD, Gordon K, Aschendorff A, Borucki L, Bunne M, Burdo S, et al. European Bilateral Pediatric Cochlear Implant Forum Consensus Statement. Otol Neurotol. 2012;33(4):561-5. doi: 10.1097/MAO.0b013e3182536ae2.

58. Reeder RM, Firszt JB, CadieuxJH, Strubea MJ. A Longitudinal Study in Children With Sequential Bilateral Cochlear Implants: Time Course for the Second Implanted Ear and Bilateral Performance. J Speech Lang Hear Res. 2017;60(1):276-87. doi: 10.1044/2016_JSLHR-H-16-0175.

59. Sbompato AF, Corteletti LC, Moret Ade L, Jacob RT.Hearing in Noise Test Brazil: padronização em campo livre- adultos com audição normal. Braz $J$ Otorhinolaryngol. 2015;81(4):384-8.

60. Scherf FWAC, Deun LV, Wieringen AV, Wouters W, Desloover C, Dhooge I, Offeciers E, Deggouj M, Raeve L, Bodt M, Heyning PHV. Functional outcome of sequential bilateral cochlear implantation in young children: 36 months postoperative results. Int $J$ Pediatr Otorhinolaryngol. 2009;73(5):723-30. 
61. Scherf FW, Arnold LP. Exploring the clínical approach to the bimodal fitting of hearing aids and cochlear implants: results of an international survey. Acta Otolaryngol. 2014;134:1151-7.

62. Sharma A, Tobey E, Dorman MF, Bharadwaj S, Martin K, Gilley P, et al. Central auditory maturation and babbling development in infants with cochlear implants. Arch Otolaryngol Head Neck Surg. 2004;130:511-6.

63. Sharma A, Dormann MF, Kral A. The influence of a sensitive period on central auditory development in children with unilateral and bilateral cochlear implants. Hear Res. 2005;203:134-43.

64. Sharma A, Dorman MF, Spahr J. A sensitive period for the development of the central auditory system in children with cochlear implants: implications for age of implantation. Ear e Hear. 2002a;23(6):532-9.

65. Sharma A, Dorman MF, Spahr J. Rapid Development of cortical auditory evoked potentials after early cochlear implantation. Neuro Report. 2002b;13(10):1365-8.

66. Sharma A, Gilley PM, Dorman MF, Baldwin R. Deprivation-induced cortical reorganization in children with cochlear implants. Int $J$ Audiol. 2007;46:494-9.

67. Smulders YE, Rinia AB, Rovers MM, van Zanten GA, Grolman W. What is the effect of time between sequential cochlear implantations on hearing in adults and children? A systematic review of the literature. Laryngoscope. 2011;121:1942-9.

68. Sparreboom M, Van Schoonhoven J, Van Zanten BG, Scholten RJ, Mylanus EA, Grolman W, Maat A. The effectiveness of bilateral cochlear 
implants for severe-to-profound deafness in children: a systematic review. Otol Neurotol. 2010;31(7):1062-71.

69. Sparreboom M, Snik AFM, Mylanus EAM. Sequential bilateral cochlear implantation in children: development of the primary auditory abilities of bilateral Stimulation. Audiology and Neurotology, 2011;16:203-13.

70. Steffens T, Lesinski-Schiedat A, Strutz J, Aschendorff A, KlenznerT, Rühl $S$, et al. The benefits of sequential bilateral cochlear implantation for hearingimpaired children. Acta Otolaryngol. 2008;128(2):164-76.

71. Stickney GS, Zeng FG, Litovsky R, Assmann P. Cochlear implant speech recognition with speech maskers. J Acoust Soc Am. 2004;116(2):1081-91.

72. Strom-Roum H, Laurent C, Wie OB. Comparison of bilateral and unilateral cochlear implants in children with sequential surgery. Int $J$ Pediatr Otorhinolaryngol. 2012;76(1):95-9.

73. Tomblin JB, Barker BA, Spencer LJ, Zhang X, Gantz BJ. The effect of age at cochlear implant initial stimulation on expressive language growth in infants and toddlers. J Speech Lang Hear Res. 2005;48(4):853-67.

74. Tyler RS, Parkinson AJ, Wilson BS, Witt S, Preece JP, Noble W. Patients utilising a hearing aid and a cochlear implant: speech perception and localisation. Ear Hear. 2002;23:98-105.

75. Valente SLOL. Elaboração de listas de sentenças construídas na língua portuguesa [Dissertação]. São Paulo: Pontifícia Universidade Católica de São Paulo; 1998.

76. Van Hoesel RJ, Tyler RS. Percepção da fala, localização e lateralização com implantes cocleares bilaterais. J Acoust Soc Am. 2003;113:1617-30. 
77. Wolfe J, Baker S, Caraway T, Kasulis H, Mears A, Smith J, Swim L, Wood M. 1-year postactivation results for sequentially implanted bilateral cochlear implant users. Otol Neurotol. 2007;28(5):589-96.

78. Yamaguchi CT, Goffi-Gomez MVS. Perfil audiológico do usuário implante coclear e aparelho de amplificação sonora individual na orelha contralateral: resultados preliminares. CEFAC. 2009;11(3):494-8.

79. Yamaguchi CT, Goffi-Gomez MVS. Prevalence of contralateral hearing aid use in adults with cochlear implants. Int Arch Otorhinolaryngol. $2013 ; 17: 370-4$.

80. Yang WS. Delayed cochlear implantation in adults with prelingual severeto-profound hearing loss. Otol Neurotol. 2011;32(2):223-8.

81. Zeitler DM, Kessler MA, Terushkin V, Roland TJ Jr, Svirsky MA, Lalwani AK, et al. Speech perception benefits of sequential bilateral cochlear implantation in children and adults: a retrospective analysis. Otol Neurotol. 2008;29(3):314-25. 